\title{
Teaching Supply Chain Management: A qualitative and quantitative approach to developing a supply chain management education framework
}

\author{
By \\ Joseph Walden \\ (C) 2018
}

MS, Engineering, University of Kansas, 2012

MMAS, US Army Command and General Staff College, 2001

MS, Systems Management, Florida Institute of Technology, 1989

MBA, Florida Institute of Technology, 1988

Submitted to the graduate degree program in

Education and the Graduate Faculty of the University of Kansas in partial fulfillment of the requirements for the degree of Education, Doctorate

Chair

Joseph O'Brien

Member

Steven White

Member

Heidi Hallman

Member

Bruce Frey

Member

Dennis Karney

Date Defended: 7 May 2018 
The dissertation committee for Joseph Walden certifies that this is the approved version of the following dissertation:

Teaching Supply chain management: A qualitative and quantitative approach to developing a supply chain management education framework

Chair: Joseph O’Brien

Date Approved: 14 June 2018 


\section{Abstract \\ Teaching Supply chain management: A qualitative and quantitative approach to developing a supply chain management education framework}

Supply chain management is a new but ever evolving field, which results in an ongoing gap between what the field requires and those possessing the skills necessary to meet the field's requirements. While academic preparation of supply chain management professionals is one critical way to address this gap, research suggests that such academic programs possibly are contributing to, rather than closing, that gap. As noted, by Birou, Lutz, and Zsidisin (2016) though, there are few studies that have examined the substance of the undergraduate supply chain management curriculum. Using a mixed methods approach, this study is the largest analysis of undergraduate syllabi of introductory supply chain management courses by looking at seventy-eight introductory supply chain management syllabi from both Gartner Top 25 Schools and those not on the Gartner list, as well as job announcements for entry level supply chain management position. The syllabi revealed that inventory management and procurement/contracting were the most frequently listed topics, however, the syllabi analysis also revealed a number of courses containing a large content of traditional operations management topics. This gave credence to the claims of Alakin, Haung, and Willems (2016) that some courses were operations management courses that had their titles changed to supply chain management.

The syllabi of the Gartner Top 25 Schools when compared to the frequency distribution for the job announcements revealed an $88 \%$ match between what is being asked for and what is reflected in the syllabi. The syllabi for the non-Top 25 Schools revealed a $36 \%$ match after doing a thematic grouping of similar topics. The thematic groupings were created by using the APICS Dictionary and APICS Body of Knowledge for related terms. The thematic grouping helped to 
link related terms into related groupings of key terms and helped to compare the terms from the syllabi to the groupings used by Johnson and Pyke (2000) in their initial supply chain management education framework.

My research removed the modules of location analysis and product design and relocated these topics to a module or grouping titled "Operations Management Topics" with the understanding that some operations management understanding is necessary for teaching supply chain management. The new framework also moved the Johnson and Pyke grouping of service and after sales support to a new grouping titled "Customer Support." The new framework also added modules or groupings for supply chain management basics and terminology, professional development and emerging supply chain management concepts. The 2000 framework also included a module for marketing which is a separate business discipline and while students need to understand the link between marketing and supply chain management, eliminating this module frees up classroom time for other critical topics. 


\section{Dedication}

A very special thank you to Joe O'Brien who has served as my advisor, committee chair and friend over the past four years. Thank you to the other members of my committee: Steve White, Bruce Frey, Dennis Karney and Heidi Hallman for your patience, mentoring and guidance. A special thank you to Susan McGee for her help and patience throughout the entire program. Thank you to Suzanna Emelio of the School of Business for editing the final paper.

The research and the resulting course improvements are dedicated to my students, both past and present and my wonderful Teaching Assistants that have picked up the slack during the research project.

My wife Kay and my two daughters, Amber and Bobbi, have provided constant support and encouragement throughout this process. There is no way I could have done this without you.

Although I lost him during the course of this research, without the constant support, encouragement and love of my Dad, Tom Walden, Sr., I would not have accomplished any of the things I have in my careers. My second Mother, Jan Walden, has provided so much encouragement and enthusiasm throughout this entire project, this is just a small way of saying thanks for the support and encouragement. 


\section{Contents}

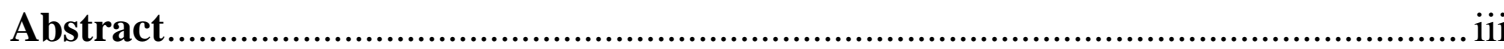

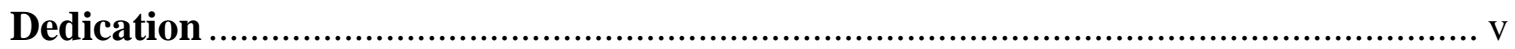

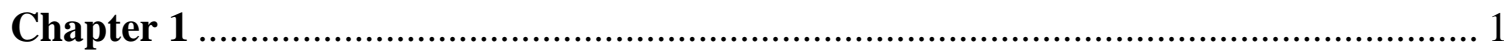

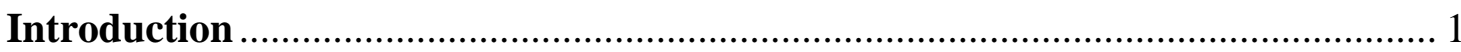

Defining Supply Chain Management and its Importance ...................................... 1

Supply Chain Management as a Discipline ………………….......................... 7

The Supply Chain Management Discipline, Curriculum and the Talent Gap...... 11

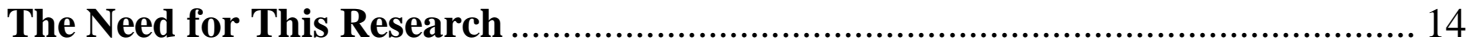

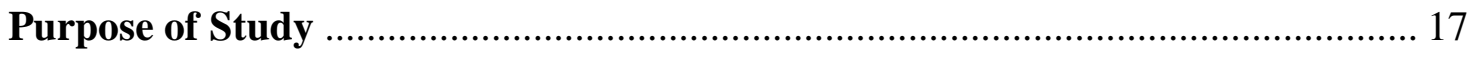

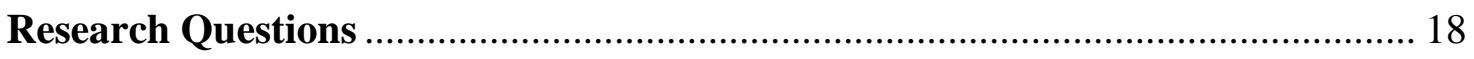

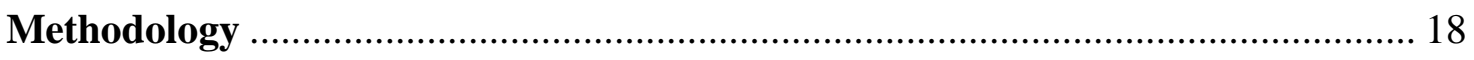

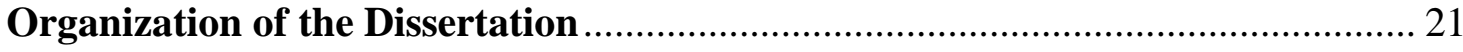

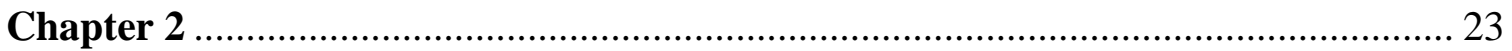

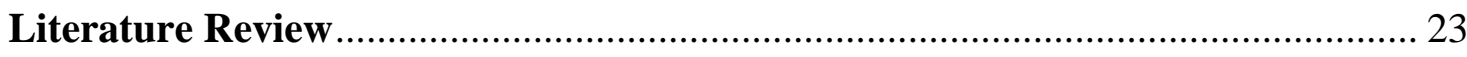

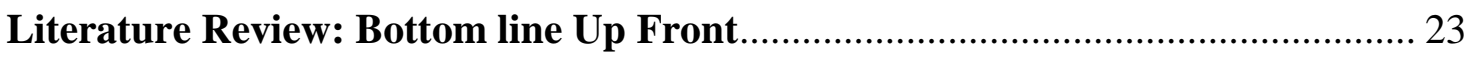

Is there a talent gap?

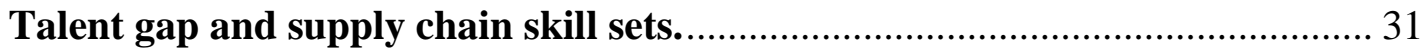

Literature on the link between academics and talent gap. ................................. 33

Literature on curriculum development. ............................................................ 39 
Literature on Academic - Corporate Link.

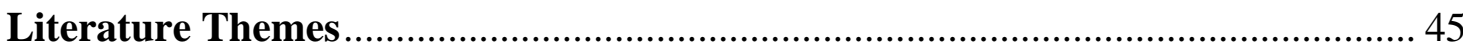

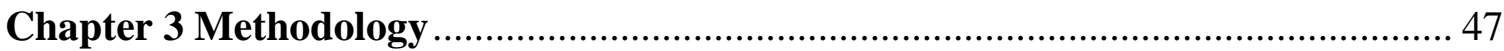

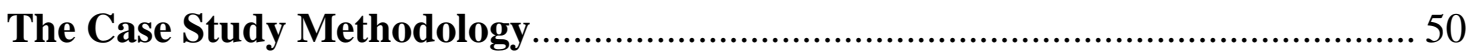

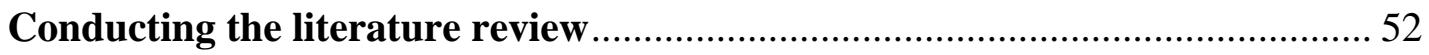

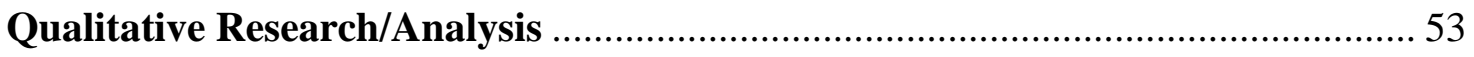

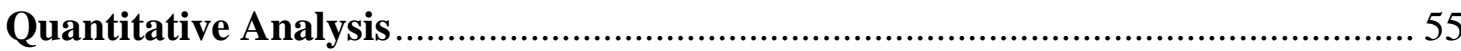

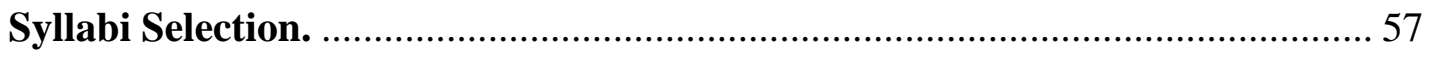

Job Announcement Selection Process. ......................................................... 70

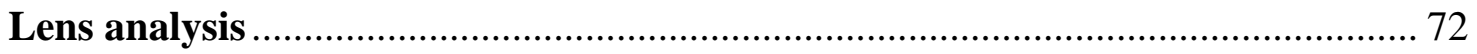

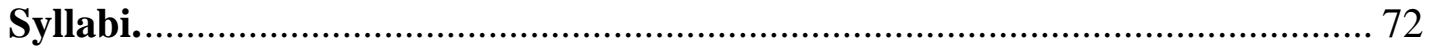

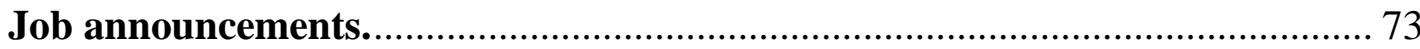

Qualitative and Quantitative Analysis ....................................................... 75

What Did All of This Provide? ........................................................................ 77

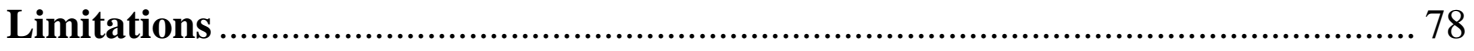

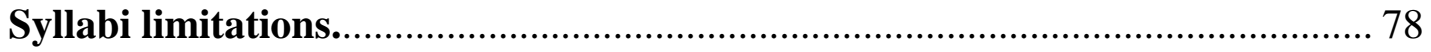

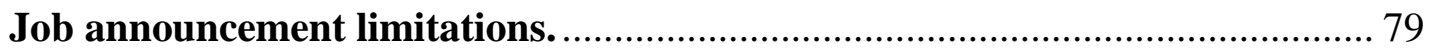

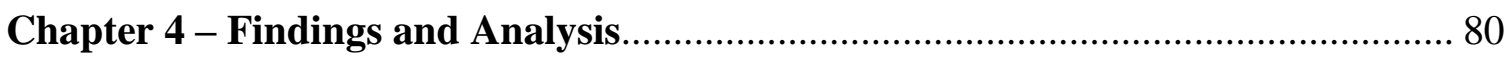

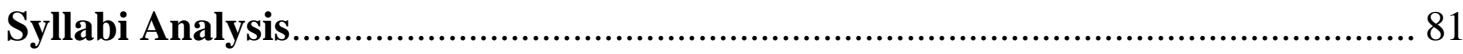

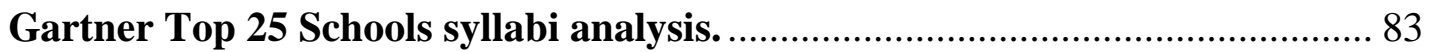




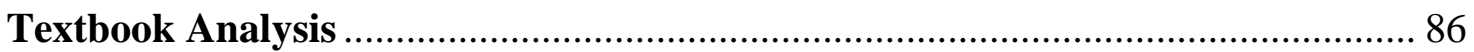

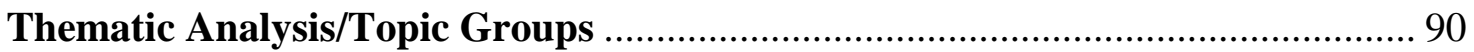

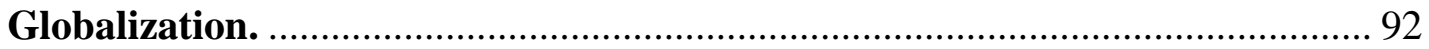

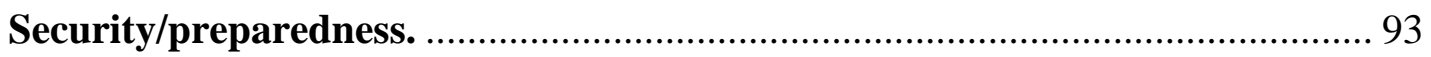

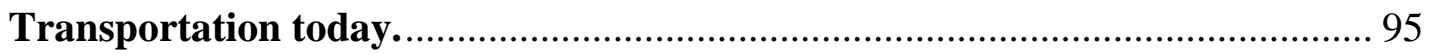

Track and trace.

Additional Thematic Groupings...................................................................... 95

Topics in the inventory management theme group. ………………….............. 96

Topics in the procurement theme group............................................................ 97

Topics in the operations management theme group.......................................... 99

Topics in the supply chain management basics and terminology theme group.

Topics in the quality/metrics theme group.................................................. 102

Topics in the information systems theme group. .............................................. 103

Topics in the customer service management theme group. .............................. 104

Topics in the supply chain emerging concepts theme group............................. 105

Topics in the professional development theme group. …………………......... 106

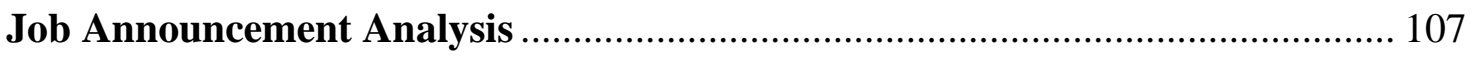

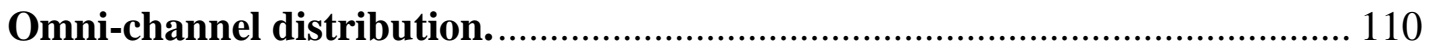

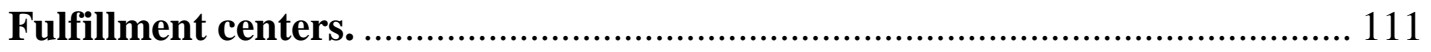


Comparison of Job Announcements to Syllabi

Top 25 school syllabi compared to the job announcements............................ 114

Non-top 25 school syllabi compared to the job announcements....................... 118

Is there a correlation between the two sets of data? ......................................... 122

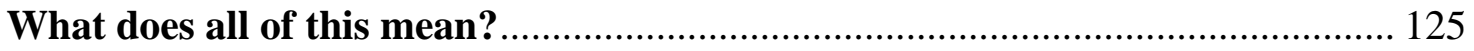

Chapter 5: Conclusions and Recommendations ……………………………..... 126

Comparison of Chapter 4 Analysis to Johnson and Pyke and Follow-on

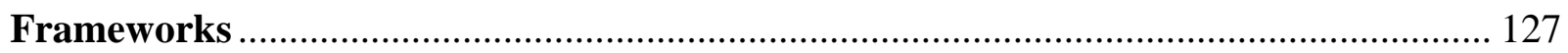

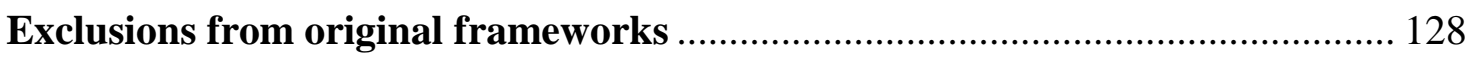

Other Modifications from Previous Frameworks ................................................... 129

Johnson and Pyke Conclusions and Recommended Changes................................. 131

New Supply Chain Framework for Introductory Supply Chain Management .. 131

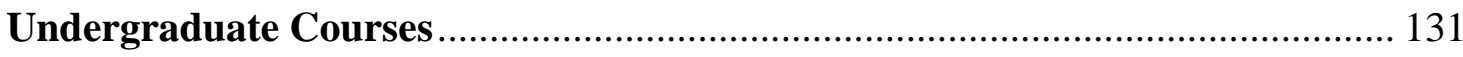

Supply chain management topics for a new framework................................. 135

Inventory management topics for a new framework....................................... 136

Procurement topics for a new framework.................................................... 136

Operations management topics that should be part of a new framework....... 137

Metrics and performance management topics for a new framework.............. 139

Information systems topics for a new framework. ………………………....... 140

Customer service topics for a new framework................................................ 141 
Manufacturing topics for a new framework.

Quality topics for a new framework....................................................... 143

Emerging concepts topics for a new framework......................................... 144

Professional Development topics for a new framework. .............................. 146

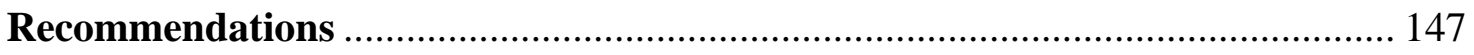

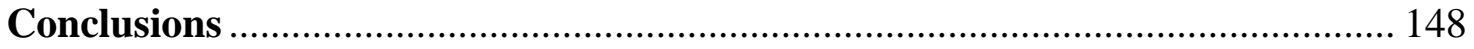

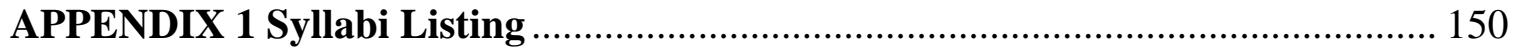

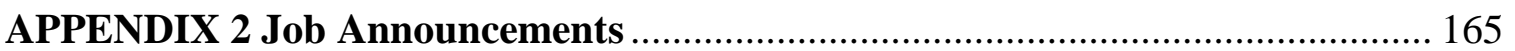

APPENDIX 3 APICS Supply Chain Industry Terminology ............................... 170

APPENDIX 4 - APICS Operations Industry Terminology ............................... 176

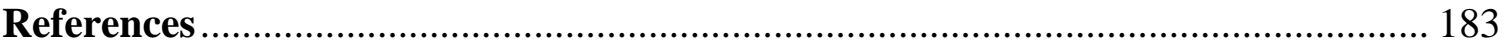




\section{Chapter 1}

\section{Introduction}

Supply chain management is a relatively new discipline in business and in academia. The term supply chain management was first used around 1982 and the first supply chain management program was established at Syracuse University in 1998. Most schools did not have a supply chain management program until the first decade of the 2000s. The content of such curricula is still evolving because of the relative newness of supply chain management as an academic discipline and the way that the supply chain management profession continues to morph as more companies adopt the concept and as customer expectations constantly change. The "Amazon Effect," for example, has given consumers the idea that almost anything is available with a two-day lead time using Amazon Prime ${ }^{\circledR}$. This new consumer attitude has resulted in a growing emphasis on supply chain management, the location of the desired products and the delivery of those products. However, as the industry has morphed and grown, a clear framework for what should be taught in a supply chain management program has not been addressed in almost fifteen years. Prior to reconsideration of a curricular framework for supply chain management, this study seeks to begin learning what content now is included in such curricula.

\section{Defining Supply Chain Management and its Importance}

What is supply chain management and why is it important? Supply chain management is the lifeblood of any organization. The successful management of supply chains can lead to the survival or ruin of a company. Supply chain management is the aspect of any business that runs 
from the sourcing of raw materials through the production of products, the delivery of those products to the customers and, if necessary, processing the return of those products back from the customer if there is an issue with the product. Supply chain management touches every consumer and every business regardless of the type of business or the location of the customer. Estimates show that the value of supply chain services may triple in value between now and 2030 to an estimated $\$ 27$ trillion (PwC, 2017).

What is a supply chain? While the term would imply a linear chain, it is not that simple. APICS (APICS was initially formed as the American Production and Inventory Control Society in the late 1950s; as of 2005 it is simply known as APICS) defines a supply chain as "the global network used to deliver products and services from raw materials to end customers through an engineered flow of information, physical distribution, and cash" (Blackstone, 2013, p. 172). There may be many individual supply chains linking into a company's supply chain. For example, there are several hundred parts in the assembly of an iPhone. Each one of those parts has its own supply chain feeding into the Foxconn assembly plant where the iPhone is assembled. This supply chain then extends to the storage points and retail activities that sell the iPhone.

In a supply chain, the design of a product will drive the need for sourcing materials; the next link in the supply chain is the delivery of the materials to the manufacturer. Once received, then the materials have to be manufactured or assembled and then delivered to the distribution center for temporary storage. Finally, once a customer or retailer places an order for the product it has to be retrieved from a stockage location, packed and shipped directly to a customer or purchased in a retail facility. 
In the example below, I have shown a simplified supply chain for a K-Cup. There are three supply chains feeding into the assembly plant: the supply chain for the plastic cup, the supply chain for the coffee, and a supply chain for the foil lid. Each of these supply chains may have multiple supply chains feeding into their operations. At the K-Cup assembly plant the supply chain operations of assembling the K-Cup feed the next supply chains, which are the movement of the product to the distribution centers to support stores and other large retailers and the movement to a fulfillment center to support the sale of the cups to individuals. In this example, the supply chain for the coffee runs from the planting of the tree to the picking of the berries, the drying of the beans, the roasting process, the grinding process and the delivery of the coffee to the K-Cup company. This same company may also have a link of its supply chain that goes to major retailers, smaller companies that roast their own coffee beans and even a link that runs from the grower to the individual consumer that buys direct from the farm.

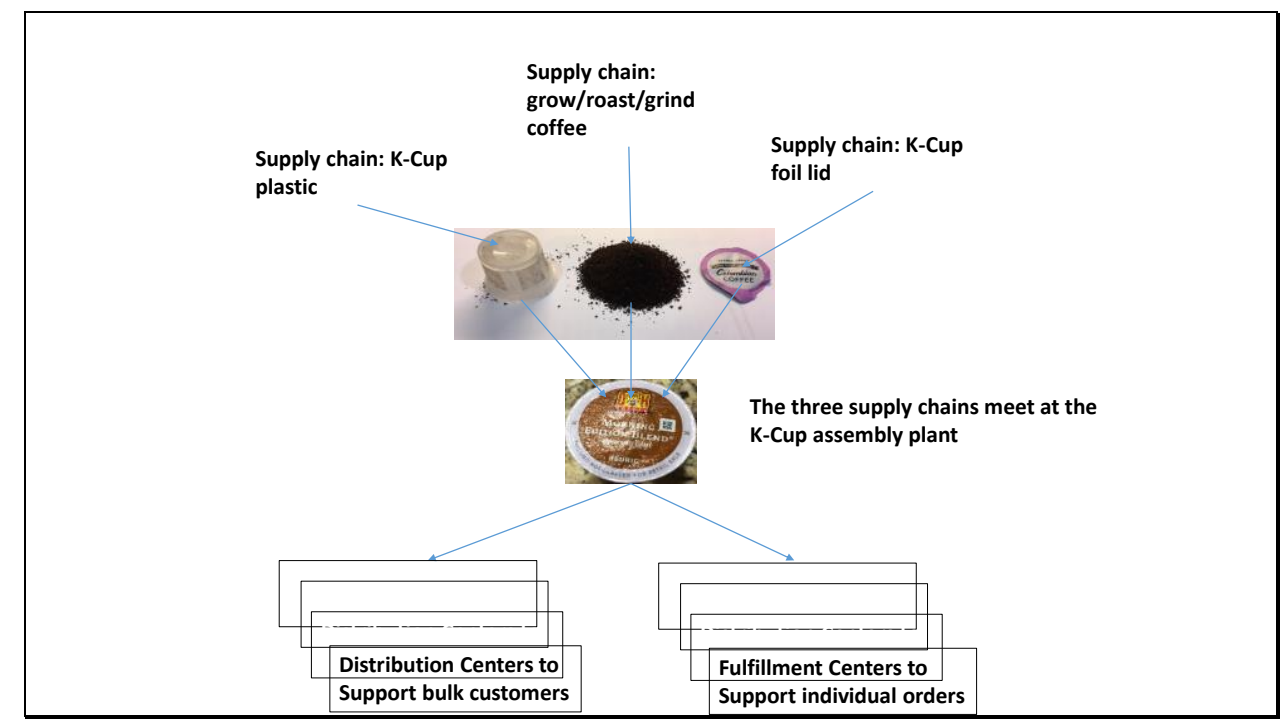

\section{Figure 1-1: Simple Depiction of a K-Cup Supply Chain}

Why is supply chain management important to companies and consumers? Supply chain managers are responsible for planning how products will get to the customer regardless of what 
conditions may be present. Without a background in planning and critical thinking, external interruptions may impact the ability to deliver the products to the customer in a timely manner. Consider the impacts to the customers and the supporting supply chains with the arrival and aftermath of Hurricane Harvey. The ripple effects of interruptions to the supply chain because of Hurricane Harvey had far reaching effects. The impacts to the petroleum supply chain became evident quickly as local gas prices rose as much as $\$ 0.40$ within a few days and then settled back to lower levels within a few weeks. With the Port of Houston being the sixth largest port in the US and the primary port for major companies such as Walmart for delivery of foreign made products, the delays resulted in shortages in some areas of the country. The inability to move products from the area ports due to flooded roads, airports and rails led to price increases and product shortages.

The same skills needed in military supply chain management such as emergency resupply and rapid supply chain management are also critical in commercial supply chains. The lack of emergency and contingency planning skills may have played a role in the recovery from the hurricane. Hurricane Irma impacted the pharmaceutical supply chains. Approximately $80 \%$ of all pharmaceuticals for the US are produced in Puerto Rico. The damage from Irma left the factories closed, the roads damaged, and an inability to receive necessary raw materials or ship finished products based on the damages to the road network and the ports. The trickle-down effect was a shortage of flu vaccines that led to larger numbers of flu patients. The unexpected high number of flu patients then led to a shortage of plastic fluids bags also made in Puerto Rico, for the hospitals to use to treat the flu patients.

What makes the study of supply chain management and supply chain management curriculum important is the impact that it has on businesses and customers. Without supply chain 
management, there would be no computer to write this paper, no paper to print the paper out or any printer to print the paper. Without the proper skill sets, students will not be prepared to successfully enter the career field. If students are not prepared to enter the career field, they may not be successful or may not even be hired for a supply chain job.

The term supply chain management first appeared in public print in Christopher's book, Logistics Management (1992). The Supply Chain Council created one of the first true models of the supply chain in 1995 in an effort to describe what a supply chain looked like. This model has been updated and revised over the past twenty-three years to more accurately reflect the best practices of industry. The Supply Chain Council description of the supply chain is basically that the supply chain runs from the suppliers' suppliers to the customers' customers or from raw material to the ultimate end user of a product. The more simplistic definition of supply chain management may come from what most companies call the "six rights." These six rights are 1) getting the right product; 2) to the right place; 3) at the right time; 4) in the right quantity; 5) in the right condition; and 6) with the right billing to meet the needs of the customer. These six rights make up the components of a supply chain metric, known as perfect order fulfillment, that measures how well a supply chain is taking care of its customers.

Often the terms logistics and supply chain management are used interchangeably. They are not interchangeable terms. This confusion surrounding the terms is partially due to the fact that logistics has been around for centuries and partially due to a lack of education by the supply chain community in informing the public what supply chain management really is. This may also be a result of some lack of agreement in the supply chain community on what the term really means. Warehousing, which is a subset of supply chain management, is mentioned as early as 1700 BC in Egypt. Logistics is a subset of supply chain management and has been part of 
military and business lexicon since as early as the writings of Sun Tzu in 512 BC in China and in discussions concerning Alexander the Great and his Macedonian Army movements across Europe and Asia in 323 BC. Logistics is a subset of supply chain management and while it needs to be discussed as part of the overall supply chain curriculum it is no longer a standalone discipline.

Every major professional organization appears to have its own definition of supply chain management. The three major organizations, APICS (originally formed as the American Production and Inventory Control Society), the Council of Supply Chain Management Professionals (CSCMP) and the Institute of Supply Management (ISM) all have common components of sourcing, information flow and end-to-end management as parts of their definitions. The most commonly accepted definition comes from APICS: "The design, planning, execution, control and monitoring of supply chain activities with the objective of creating net value, building a competitive infrastructure, leveraging worldwide logistics, synchronizing supply with demand, and measuring performance globally" (Blackstone, 2013, p. 172). CSCMP defines supply chain management similarly as "Supply chain management encompasses the planning and management of all activities involved in sourcing and procurement, conversion, and all logistics management activities. Importantly, it also includes coordination and collaboration with channel partners, which can be suppliers, intermediaries, third party service providers, and customers. In essence, supply chain management integrates supply and demand management within and across companies" (CSCMP, 2018). The definitions from the professional organizations are similar and include the concept of raw material to end user and the coordination or flow of information. The two definitions are shown here to demonstrate that there is not one singularly accepted definition which could lead to some of the differences in 
what is taught in introductory courses and some of the confusion in the industry as to exactly what supply chain management is.

\section{Supply Chain Management as a Discipline}

A business discipline is "the practices that help a business grow" (Richards-Gustafson, 2017, para. 1). If a business discipline is indeed the practices that help a business grow, then supply chain management qualifies as a business discipline just as operations management qualifies as a business discipline. Supply chain management qualifies in that for a company to make money, they need products or services. To provide those products or services, the company depends on a supply chain to get the products or services to the customer and services within a company depend on a supply chain to get the products necessary to provide the service.

If you think about the food service industry as a service, you must understand that products are necessary to provide that service and those products each have a supply chain. If you consider Apple's iTunes as a product or service, it is necessary to understand that a product - iPhone/iPad/iPod/computer - is necessary to take advantage of the service of downloading music. Each of those products has a supply chain to produce and deliver them, thus making supply chain a business discipline.

As a business discipline it is easy to make a case that supply chain management is indeed a discipline based on the previously discussed definition of a business discipline. For this research it is important to also establish supply chain management as an academic discipline. Lancioni, et al. (2001), first referred to supply chain management as a discipline in higher education. Rogers and Braziotis (2016) wrote, "Currently, there is no consensus in terms of what constitutes course content" (p. 1). This is one of the issues with trying to create a framework for introductory supply chain management courses. The fact that the Association to Advance 
Collegiate Schools of Business (AACSB, 2016) report over one hundred and eighty schools have a supply chain management major or concentration would indicate that the accreditation board for business schools recognizes supply chain management as an academic discipline. This research project seeks to make the link between what the business discipline needs and what the academic discipline is providing.

Is supply chain management a separate academic discipline or is it a subset of other business disciplines? The online dictionary dbpedia.com defines an academic discipline as "a branch of knowledge that is taught and researched at the college or university level. Disciplines are defined (in part), and recognized by the academic journals in which research is published, and the learned societies and academic departments or faculties to which their practitioners belong" (dbpedia, n.d.). If this definition is accurate, then supply chain management qualifies as an academic discipline in that over 189 schools offer degrees in supply chain management at the undergraduate or graduate levels and the academia in this discipline produce journal articles and research papers on supply chain management topics.

A business discipline taught in schools as an academic discipline should have a framework or recommended curriculum to guide what is taught to students of that discipline based on what the business discipline requires of its new employees. One of the goals of this research project is to determine if an updated recommended curriculum should be developed to help universities better prepare students to meet the challenges of the changing supply chain management discipline by developing a recommended curriculum for introductory supply chain courses.

Supply chain management is not a stand-alone discipline. It has links to other aspects of business such as marketing, finance, accounting, and international business. This can best be 
seen in what is known as the supply chain star as shown below (Supply Chain Leadership Center, 2017). When developing supply chain curriculum or discussing supply chain topics, it is imperative that the reader understands the symbiotic relationship between supply chain management and other business disciplines. The supply chain star developed by the Supply Chain Research Center helps to demonstrate the interrelationships between common business topics and supply chain management. The supply chain star in Figure1-2 shows that each of the other business disciplines are critical to the success of supply chain management and should be considered in the curriculum development process. In speaking with the developers of the supply chain star, the intent of the star is not to depict supply chain management as the center of the business universe, but rather to show that effective supply chain management is not possible without the integration and synchronization of the other business disciplines. Any of the other disciplines could be moved to the center and supply chain to the periphery to make the same support case for the other disciplines.

The goal of the supply chain star is to simply show that supply chain management is not a silo activity in business but integrated with every other aspect of business. For example, a supply chain can have the best products in the world but if the marketing function does not let the customers know the products are available, there is no sale and no value added to the company. Conversely, the marketing personnel can develop and implement the greatest marketing campaign ever designed but if the supply chain cannot deliver the products then the customer will be disappointed. All of the functions or disciplines shown in the supply chain star have to have a customer focus and work together to add value to the company. 


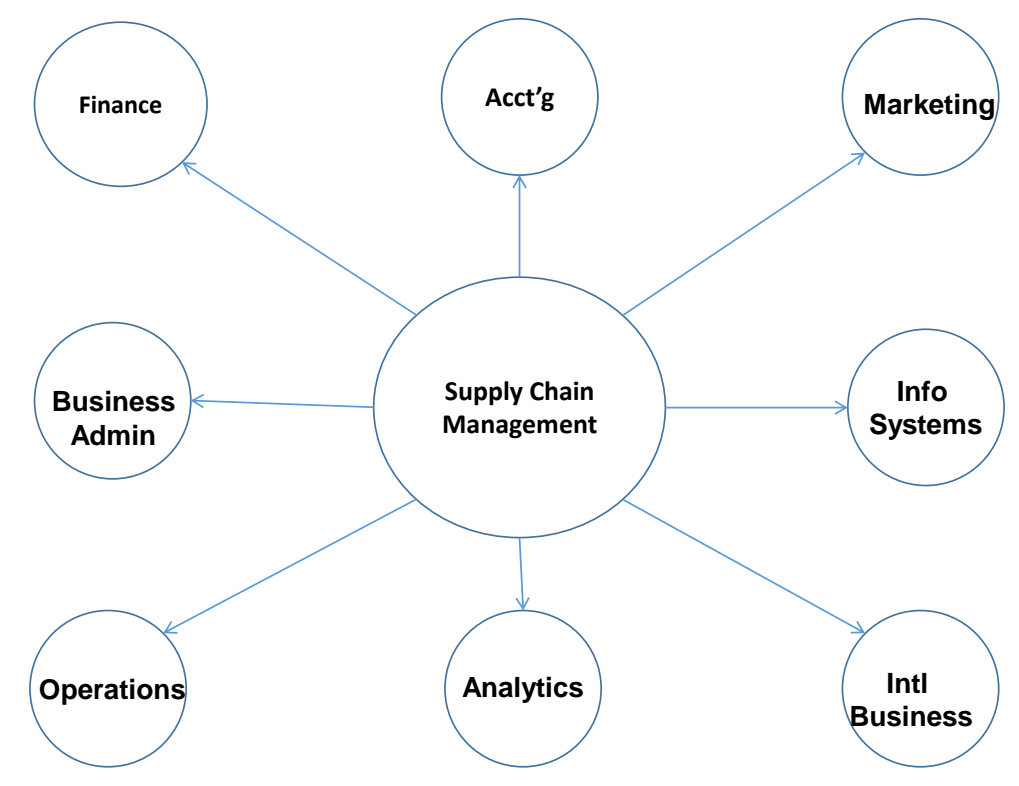

Figure 1-2: The Supply Chain Star

However, although commercial industry continues to gain an understanding of the synergies and interrelationships between the common business functions, it appears that some universities may have simply taken the old operations management classes and rebranded them as supply chain management classes to take advantage of the industry focus on supply chain management as suggested by Akalin, Huang and Willems (2016). Many university job announcements still mention the operations management professional forum INFORMS as a forum for hiring new faculty. This would appear to indicate that the hiring focus and the resulting teaching focus are still on operations management and not on supply chain management.

A recent discussion with a group of supply chain management faculty from some of the non-Top 25 schools revealed that the majority of the supply chain faculty (at one particular university) believes that operations and supply chain management are the same. This would add more credence that schools are hiring operations management faculty to teach supply chain 
management classes. This may be related to the suggestions of Akalin, et al. (2016), that some schools have simply changed the title of courses from operations management to supply chain management without changing the curriculum.

\section{The Supply Chain Management Discipline, Curriculum and the Talent Gap}

The importance of knowing what educators say they are teaching in supply chain management courses is predicated on the assumption that there is a need to expand supply chain management offerings at universities to help meet the growing talent gap in the supply chain management career field. This research project is based on the assumption that what is reflected in a course syllabus is what is being taught, or at least what the instructor believes is important in the study of supply chain management. It is also based on the assumption that there is (or should be) a relationship or correlation between what industry wants in its entry level supply chain managers and the academic content that students are being taught.

Industry continues to report that there are not enough graduates with the proper supply chain management skill sets graduating from universities. In a research brief published by DHL Supply Chain (2017) it was "estimated that demand for supply chain professionals exceeds supply by a ratio of $6: 1$, with some predicting that ratio could be as drastic as 9:1" (p. 1). The study goes on to say that the increase in demand for supply chain personnel is coupled with “changing job requirements" (p. 5). These changing requirements included leadership skills, strategic thinking, critical thinking, people skills and problem-solving skills along with operational expertise. This research project is focused on the content of what is being taught and not these mentioned skill sets themselves.

While a new graduate would not have the operational expertise mentioned by DHL, the ability to think critically and solve problems should be part of the undergraduate business 
experience. The DHL study concluded with the statement "The supply chain industry has a clear challenge ahead of it in tackling the talent shortage" (p. 9). Part of the solution may lie in determining if the content addressed in supply chain management courses addresses the needs of businesses.

A pilot study conducted in 2017 to look at supply chain education offerings compared a random sample of ten introductory supply chain management syllabi to three different sets of twenty job announcements for entry level supply chain management positions. The comparison of the selected syllabi topics to the job announcement requirements from March and April 2017 revealed eight topics that were asked for in the job announcements that were not covered in the syllabi subjects (team member, continuous process improvement, communicate, engineering, material, transportation, certification, environment). There were also six topics covered in the syllabi instruction that were not asked for by industry in the job announcements (forecasting, globalization, strategy, project management, services, and lean). The pilot study was constrained by the limited number of syllabi used for the analysis, however, it did provide sufficient information to show that there may be a disconnect between what is being taught by universities in their introductory supply chain management classes and what industry is seeking for entry level supply chain manager positions. Just because a topic was taught and not asked for does not mean that it was not important as it may be a subset of another requested topic. For example, forecasting was taught but not requested; however, inventory management was asked for and forecasting could be considered a subset or implied aspect of inventory management.

The AACSB is the accreditation board for business schools. Their latest data shows that the 500+ member schools had enrollment of over 990,000 students in 2015 but only 0.6 percent of those students are graduating with a major or concentration in supply chain 
management/logistics/transportation (AACSB, 2016). With numbers this small and the need for supply chain management professionals growing as industry continues to realize the value of supply chain management to corporate profitability, it is critical that supply chain management instructors are teaching the right skill sets to their graduates. Because of the documented shortage of supply chain management graduates coupled with the growing demand for supply chain management professionals, recruiters for supply chain management jobs may have to widen the search criteria for job candidates; this points to the need to expose undergraduate students to supply chain management topics and subjects in their introductory supply chain management classes.

While the number of schools offering supply chain management courses continues to grow, the output of students in both numbers and background would appear to be insufficient to meet the needs of industry. This would indicate that there may be an industry wide issue linked to a disconnect between what industry continues to ask for in entry level supply chain management positions and what schools are teaching to meet the needs of industry. This is not a new problem. As early as 1977, Piercy, et al. (1977), stated "the academic community is not in tune with today's needs of industry" (p. 75). They went on to state that academia being out of tune with industry leads to ill prepared students. Although supply chain management was not a part of the business lexicon at that time, the issues that were identified for logistics and transportation courses, which are now a part of supply chain management, appear to be continuing as pointed out by Gravier and Farris (2008) with their observation that students are graduating from supply chain programs but are not properly and fully prepared for the job market. My study focuses on the link between university introductory supply chain management course curriculums and the needs of industry in preparing students for the commercial world. 


\section{The Need for This Research}

The purpose of this study was to develop a recommended curriculum for introductory supply chain classes to expose undergraduate students to supply chain management concepts. Why is such a study necessary? Primarily because the supply chain management career field has changed over the past twenty years because of the changing business environment, globalization, increased emphasis on gaining efficiencies by reducing or eliminating non-value adding activities and practices and a growth in the realization that adopting supply chain management principles can lead to greater profitability.

Another key aspect mandating this study is the changing requirements for supply chain professionals as more companies become aware of the criticality to success from proper supply chain management practices. Christopher called the changes in the supply chain management career field as a "rapid rate of change" (2016, p. xiii) in the supply chain management career field requirements. This changing requirement base should drive frequent curriculum reviews and a standard framework for teaching supply chain management to ensure that students are fully prepared to enter the supply chain management field. However, the only two studies that proposed a framework for supply chain management education were published in 2000 (Johnson \& Pyke) and 2004 (Bandhopadhyay) when the discipline was brand new. Some schools that I talked with have not conducted a curriculum review since the beginning of their programs a decade ago. All of this point to the need for an updated study on what a recommended curriculum for teaching supply chain management should contain if we are going to best prepare our students to help fill the talent gap. 
In addition to the small number of graduates, this talent shortage problem may be linked to what skills and knowledge students in introductory supply chain course are bringing to the table from their respective supply chain management classes. The last comprehensive study of what should be studied was a 2004 update (Bandyopadhyay) of the recommended curriculum published in 2000 (Johnson \& Pyke) when the discipline of supply chain management was still relatively new. When Johnson and Pyke started researching what to teach in supply chain management, most of the schools that have supply chain management programs today did not have these programs. When Bandyopadhyay updated the curriculum in 2004, he made it clear that the growth in demand for supply chain graduates provides "a tremendous opportunity for preparing our university students into a supply chain management career path" (p. 67). Since these two studies, most of the discussions have focused on MBA courses rather than undergraduate courses. Figure 1-3 lists the topics that Johnson and Pyke (2000) and Bandyopadhyay (2004) recommended be included in a supply chain management curriculum. 


\begin{tabular}{|c|c|}
\hline Johnson and Pyke & Bandyopadhyay \\
\hline$(2000)$ & (2004) \\
\hline Location & Location \\
\hline $\begin{array}{l}\text { Transportation and } \\
\text { Logistics }\end{array}$ & $\begin{array}{l}\text { Transportation and } \\
\text { Logistics }\end{array}$ \\
\hline $\begin{array}{l}\text { Forecasting/Inventory } \\
\text { Planning }\end{array}$ & $\begin{array}{l}\text { Forecasting/Inventory } \\
\text { Planning }\end{array}$ \\
\hline marketing & marketing \\
\hline $\begin{array}{l}\text { sourcing/supplier } \\
\text { management }\end{array}$ & $\begin{array}{l}\text { sourcing/supplier } \\
\text { management }\end{array}$ \\
\hline information & information \\
\hline product design & product design \\
\hline $\begin{array}{l}\text { service and after sales } \\
\text { support }\end{array}$ & $\begin{array}{l}\text { service and after sales } \\
\text { support }\end{array}$ \\
\hline \begin{tabular}{|l|} 
reverse \\
logistics/green
\end{tabular} & reverse logistics/green \\
\hline outsourcing & outsourcing \\
\hline metrics/incentives & metrics/incentives \\
\hline \multirow[t]{3}{*}{ global issues } & global issues \\
\hline & just-in-time \\
\hline & total quality \\
\hline
\end{tabular}

Figure 1-3: Johnson and Pyke compared to Bandyopadhyay

Southern (2011) addressed the historical development of supply chain management curriculums over the past forty years from stovepipe subjects to an integrated curriculum today. In his discussion, Southern points out curriculums of the $21^{\text {st }}$ Century are "characterized by a slow evolution from logistics to supply chain management in both academic and business circles" (p. 60). However, he also points out as did Akalin, Huang, and Willems (2016) that many of these curriculum changes were in name only and simply a change from operations management to supply chain management without changing the curriculum itself. Akalin, et al. (2016), point out several topics included in both Johnson and Pyke's framework and Bandyopadhyay's framework such as total quality management, inventory planning, forecasting, 
and production planning that are traditional operations management topics as an indicator that some universities simply changed names of courses without changing the course content.

\section{Purpose of Study}

Supply chain management is a new but ever evolving field, which results in an ongoing gap between what the field requires and those possessing the skills necessary to meet the field's requirements. While academic preparation of supply chain management professionals is one critical way to address this gap, research suggests that such academic programs possibly are contributing to, rather than closing, that gap. There are few studies that have examined the substance of the undergraduate supply chain management curriculum as pointed out by Birou, Lutz and Zsidisin (2016), particularly in relation to what experts consider essential skills for those in supply chain management. This study is the largest analysis of undergraduate syllabi of introductory supply chain management courses by looking at seventy-eight introductory supply chain management syllabi. The previously largest undergraduate study looked at twenty-four syllabi (Birou, Lutz, \& Zsidisin, 2016).

The goal of this study was to feed future research into the development of a curriculum review guide for conducting/updating curriculums to ensure that supply chain graduates are fully prepared for the growing job market. The rationale for the study was based on the hypothesis that with an increasing demand for supply chain talent, it is imperative that academia best prepare the students for what they need to know to be competitive for the best jobs. Using a conceptual funnel approach the overarching concept is the teaching of supply chain management at the university level and the needs of industry based on the growth of supply chain management as a career field. The focus is on what is being taught in the supply chain courses. With a further funneled focus on what is reflected in the syllabi as important to be covered in introductory 
supply chain courses compared to what is being asked for by industry. Is what is reflected in the syllabi meeting the needs of industry? Using the focused funnel approach to frame the problem provides a picture of the inputs leading to the focus of this study, which was what should a recommended curriculum for introductory supply chain management courses look like? What ought to be taught in an introductory supply chain management course? This leads to the foundational questions of this research project.

\section{Research Questions}

A. What is alike and different between what supply chain management introductory course syllabi expect of students and what the field requires of those entering the supply chain management career field?

(1) What do supply chain management companies require of those entering the field?

(2) What do supply chain management introductory course curricula/courses require of students?

B. What might the supply chain management introductory course syllabus need to address to close the gap between curriculum expectations and job requirements?

\section{Methodology}

This study used a case study approach to look at what was being taught in the introduction level supply chain management courses. The focus of this project was "What are we teaching and why are we teaching it?" while trying to answer the question "Is there a better way?"

The data collection was a combination of literature analysis to determine what is being written about supply chain management education coupled with reviews of randomly selected 
supply chain management job announcements, and selected supply chain management syllabi. The analysis combined both a qualitative case study approach coupled with some quantitative analysis of the most commonly used terms in the syllabi and job announcements to determine the relationship of the frequency of use of key topics in the job announcements and syllabi. The quantitative analysis was used to establish the relative importance of the topics based on the frequency of use in the job announcements and syllabi.

Did the syllabi and job announcements address the same or similar terms and topics? The key terms used were based on the APICS Certified in Production and Inventory Management Basics of Supply chain management module required terminology. The Basics of Supply Chain Management module of the APICS Certification process provides a certification in a consistently updated testing of a student's knowledge of supply chain management terms, topics and concepts. For this study, the listing of key terms was used for comparison with the syllabi and job announcements and this listing was included as an appendix (See Appendix 3).

The analysis of the data compared the frequency of the topics that are being taught according to the syllabi with the frequency of the topics that human resources professionals are asking for in the job announcements for entry level supply chain managers. There were two major assumptions in the analysis of the job announcements and syllabi. The first assumption was that the syllabi reflect what is being taught and the currency of the topics. The second assumption was that the job announcements accurately reflected the needs of industry in entry level supply chain management jobs.

The job announcements came from online job boards (jobsinlogistics.com, Careerbuilder.com, indeed.com, USAjobs.gov, and Monster.com) with the search criteria being "entry level supply chain manager" positions. The job announcements were pulled down every 
two weeks from September 2017 until November 2017 and provided seven separate sets of announcements. The job announcements were qualitatively coded for key terms that were then quantitatively ranked based on their frequency of appearance. This coding considered specified versus implied skills. A specified skill/knowledge area is a term clearly stated in the job announcements and syllabi such as inventory management. An implied skill/knowledge area for inventory management based on my forty years of experience with inventory levels in excess of $\$ 1$ billion has to include forecasting and demand planning to ensure the right quantity of inventory is available to meet customer demand. Therefore, while forecasting may not be specifically asked for in job announcements or specifically stated as a topic in a syllabus, it should be discussed to ensure proper inventory management concepts are clear.

The comparison of the frequency distributions of the job announcements and syllabi key words enabled the analysis of what skills and knowledge are being taught to what skills and knowledge are being recruited for. This allowed for the comparison and analysis of what academia thinks is important for students and what industry thinks is important for the job candidates that they are interviewing and hiring. The analysis identified similarities and gaps in the processes.

A major assumption or limitation to this study is that the syllabi reflect topics that are taught in the classroom while the job announcements may contain the same topic, but recruiters that are developing the job announcements are looking for abilities and skill sets and not just exposure to the concept or topic as was pointed out in a recent article in the Supply Chain Management Review (Baehr, 2018). 


\section{Organization of the Dissertation}

The remainder of the dissertation is organized as follows: Chapter two is a thorough review of the current, relevant literature on the supply chain talent gap, what is being taught in introductory supply chain courses and historical and current literature on what should be taught in a supply chain management course. These three areas helped frame the research questions and helped establish that there is a need for a supply chain management course framework to help improve undergraduate knowledge levels and prepare students to be competitive in the supply chain job market.

Chapter three details the methodology that was used in capturing the necessary data, compilation of the data, analysis to turn the data into useful information to help form the basis for conclusions and recommendations. The methodology was a combination of both qualitative and quantitative approaches and addresses the use of the case study approach that I used in capturing, coding, and analyzing the data.

Chapter four contains the findings of the study from both a qualitative perspective as well as a quantitative perspective. The qualitative perspective looked at what topics were discussed and what skills/knowledge sets were asked for by recruiters. The quantitative perspective looked at the frequency of the topics to determine a frequency distribution and rankings of what topics were discussed/requested from most frequent to less frequent.

Chapter five contains the analysis and findings to make recommendations about a framework for developing supply chain management curriculums for the introductory level courses. The recommendations are dependent on the data analysis and findings. I also addressed the limitations of the study and my recommendations for future research in the field of supply chain management education. 
The appendices for the study are as follows:

Appendix 1: Data Inventory - Syllabi used in analysis

Appendix 2: Data Inventory - job announcements

Appendix 3: Listing of Key Supply Chain Terms from the APICS Basics of Supply Chain Management Certification Module

Appendix 4: Listing of Key Operations Management Terms from the APICS Certified in Production and Operations Management Operations Module 


\section{Chapter 2}

\section{Literature Review}

"Rigorous research can only be conducted in relation to the existing knowledge.

Literature reviews are therefore an essential part of the research process" (Seuring, Müller, Westhaus, \& Morana, 2005). The goal of this literature review was to establish what has already been studied and/or written about teaching supply chain management. A secondary goal of the literature review was to provide a link between what has been studied in supply chain management education, curriculum development and the coordination or lack of coordination/collaboration between industry and academia in developing this curriculum. The literature review for this study was broken into three major areas of concern within the supply chain management career field. The first was the talent gap; the second area of the literature review looked at curriculum development issues; the third major area was the link between what universities are teaching and the impacts on the talent gap. The literature review focused on whether there was a need for a recommended curriculum for teaching introductory supply chain management classes based on previous supply chain management research.

\section{Literature Review: Bottom line Up Front}

- The literature and trade magazines confirm the reality of the talent gap based on growing content requirements (MHI, 2015; Ackerman, 2016; Ryder, 2017), growth in the supply chain industry (Harrington, 2015; Stevens, 2017) and a shortfall in the quality of what is being taught in university courses (Gravier \& Farris, 2008; Maloni, Scherrer, Campbell, \& Boyd, 2016). 
- The review of literature concerning supply chain management talent and supply chain management curriculums to meet the needs of the talent shortage reveals that while there has been a great deal written about supply chain management, there has been very little focus on the topic of supply chain management curriculum development. Jordan and Bak (2016) confirmed this in their review of 24 studies over 15-year period. Their research led them to the conclusion that there is a need for future research into supply chain management curriculums. This was confirmed by Birou, Lutz and Zsidisin (2016) who reported "There are relatively few studies which have been focused on SCM (supply chain management) curriculum" (p. 73).

- Research points to the gap between market needs regarding competencies within supply chain management and the acquired competencies/skills/knowledge sets of baccalaureate graduates (Wong, et al., 2001; Birou and Lutz 2013; Birou, et al., 2016).

- The first proposed framework for teaching supply chain management was published in 2000 when the discipline of supply chain management was still relatively new in academia (Johnson \& Pyke, 2000).

- The APICS Basics of Supply Chain Management Exam Book (2016) contains a list of four hundred and forty-nine key terms approved by industry as critical for understanding supply chain management and required understanding for taking the Basics of Supply chain management exam as part of the APICS certification process. This list of terms will serve as the foundation for the first coding of the syllabi and job announcements. In addition, the Gartner Top 25 Supply Chain Schools (2016) identifies supply chain competencies and leading and trailing programs based on the Gartner model. This report has a high level of credibility with industry leaders, as they are part of the research survey 
respondents. As a result, the study looked at the topics taught by the Top 25 Schools for 2016 and some of the schools in the 2014 rankings when the provided syllabi fell into the 2013-2014 timeframe of the 2014 rankings.

\section{Is there a talent gap?}

Why is it important in this particular research to establish is a talent gap exists? The existence of a supply chain management talent gap could indicate that because of the lack of qualified supply chain graduates to industry's needs, recruiters need to widen the scope of their recruiting efforts to reach more than just supply chain management graduates. If recruiters are forced to cast a wider net to reach qualified candidates, then there is a need for an introductory supply chain management course to reflect the content desired by industry so as better prepare non-supply chain business students for future job opportunities in supply chain management.

Does the literature reveal a talent gap in the supply chain management career field and if so, is it a gap in the number of qualified applicants to fill the positions, a gap in the skill sets of the potential job applicants or an issue of both numbers and skills? If no gap exists, then there is no need to review what is being taught to fill the gap. While the issue of a talent gap is not a new phenomenon, it continues to gain momentum in trade magazines, website editorials and research papers and was the focus of a study by the University of Tennessee at Knoxville that attempted to explain why there was a talent gap and the need for qualified candidates to fill the vacancies (Scott, Burnett, Dittman, Stank, \& Autry, 2015). The UT study went on to explain that "supply chain management continues to evolve... This has led to significant shortages for talent" (p. 3). But this is not news in the supply chain world, but perhaps overlooked by too many practitioners and academicians. Lancioni identified the coming talent gap as early as 2000 as well as some of 
the same issues (complexity, rapid changing requirements, analytic and e-commerce) that are still being discussed today.

It is difficult to pick up a trade magazine without finding an article or commentary on the "Supply chain management Talent Gap." One estimate from a peer-to-peer focus group session at the APICS 2015 Conference placed the requirement for skilled supply chain management workers around two million by 2025 (2015). Another attendee stated that his company was facing the reality of over $50 \%$ of his supply chain work force reaching retirement age in the next “few years.” Similarly, Mike Burnette (2014) stated that discussions with supply chain leaders point to the talent gap and that finding quality graduates to fill the gaps may be the number one challenge facing supply chain leaders worldwide. Couple this with the continued realization that competitiveness in today's business environment depends on a responsive, agile supply chain and it starts to become obvious that the talent gap is a reality. A similar talent gap exists in supply chain management programs as most universities struggle to attract both faculty to meet the growth requirements for teaching supply chain management undergraduate courses and students to complete doctorates in supply chain management, creating the "perfect storm" in the supply chain management talent acquisition and retention: a shortage of available talent; an increase in retirement rates for baby boomers; and, a faculty shortage to educate the next wave of new employees.

In an article for Industry Week Magazine, Roussel discussed the talent shortage in supply chain management and went as far as saying that there will be a "war for talent" due to the shortage of educated or trained professionals to fill the gaps in the demand for supply chain talent (2014). In a similar commentary in 2011, noted supply chain author Dave Blanchard warned that there is not and will not be a sufficient supply of supply chain managers to fill all of 
the present and future jobs in the field (2011). In a more recent article Blanchard stated: "Supply chain management is getting exponentially more complex, so supply chain talent is the price of admission to the next decade" (2014).

Given that the talent gap does exist in the supply chain management career field, why is there such a gap in 2018 if authors such as Laniconi (2001) predicted such a gap almost eighteen years ago? As Ackerman pointed out, there has been a shift in the knowledge and skill sets for personnel in the supply chain management career field (Ackerman, 2016). Revealing that the talent shortage is not a new issue, the Massachusetts Institute of Technology's Center for Transportation and Logistics prepared a research report in 2010 that asked the question "Are you prepared for the supply chain talent crisis?" The introduction to this study stated the problem very succinctly but since the problem continues to be an issue seven years later it would appear that few in the industry took the time to read the report. "Supply chain faces a severe shortage of talent at a time when the demands on the profession have never been greater. Globalization, market uncertainty, shifting demographic patterns and the emergence of supply chain as a strategic function are some of the factors that are driving the skills shortfall” (Cottrill, 2010). While not addressing the skill sets that Cotrill spoke of, this research project assumes a link between the skills that industry desires and the building of the knowledge that the skills are based upon.

What is causing this talent gap that has been identified or forecasted since 2001? In a research project conducted for Ryder (2017), there was a white paper published on the supply chain talent gap and the challenges facing businesses in attracting and retaining the right personnel. "Supply chain talent management is extremely challenging work. The skills required to be successful in a supply chain organization are diverse, complex, and broad. This combined 
with the current market situation where the demand for most of these skills exceeds the supply creates a huge business challenge" (p. 7). They also report "Global economic growth and rising consumer demands are creating a shortage in supply chain talent management from the warehouse to the executive suite" (p. 2).

In a Wall Street Journal article, Stevens (2017) discussed the growth in employment needs for Amazon as they continue their expansion from six facilities in 1999 to 230 facilities in 2017 with more to open soon. Although the hiring squeeze that Stevens wrote about is focused on the warehouse workers, there is also an impact on the warehouse and distribution management levels to manage the growing number of e-commerce fulfillment facilities. This result according to Stevens is a growing trend to hire from competitors. Hiring from competitors would seem to simply perpetuate the talent squeeze. While the hiring of competitors' talent is not new, it does not solve the issue. In 1999, Amazon sought out the supply chain staff of Walmart to help start their new ventures away from a virtual company owning nothing to a company with retail inventory and distribution centers. In 2017, Target did the same thing by hiring Amazon employees to help improve the Target online sales strategy. The problem with this personnel strategy is that it does not help fill the gap, it only shifts the holes or gaps to a different company. Instead of hiring from competitors, if a common framework could be established for teaching supply chain management at the introductory level, students would at least be aware of the job market and common topics necessary to be competitive for the supply chain management jobs.

Respected supply chain guru Ken Ackerman (2016) in an editorial for DC Velocity magazine states "Ironically, the shortage of skilled workers is accompanied by an overage of people who are impaired, unskilled, or have skills that are not needed in today's marketplace. Simply stated, the problem is this: The need for a variety of educational skills exceeds the 
number of people who already have those skills" (para 3). Ackerman goes on to state that the old ways of acquiring talent will not work today. Here lies one of the problems that is driving this research project - corporations are trying to acquire talent today in the same way that they did twenty years ago when the talent pool supply outnumbered the talent demands. When there is a documented talent shortage as pointed to by Ackerman, there needs to be a new approach to educating the new talent through a partnership between universities and the recruitment of that talent by corporations.

According to the Materials Handling Institute (MHI) in their 2015 Annual Industry Report (2015), echoing Ackerman, there are lots of factors that do and will contribute to the talent gap, including changing skill sets and also the issue of the graying of the workforce. MHI also suggests that there may be over one million new jobs created in the next five years. These new jobs are a combination of the requirement for new skills, a growing focus on the importance of supply chain management in corporations and the graying of the workforce.

In a white paper study by the Robert H. Smith School of Business at the University of Maryland in 2015 entitled "Solving the Talent Crisis," Lisa Harrington states "Supply chain talent is in short supply worldwide." Harrington goes on to state that the security of the industry depends on meeting this talent shortage directly with a strategy to not only attract new talent but retain that talent in an industry that has a $15 \%$ turnover rate. In other words, just attracting new talent is not the full answer to the problem, companies need to retain the talent that they do have to prevent employee turnover. Harrington further states that the "demand for supply professionals exceeds supply by a ratio of 6 to 1" (Harrington, 2015).

"Demand for top talent increases as supply chain volumes and complexity rise, but the supply of talent is decreasing" (Scott, Burnett, Dittman, Stank, \& Autry, 2015, p. 3). The 
changes in the complexity of supply chain management over the past couple of decades has produced a much larger need for supply chain management talent in all corporations. This has led to "significant shortages for talent and the need for existing talent to have a dramatically different outlook about their roles and expectations" (Scott, Burnett, Dittman, Stank, \& Autry, 2015, p. 3). According to Scott et al., the new supply chain requirements point to the need for trained and educated leaders with the ability to "lead multifunctional processes which span the business." At the same time, it would appear that many studies are pointing to the need to have new talent with a global perspective and possessing "soft skills" such as being able to communicate and work on teams.

"Supply chain management talent is arguably the most difficult and unique of all business requirements. The skills necessary to be successful in a supply chain organization are diverse, complex, and broad" (Scott, Burnett, Dittman, Stank, \& Autry, 2015, p. 4). In a report in the Supply Chain Management Review, Ruamsook and Craighead (2014) from the Center for Supply Chain Research, Smeal College of Business, at The Pennsylvania State University, echo the ratio of jobs to graduates from supply chain programs at 6 to 1 . They also state that the growth of demand for supply chain talent may reach upwards of twenty-six percent between 2010 and 2020. This growth rate is almost two times the rate of growth for most industries. This leaves supply chain companies scrambling to not only find talent but, as Harrington alluded to, retaining talent and preventing employee turnover and turmoil. Ruamsook and Craighead (2014) appear to be in agreement with Ackerman and the MHI when they state that the changes in the requirements for supply chain managers will also impact this talent shortage issue. "In fact, it is projected that three out of four jobs in supply chain will change" and "that 60 percent of all new jobs in the 21st Century will require skills that only 20 percent of the workforce possesses" (p. 
14). They also stated that this is not a short-term aberration and that the talent shortage will continue to impact all aspects of the supply chain management career field.

\section{Talent gap and supply chain skill sets.}

Part of the talent gap can be attributed to the changing demand for skill sets in the supply chain practice as discussed by Lorentz, et al., in their discussion of establishing priorities for supply chain skills developments (Lorentz, Toyli, Solakavi, \& Ojala, 2013) or the "rapid rate of change" in the supply chain as discussed by Christopher (2016). The same point is made in the research of Leon and Uddin with regard to the issue of finding and retaining supply chain talent as a result of the changing skill sets requirements since the implementation of supply chain management as a strategic focus in the 1990s (2016). This leads to the idea of reviewing job announcements and future research that includes interviewing supply chain professionals to ascertain if course topics are meeting the needs of industry. While it is understood that industry is looking for skill sets, the assumption is that the course content as reflected in the syllabi will not necessarily provide skill sets but will provide the knowledge that these future skill sets are built upon.

Contained in this mix of necessary skills that universities need to educate graduates in is analytical skills (as pointed out by Lancioni in 2000) - in other words, the graduates need the ability to know what numbers mean and not just how to put them in an Excel spreadsheet. Companies have expressed the desire to have graduates that have an understanding of how operations fit the overall strategic direction of the company as well as the ability to think creatively and problem-solving skills. Velazquez (2015) alludes to this need for analytical skills and critical thinking when discussing the use of simulations to help students understand the 
"consequences of each decision" and how the ability to analyze data leads to a big picture understanding of efficiency and effectiveness in operations.

Communication skills and international experience (internships or study abroad) were also considered important according to Cottrill (2010). This study by Cottrill confirms that feedback provided from peer-to-peer discussion groups from the Warehousing Education and Research Council (WERC), the Southern Africa Production and Inventory Control Society (SAPICS) and American Production and Inventory Control Society (APICS) focused groups I hosted on best practices and how to teach supply chain management. However, Cottrill concludes his discussion of necessary skills to fill the talent gap by stating "What I have seen is that a broad knowledge and skills set across the supply chain is really lacking at universities" (p. 6). This observation links part of the issue with the talent gap with what is being taught at universities in supply chain management programs.

Florida Institute of Technology (FIT) was one of the first universities to offer a degree or a concentration in Logistics Management before the advent of supply chain management. In an online article, FIT pointed out that "Supply chain skills evolving, growing in demand: Jobs for supply chain professionals are projected to increase in the coming years....the U.S. Bureau of Labor Statistics reports that jobs for supply chain professionals, or logisticians, will rise by $22 \%$ between 2012 and 2022 - that's twice the average growth rate projected for all occupations during the same decade" (2017). FIT used this platform to make a pitch for the value of their online masters' degree program in supply chain management. In the article, FIT discusses the skills such as technical skills related to inventory management, financial management, information technology and systems thinking while emphasizing how their program meets these requirements in the classroom and in cooperative programs and internships. 
Hiring the right person for the job is akin to the analogy of James Collins (2001) in his book, Good to Great, when he discussed getting the right people on the bus and in the right seats while removing the wrong people before leaving the station. Getting the right employee that meets the needs of the company is part of the process of getting the right people on the bus. Zinn and Goldsby (2017) listed attracting and retaining supply chain talent as one of the top challenges that needs to be researched.

The talent shortage can be summed up simply with a statement by Price Waterhouse Cooper (PwC): “The race is on! Good employees aren't just a commodity anymore, they've become a scarce resource" (2017, p. 1) .The PwC white paper "Winning the Talent Race" summed up the issue with the idea that talent acquisition and retention should be at the top of every supply chain management organization's priority list for the next 20 years. Talent acquisition is linked to the quality of the graduates coming from supply chain courses. The quality of supply chain graduates is linked to the focus of this paper: what are students being taught compared to what industry wants? The PwC white paper reveals that $29 \%$ of executives that they surveyed expressed concern over finding employees with the right skills (p. 15).

\section{Literature on the link between academics and talent gap.}

"The competition to hire supply chain graduates is more intense than ever. Supply chain organizations that have strong connections with university programs have a material advantage in building and maintaining strong talent pipelines" (Stifler, 2018).

Is there a link between academia and the talent gap for supply chain management? Can universities help fill the talent gap? Based on their review of eight supply chain management course syllabi, Johnson and Pyke developed a framework for teaching the new academic 
discipline of supply chain management (2000) and recommended developing courses around the ten major areas as shown in Figure 1-3. While Johnson and Pyke provided a good start to teaching supply chain management, they approached the new discipline from an operations management perspective because of their backgrounds in operations. While not a bad start, the rapid rate of change alluded to by Christopher (2016) would seem to indicate that a modification or revision of the framework from 2000 may be needed. Schwarz and Singhal though suggest challenge possibly faces business schools that might seek to operationalize such as framework as "business schools aren't training their own doctoral students to be the kind of faculty they want to hire;" (1998, p. 90) leading the authors to point out that if supply chain management faculty do not understand the interrelations of the different business topics to supply chain management (See Figure 1-2 for the interrelationships), then the students will graduate without knowing how the different business disciplines relate as shown in chapter 1 with the supply chain star.

\section{If there is a link, is it related to the syllabi content?}

"If logistics academics want to lead rather than follow practitioners, then we must gain extreme relevance in our research.” (Seuring, Muller, Reiner, \& Kotzab, 2005)

Why is looking for this link important? If there is no relationship between academia and preparing future supply chain management employees, then there is no need to update the twodecade old framework. Yen-Chun (2007) looked at the education of supply chain management students from an international perspective. He identified a trend away from collaborating with businesses leaving a huge gap in the development of qualified talent and the decades old concern of how supply chain management should "fit into an undergraduate business curriculum." This concern was addressed as early as the 1970s in relation to logistics management, a precursor to supply chain management. Although Yen-Chun's paper is eleven years old, the statement would 
appear to be still a valid statement and points to the need for industry and academia to collaborate on what should be taught and what is actually taught.

In 1978 Peter Gilmore (1978) hosted educators from sixty-four colleges and universities at Harvard University to discuss logistics education. Part of the discussions centered on establishing a framework for teaching logistics and whether logistics (now considered a subset of supply chain management) should be a separate discipline or included as part of other curriculums. The consensus of the attendees was that the curriculum should include logistics, distribution management, systems management, distribution channels, logistics theory, quantitative methods, and cost analysis. A key issue identified by this forum was the lack of academically qualified professors with degrees in logistics (prior to supply chain management as a discipline, the functions of transportation, distribution and warehousing which are now a part of supply chain management were considered part of logistics) on the faculty, which was also identified in other literature as an ongoing issue (Schwarz \& Singhal, 1998). The forum also identified a need to have industry-based research vice technical research. Industry based research would provide the faculty with current and relevant topics to present to students to better prepare the students for entry into the work force. Although this forum was conducted almost 40 years ago, some of the issues then are still current today pointing towards the need for a recommended curriculum for supply chain management.

\section{Universities and Supply Chain Talent/Skills.}

Lambert, Cooper, and Pugh (1998) stated that one of the aspects that should be included in supply chain education is the integration of activities and learning how to map the supply chain from the sourcing of raw materials to the delivery of the product to the intended customer. This is the only paper encountered in the literature review that mentions the need for knowing 
how to map the supply chain. Knowing where materials come from, how they get to the factory and how they get from the factory to the customer is critical to understanding the supply chain and teaching what a supply chain is and does. Tied to this issue are the modern day concerns of sourcing from companies and countries using slave labor. Without a holistic view of the supply chain, this knowledge may not be possible.

The idea of the supply chain going from the sourcing of raw materials to the ultimate end user of the product is a vital component of the APICS-SCC Supply Chain Operations Reference (SCOR) Model (APICS, 2017). This model of the supply chain is also a key component of the analysis contained in the Gartner Top 25 Supply Chain Education Programs ranking of university supply chain management programs. A series of questions concerning curriculums are centered on the six components of the SCOR Model: Plan, Source, Make, Deliver, Return and Enable.

While the Gartner Research focus is on the use of the SCOR Model, a research study published in the International Journal of Logistics Management in 2008 looked at the literature up to that point that focused on the curriculum, content and pedagogy of supply chain and logistics education. This study determined that supply chain "education continues to benefit from strong ties to industry. Additionally, four principle macro-environmental factors were discovered that impact the current status of logistics education: an increase in the number of logistics education programs, limited supply of logistics trained faculty, changes to content requirements, and a changing teaching environment" (Gravier \& Farris, 2008, p. 233). Their views seem to be in contrast with Reddy and Velazquez on the lack of collaboration between industry and academia to prepare the best possible supply chain talent coming out of universities. 
In compiling their literature review on logistics and supply chain education, Gravier and Farris did discover that there was an evolution between the 1960s and the 1980s (Gravier \& Farris, 2008, p. 239) from what the discipline of logistics is to "what are we teaching?" Perhaps it is time to do the same analysis again based on the continuous changes in the supply chain management concepts. The concept of what is taught Supply chain management as a concept is a relatively new concept in business as it first appeared in the Financial Times out of London in 1989. By researching articles back to the 1960s, Gravier and Farris establish a nice historical timeline but may have clouded the issue by not looking at more modern studies and articles that focus on supply chain management versus simply logistics management.

Gravier and Farris state clearly that "The evolution of logistics education has implications for pedagogy, curriculum, and industry" and that "all too often new graduates have arrived at the workplace less than adequately prepared for careers" in supply chain management (p. 234). However, because of their closeness to the problem, they do not put the blame for these shortcomings in preparation on academia.

van Hoek, Godsell and Harrison (2010) addressed the issues of talent development, talent shortages in industry and collaboration with academia, "The shortage of supply chain (SC) talent experienced in industry helps explain the continued growth in SC educational offerings since the mid to late 1990s that has continued until recently...They point to a lack of courses, faculty and dean support" (2010, p. 142). The authors recommended a "multi-industry partnerships and for faculty to be informed about the changing educational needs of industry so that teaching programmes remain current."

Lancioni, Forman, and Smith (2001) postulated that one of the drawbacks to this multiindustry partnerships and informed faculty may include "the uncertainty of knowing whether 
logistics/supply chain is its own discipline or a part of another body of knowledge" and a stovepipe approach to teaching logistics/supply chain that is not tied to the inter-discipline requirements of industry for supply chain talent (p. 55). There may be some credence here in that supply chain courses fall under a wide variety of departments at universities from Marketing to Decision Sciences to Economics to Business Management and some major universities with a separate supply chain management department. The lack of inter-disciplinary education is the comment here that creates the most concern. If industry partnerships are established and industry is telling universities what they need in supply chain graduates, there should be a very well established multi-discipline approach to the curricula with regular curricula assessments to make sure the faculty and the pedagogy remain current and relevant.

Lancioni, et al., also identified a trend in supply chain programs that have Supply Chain Centers established at the universities. Amazingly, in their study the third most common reason for the establishment of a Supply Chain Center at universities was "support the teaching efforts of the logistics faculty (only $9.2 \%$ of their respondents)" and the fifth most common reason was to "assist the faculty in the development of courses (only 7.5\% of their respondents)" (Lancioni, Forman, \& Smith, 2001, p. 59). What is of interest here is the relatively small number of respondents that believed that the purpose of their supply chain center was to help support the teaching efforts.

One of the research questions of my research is what would a supply chain management framework look like based on the similarities and gaps between what is taught in universities and what is asked for by industry? The writings of Lancioni, et al., point to the need for collaboration between universities and industry to help develop the talent needed to fill the gaps in supply chain management. 


\section{Literature on curriculum development.}

Did previously published research/papers discuss curriculum development? If there is a shortfall linked to academia, as shown above, what does the literature say about supply chain management curriculum development?

It is important to look at the historical record of research and discussions of supply chain management as a discipline and determine if any research or discussions have looked at curriculum development. Supply chain management is a relatively new discipline in business. The term supply chain management first appeared in print in a series of papers out of England written for Booz Allen Hamilton (Oliver \& Webber, Supply Chain Management: logistics catches up with strategy, 1992). However, the common usage of the concept in business did not really catch on until the late 1990s. As the concept has continued to develop, it is important to make sure that the curriculum in business schools is properly preparing students for the jobs that they will face.

As early as 1977, several authors and academicians were discussing the transportation and logistics academic curriculums from an industry perspective (Mundy, Langley, \& Gibson, 1977) (Piercy, Krampf, \& Bernville, 1977). The consensus from both papers was that there was a wide gap between what industry needed and what was being taught. A gap that still appears to exist forty years later. The conclusions of these two early papers on curriculum before the advent of the supply chain concept can be summed up from the results of the study by Piercy, et. al., "Generally speaking, the academic community is not in tune to today's needs of industry" (p. $75)$.

Mundy, Langley, and Gibson (1977) evaluated the curriculum requirements for transportation and logistics courses. They introduced the paper with "Many business leaders 
have argued that present-day curricula of universities do not properly prepare individuals for careers in the new physical distribution/logistics area" (p. 33). This is not totally out of line with the practices of the $21^{\text {st }}$ Century. van Hoek identified the need for supply chain educators to remain current with industry trends and stop teaching "textbook skills" that are dated (2001). In the European Business Review, respected consultant, author and academic Ronald Ballou (2007), stated that the move from logistics and transportation to a more holistic supply chain management curriculum would require the addition of new topics and relevant discussions. Ballou also insinuated that there are still disconnects between industry and academia. Topics such as fulfillment, integration of activities, demand planning, customer support and supply chain security and preparedness continue to be hot topics in conference proceedings but do not appear to be making their way into textbooks and classroom syllabi. In a 2016 paper, Wieland, Handfield and Durach came to the conclusion that of over 1,000 supply chain management research papers published between 2010-2015 none of them addressed supply chain management curriculum development (2016).

“As with any emerging field, physical distribution (Part of what is now known as supply chain management) currently suffers from a lack of standardized definitions and vocabulary. The overall field would gain significantly from a clear definition of subject matter and issues. Supply chain management has received great attention from both research and practice. 'What do we know about supply chain management? Not much' would be an honest but immeasurable answer" (Halldorsson \& Arlbjorn, 2005, p. 118). In their study the authors looked at seventy-one published papers on supply chain management to establish a baseline for what the discipline included. Of these seventy-one papers, only twenty-five of the papers tried to describe what supply chain management is while none of the academic papers attempted to describe how to 
teach supply chain management or even how to explain the various methods and concepts of supply chain management to students interested in the field. Eleven years later, Jordan and Bak came to a similar conclusion based on their research and analysis of twenty-four studies spanning fifteen years to determine skills that supply chain graduates should possess (2016). The findings of their study detailed the critical skill sets that supply chain graduates should have. However, the recommendation of their study was that there should be future research into a teaching framework for supply chain management.

Similar studies by Tan (2001), Vidal and Goetschalckx (1997), and Croom, Romano and Giannakis (2000) out of Europe all addressed the definitions and framework for supply chain management. Tan even went so far as to categorize the topics of supply chain research papers as did Croom, et al. However, while providing good background on the discipline of supply chain management and reviewing over 380 papers between the three studies, none of the studies addressed the idea of teaching supply chain management topics or the development of a curriculum to teach the identified skills and components of supply chain management. This is a trend we will see throughout the majority of the literature published on supply chain management. The studies out of Europe recommended developing a supply chain management framework for better understanding and modeling supply chain management but did not address the education aspect in any of their frameworks.

\section{Literature on Academic - Corporate Link.}

What did the literature say about the link between academia and industry with regards to curriculum development? Answering this question may point to a need for collaboration between 
academia and business to develop a current, relevant curriculum to better prepare supply chain management students and other business majors for supply chain management careers.

In analyzing supply chain management curriculums at the top ranked schools, Bahouth, Hartmann, and Willis (2014) reported: "Common criticisms of academic program designs in comparison to practitioners' stated needs are that coursework emphasizes theoretical models that are poorly understood or too difficult to apply and that academics are slow to recognize and respond to new approaches or lag practice" (p. 286). However, their conclusions fell in line with the recommendations of Johnson and Pyke (as shown in Figure 1-3) from fourteen years earlier and was based on the course titles of the courses evaluated rather than the syllabi of those courses.

Supply chain management "in its widest scope of understanding - is an extremely rapidly developing field of knowledge and practical applications. This development goes in different directions: the one of new concepts, strategies, organizational solutions on one hand, and the one of new technical applications on the other. These ongoing challenges demand an ongoing updating of professional knowledge and skills... and higher education levels must be part of these dynamic changes to enable their graduates to meet employers' needs and perform in the market (Neumann, Krzyaniak, \& Lassen, 2001).” The authors go on to say that there is a lack of structure in logistics and supply chain programs and no existing framework for identifying the gaps in the education process at the university level to provide graduates with the proper knowledge and skills to be successful in logistics and supply chain management positions.

Only two research papers addressed the concept of improving the quality of supply chain education. In a 2016 publication in the International Journal of Quality and Reliability Management, Sarrico and Rosa discussed the need for universities to produce graduates with 
knowledge of both national and international operations and supply chain management (2016). In their research findings, Sarrico and Rosa established a need to have collaboration between government sectors, manufacturing industries and universities in order to improve the quality of supply chain programs and the offerings of these programs. Sarrico and Rosa built the case for industry and government sectors as the customers of the university programs and the need for these programs to listen to the needs of their customers.

Likewise, Niine and Koppel (2015) addressed improving logistics and supply chain education by focusing on the technology advances in the supply chain profession. As supply chain management information systems continue to improve, it is important to understand that many companies use proprietary software in their supply chain operations which, may be difficult to address in classroom settings or in job announcement criteria. These authors focused on providing an interdisciplinary approach to supply chain education and providing graduates with a broad background in supply chain technology. They addressed the need to have quality graduates for companies to continue to have sustained competitive advantages and the agility to respond to customer needs. Niine and Koppel also addressed the link between university offerings and a thorough understanding of the current supply chain environment by working with industry to develop relevant programs and courses. Also of interest in this discussion was the mention of the APICS Competence Model and the International Society of Logistics (SOLE) Competence Model as foundations for future course development (Niine \& Koppel, 2015). APICS and SOLE have both developed narrowly focused competency models that address competencies in production and inventory management (APICS) and government focused logistics (SOLE) but do not address the supply chain as a whole. 
Several articles and papers have suggested that companies are responsible for reaching out to universities to establish partnerships. Peter Cappelli (2008) stated "It's time for a fundamentally new approach to talent management that takes into account the great uncertainty businesses face today" (para. 3). This fundamentally new approach has to incorporate partnerships between businesses and universities to get the right curricula to produce the right talent for the future of businesses. In the International Journal of Physical Distribution Cowell (1998) stated that a "carefully designed" supply chain program should cater to the needs of "a clearly identified market segment" (p. 242). Cowell's insights into a market segment for supply chain education points to the need for programs to identify the market for their graduates and then collaborate with that market to identify what the customers want and how the universities can meet those needs. Motorola identified this step in their initial six sigma discussions when they stated that the first step of six sigma is to identify the customer, identify what the customer wants and identify how to do it better than the competition. If universities follow that guidance and identify the employers as the customers and then collaborate with those customers to identify what skills are needed for supply chain management graduates, the supply of graduates will better match the demand for the graduates' skills. Finally, van Hoek (2000) addressed the need to link business and universities and advocated for a more integrated skill development approach to teaching supply chain management by adding academic rigor and linking the development of courses to changes in the supply chain profession to keep the courses current. Unfortunately, not much has progressed on this front and little has been written about this idea since 2000 .

As supply chain management continues to morph in the $21{ }^{\text {st }}$ Century new technical skills are required. Ten years ago, no one had considered the concept of Omni channel; fifteen years ago most of us were still grappling with how to posture our supply chain to support online sales; 
and no one knew what "big data" even meant. Lean, Lean Sigma, Six Sigma, Sales and Operations Planning, Design for Six Sigma, Sustainability and Theory of Constraints management were all relatively new to the Supply chain management world at the turn of the Century. Today these concepts along with change management and data analytics are common place in our businesses.

\section{Literature Themes}

Although supply chain management is a relatively new discipline in many business schools, the literature review revealed little discussion about the content of an undergraduate supply chain curriculum. In turn, the literature review supports notion that those seeking supply chain management employees are confronted with a talent gap that likely is due to changes in the industry over the past twenty years, the graying of the current workforce, the relatively small number of supply chain graduates, and the topics/skills addressed in the current curriculums. Finally, the literature shows that there is a perceived link between what is being taught, how the topics are determined, and the qualifications or lack of qualifications of the graduates from supply chain programs. Several researchers have pointed out that there is not a clear framework and have recommended future research into the idea of developing this framework.

The common themes in the literature review are that there is a link between the graduate rate and the talent gap; there is a gap between the skills wanted by industry and what universities are teaching; and there is a consensus among academic researchers and authors that a common framework of what should be taught and mastered before graduation is needed. These common themes in the literature point to the need for this research project to help fill this gap. 
The literature review shows a timeline of the development of supply chain management as an academic discipline and career field as shown in Figure 2-1 below.

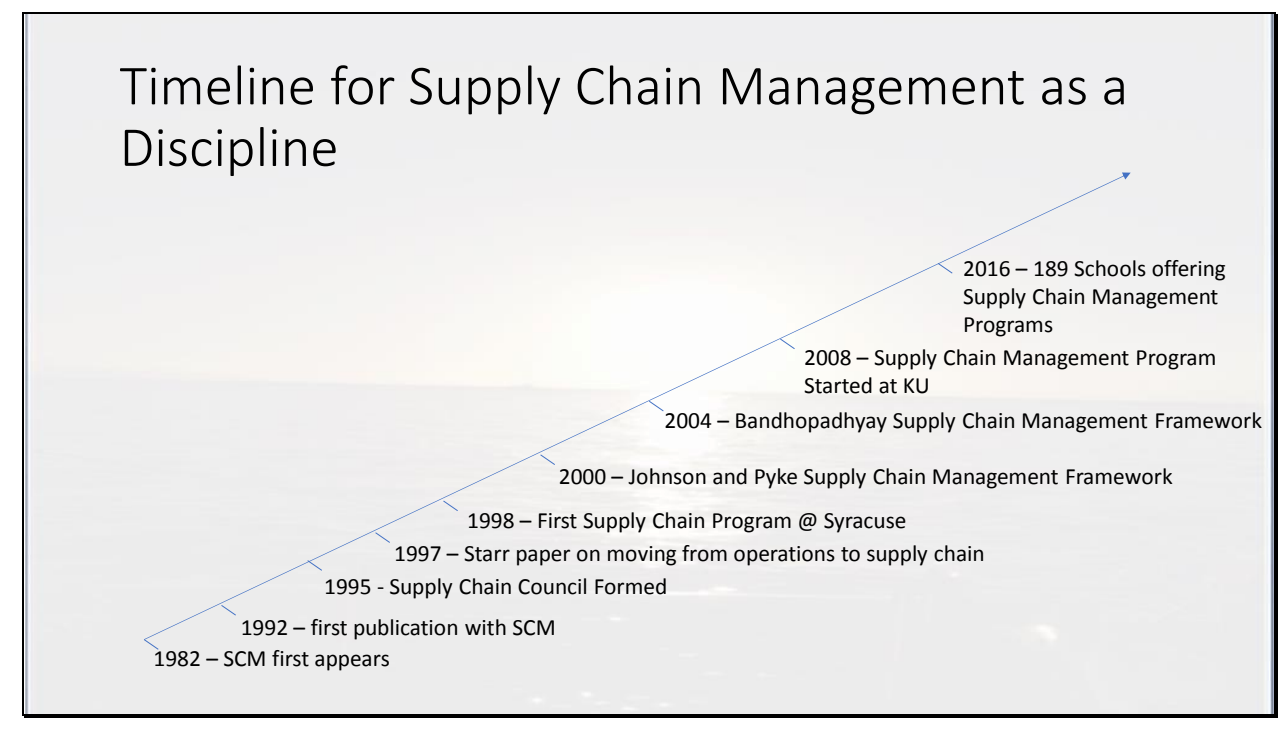

Figure 2-1: Supply chain management Discipline Timeline 


\section{Chapter 3 Methodology}

The methodology for this study used the Military Campaign Planning methodology to establish the following phases of the study:

1. Phase 0: Plan - preparation of the topic; preliminary research to establish a need for the research and initial literature review.

2. Phase 1: Pilot Study - the pilot study was conducted in the Spring of 2017 as a proof of principle that the problem existed and the link between academia and the talent gap.

3. Phase 2: Proposal preparation and approval. This phase ran from the completion of the pilot study in April 2017 until approval of the proposal and methodology in October 2017.

4. Phase 3: Data collection. This phase ran from the completion of the pilot study until December 2017.

5. Phase 4: Analysis. This phase started with the collection of the syllabi and collection of job announcements as well as the continuation of the literature review. This phase ran from September 2017 until February 2018.

6. Phase 5: Conclusions and Recommendations. Phase 5 ran from February 2018 March 2018.

7. Phase 6: Initial Draft. The initial draft was completed in April 2018.

8. Phase 7: Brief to Committee. Phase 7 was completed on 7 May 2018.

9. Phase 8: Approval of study and determination of follow on studies. Phase 8 was completed in May 2018. 
What did I do? How did I do it? Why did I do that? This chapter will answer these questions and explain how the study was conducted as well as how the data was organized and analyzed. Industry leaders have indicated 'that they' $d$ rather have employees broadly trained in all areas" (Kaplan, 2017). While realizing the complexity and breadth of the supply chain management career field, it may be impossible to cover every topic necessary for graduates in a supply chain curriculum and possibly more difficult to cover every topic with any substantive depth in an introductory supply chain management course. However, this need for broadly trained employees at least provides a starting point for evaluating the entire supply chain management curriculum by starting with the initial or introductory supply chain management courses curriculum. In a study, assumptions are used to fill gaps where facts may not be available. One of the foundational assumptions built into this study is that the syllabi reflected what academia considers important in the introductory supply chain management courses. A second foundational assumption in this study is that the job announcements reflected what industry recruiters and industry leaders believe to be important knowledge/skills/abilities in supply chain management employees or future hires.

The objective of this research project was to gain a better understanding of what introductory supply chain management course syllabi suggest about what undergraduate SCM programs consider important for students to learn and the relationship between what is taught in introductory supply chain management courses and the growing supply chain management talent gap documented in the literature review. This analysis provided the necessary information to craft a recommended curriculum for introductory supply chain management courses. This recommended curriculum will help set the conditions for success for the students in the courses 
by exposing them to and educating them in the necessary materials in the supply chain management career field.

Sun Tzu (1993), in his book The Art of War, spoke of the seven laws of warfare. While this paper is not about warfare, there is an interesting corollary here in that one of the seven irrefutable laws of warfare according to Sun was knowledge. When applying the writings of Sun Tzu to $21^{\text {st }}$ Century supply chains, one of the irrefutable laws of successful supply chains is current, relevant knowledge. This research project focused on what academia conveys as the right knowledge for introductory supply chain courses and how our students acquire the right knowledge to set the conditions for success in the commercial world.

In the Military, situational awareness is knowing what is going on in front of you, beside you and behind you. On the battlefield, situational awareness is necessary to prevent surprises and defeat by the enemy. In the supply chain management classroom, situational awareness consists of knowing the basics of supply chain management as well as the emerging concepts that students will need to understand to be successful in the commercial world. The analysis of this study will provide situational awareness of what is being taught and what should be taught to set the conditions for success of supply chain management students in particular and business management students in general in the job market.

This project was a combination of qualitative and quantitative (mixed methods) approaches to applied research with a focus on improving the quality of the practice of teaching supply chain management at the undergraduate level. The qualitative data for this research project were the key words/skills from the syllabi and job announcements. The quantitative data came from the frequency distributions created and compiled from those key words/skills and the amount of time allocated to the topics in the syllabi to create a rank ordered listing of topics and 
relative importance of those topics. While this project would appear on the surface to be somewhat evaluative in nature because of the focus on what is being taught, it was more of an applied research project as it sought to improve the quality of the supply chain management course content. This project could also be viewed as an appreciative inquiry since it sought to provide innovation in the curriculum development of supply chain management courses.

\section{The Case Study Methodology}

A case study is an empirical inquiry and in depth description and analysis of a bounded system. The system in this case study approach is the teaching of supply chain management in an introductory course. This system is a bounded system in that we are constraining the research to the introductory supply chain management undergraduate course for this project.

"Case study as an approach to qualitative research involves the specific and detailed study of a case or cases... In many instances, when researchers say they are doing case study research, they are most likely identifying a single entity to study... A case can be limited to one type of situation" (Lichtman, 2013). In this study, the first case looked at was the curriculum used for teaching supply chain management as expressed in the syllabi and the second case was the needs of industry as expressed in job announcements.

In a paper supporting a presentation in Stockholm in 2003, Johansson stated, "A case study is expected to capture the complexity of a single case, and the methodology which enables this has developed within the social sciences. Such methodology is applied not only in the social sciences, such as psychology, sociology, anthropology, and economics, but also in practiceoriented fields such as environmental studies, social work, education, and business studies (2003). This research will focus on the business studies aspect while trying to capture the “complexity of a single case," that being the case of supply chain management curriculum. 
Merriam (1992) told us that "If the phenomenon you are interested in studying is not intrinsically bounded, it is not a case" (p. 27). This research was bounded by the current curriculum in supply chain management introductory courses. Merriam went on to say, "The bounded system, or case, might be selected because it is an instance of some concern, issue, or hypothesis" (p. 28). In this case the issue was: what should be taught in a supply chain management program or supply chain management course. While the concern was: are we teaching the right topics/materials to prepare graduates for supply chain management jobs?

The data captured and analyzed in the pilot study in early in 2017 used a sample of the syllabi and compared the syllabi data with three separate sets of supply chain management entry level job announcements from the USAjobs website, the APICS job site, the WERC job site, Careerbuilder.com, and Monster.com. This current research project used USAjobs.gov, careerbuilder.com, monster.com, jobsinlogistics.com and indeed.com (referenced by Fortune Magazine as the most widely used job site in the February 1, 2018 edition (Colvin, 2018)). The change in sources for the job announcements was made because the APICS and WERC website job announcements were too specific in nature to be beneficial for this project. The pilot study showed that there was a gap between what industry was asking for in the job announcements and what academia is teaching in the classroom. This research project expanded on the pilot study analysis by expanding the number of syllabi analyzed and the different job sites and more jobs included in the search database while identifying the key skills and topics that will meet the needs of industry for new graduates.

The analysis of the syllabi, much like the methodology used in the pilot study, used a quantitative approach to rank order the topics being taught according to the syllabi. The syllabi 
topics were compared to the job announcement topics to determine if what is being taught matches what academics believe should be in a supply chain curriculum.

\section{Conducting the literature review}

A literature review is the integration of and interpretation of a topic of interest to a researcher that is designed to connect the research project to what has previously been researched. The goal of my literature review was to establish that there was a need for this particular research project and to establish the need for this project to provide a new framework for teaching supply chain management at the undergraduate introductory course level.

How were the papers and research reports selected? Why were these particular articles/papers/research reports selected and used in the literature review? A detailed search was conducted each week for the past thirty months using a variety of search engines, libraries and sources. The sources included the University of Kansas Library system, Google Scholar, Elsevier, Supply Chain Management Review and DC Velocity. The search criteria fell into several categories:

- Supply chain management + curriculum

- Supply chain management + pedagogy

- Supply chain management + talent gap

- Supply chain management + education

- Supply chain management, logistics, education

These searches provided a wide variety of papers, articles and research reports. In addition, several colleagues provided additional resources based on their knowledge of my research project. The number of articles, papers, and books that met these search criteria was two hundred and twenty-three. Each of the articles was read and then a subjective decision was made as to whether the article/paper fit the project's parameters. This subjective analysis reduced the 
papers/articles to one hundred and ten documents. Once a paper was selected for the literature review, it was again carefully reread and coded thematically based on the research questions and research goals.

The literature review showed what has been investigated and reported, what future research may be needed and what has been written about supply chain management curriculums to establish the foundation for this project and analysis while demonstrating the need for this research. The literature review helped to identify the gaps in the current research into the introductory supply chain management curriculum development. The goal of reviewing each book, article and paper was to answer the question: What is the literature telling us?

\section{Qualitative Research/Analysis}

The qualitative analysis aspect of this study involved the initial coding of the data to convert the data into information by looking for themes and concepts (a detailed description of the coding process is explained under discussions of the syllabi and job announcements). The key concepts and themes derived from the initial coding process led to establishing categories of topics that formed the foundation for the recommended curriculum for introductory supply chain classes. The coding of both the syllabi and job announcements followed this protocol:

- Initial coding: using the APICS Basics of Supply Chain Management Exam Content Manual's listing of key terms for supply chain management mastery will identify the critical terms being taught or asked for. The limitation of this coding is that with over four hundred terms in the APICS listing, not all of the key terms can be covered in a single course. The rationale for using the Basics of Supply Chain Management certification module key terms is that the recent restructuring 
of the APICS certification program separated the Basics of Supply Chain Module and the operations module which covers planning, detailed scheduling and execution of operations to provide a balanced certification process between supply chain management and operations management. The listing of key words from the Basics of Supply Chain Management provides the supply chain management key words. The operations management key words as shown in Appendix 4 are the terms that the APICS Certified in Production and Inventory Management Exam Manual classify as operations terms. These terms form the foundation for the distinction between supply chain management topics and operations topics.

- Revisiting of the coding to look for themes as well as determine the time devoted to particular topics. This was based on the number of class periods devoted to a topic, the frequency of topic discussion, projects and assignments. The frequency of discussion combined with the number of class periods devoted to a topic and the assignments for those topics provided the importance placed on the topics by academia. The goal of this phase of coding was to determine the amount of time devoted to topics to help establish professors' implied importance of the topics. This coding process did not provide the expected results as it proved impossible to discern if the number of class periods devoted to a topic was due to the importance places upon the topic by the instructor or to other factors such as whether the topics was emphasized in the course textbook. 
- Create a list of themes and key topics. Review the list of topics and frequency to determine if there are new topics or concepts that some leading schools are already teaching that have not been adopted by trailing schools.

- Relook the categories from the syllabi based on the coding and analysis of the job announcements. This relook incorporated the use of Key Words in Context analysis, the creation of word clouds for the key topics (keeping in mind that the word clouds may also identify concepts of pedagogy vice curriculum) and the use of tools such as NVivo and a concordance developing program to help identify key words and concepts. This phase of the coding/analysis helped identify themes of topics from the syllabi as well as the job announcements. These themes included specific areas such as "understanding SAP" to more generic themes such as "familiarity with business systems." The use of these themes assisted in grouping certain topics together for the development of potential curriculum modules. The use of nVivo and a concordance developing program did not prove to be of value based on the number of constraints needed to provide analysis.

- This relook of the categories and groupings of topics also identified topics that were not covered in the syllabi when compared to the job announcements and topics not asked for in the job announcements but included in the syllabi. What is not covered is just as critical to this analysis as what is covered in the classes.

\section{Quantitative Analysis}

The quantitative analysis consisted of two phases:

- The first phase of the quantitative analysis was the creation of a frequency distribution for the syllabi based on the qualitative analysis of key terms and 
topics and the frequency of the key terms in the syllabi. A frequency distribution was also created for the job announcements using the same key terms and topics listing from the qualitative analysis and coding.

- The second phase of qualitative analysis was a secondary frequency distribution based on another review of syllabi. This second frequency distribution used the key topics and terms identified in the qualitative coding and the initial frequency distribution and with a second analysis layer using the time periods, assignments, and readings allocated to the topics. This second frequency distribution for the syllabi helped identify the areas that professors are emphasizing as important based on the number of classes dedicated to a particular topic.

- These frequency distributions were rank ordered from most frequent to least frequent to establish the relative importance of key terms and topics being taught by academia and being asked for by industry recruiters. For the frequency distribution for the job announcements any topic that was requested less than five times from the one hundred and forty job announcements was discarded from the frequency distribution and comparison analysis. The cut line of five appearances discarded regionally unique topics or outliers requested for specific job requirements.

- The similarities and gaps identified by this quantitative analysis and the rank ordering of the topics formed the foundation for the analysis, findings and recommendations for a curriculum for an introductory supply chain management course. The recommended curriculum is a combination of the similarities between what is being taught and what is being asked for in the job announcements plus 
the addition of the most frequently identified needs of industry that are not currently being taught. In addition to the quantitative ranking of the frequency of the use of the terms in the syllabi and job announcements, a correlation analysis was conducted to determine if there was a relationship between the frequency of the appearance of terms in the syllabi to the frequency of appearance of the terms in the job announcements.

- The similarities and gaps analysis also identified those university programs that are leading change in their programs that can serve as the benchmarks for other university programs.

\section{Syllabi Selection.}

The syllabi collected for this sample formed the foundation of what is being reported as being taught in introductory supply chain management classes. For this analysis the following industry accepted definitions from the APICS Dictionary and Body of Knowledge (2013) were used to distinguish between operations management and supply chain management. This is necessary as a result of some of the literature review making the claim that some operations management classes were simply retitled to supply chain management without any substantive changes to the curriculum (Akalin, Huang, \& Willems; Lawrence \& Rosenblatt, 2016).

- Operations Management: "1) The planning, scheduling, and control of the activities that transform inputs into finished goods and services. 2) A field of study that focuses on effective planning, scheduling, use and control of a manufacturing or service organization through the study of concepts from design engineering, industrial engineering, management information systems, quality management, production management, accounting, and other functions as they affect the operation" (p. 115).

- Supply chain management: "The design, planning, execution, control and monitoring of supply chain activities with the objective of creating net value, building a competitive infrastructure, leveraging worldwide logistics, 
synchronizing supply with demand, and measuring performance globally" (p. 172).

- Logistics (because of its relationship to supply chain management in the above definition: "1) In an industrial context, the art and science of obtaining, producing, and distributing material and product in the proper place and in the proper quantities. 2) In a military sense (where it has greater usage), its meaning can also include the movement of personnel" (p. 94).

- Supply Chain: "The global network used to deliver products and services from raw materials to end users through an engineered flow of information, physical distribution, and cash" (p. 171)

Using the above definitions in conjunction with the course descriptions, course contents, course textbook, and course title helped to establish if a course was an operations management course, supply chain management course or operations management course retitled to a supply chain course. These definitions first enabled the selection or elimination of course syllabi by title or course descriptions that obviously were operations management courses. Second, by again using the definitions, enabled the methodology to identify courses which initially seemed like supply chain management courses and thus were included in the pool of syllabi but were operations management courses that had been renamed as a supply chain management courses. These distinctions helped support or refute the literature that claims that some supply chain courses are simply renamed operations management courses.

There was an inherent assumption built into the syllabi collection, selection and analysis processes. This assumption was that the topics reflected in a syllabus may not reflect what is actually taught in a course but does reflect what the course author deemed as important enough to be placed in the syllabus. The goal was to use syllabi that were no more than seven years old to reflect currency of topics. The syllabi selected were from the Fall Semester of 2011 through the Fall Semester of 2017. While the focus was on introductory supply chain management courses, there were some operations management courses in the sample database from schools 
that do not have an introductory supply chain management course but have supply chain management topics in the syllabus outline. The sample database also includes more than one syllabus from several schools if there was a change in professor, textbook used and/or a significant change in the topics listed in the syllabus (for example there are two syllabi from Michigan State from 2012 and from 2016 and two syllabi from San Diego State University from 2013 and 2014 that met these criteria for inclusion).If multiple syllabi from the same school were submitted and there were no changes in textbooks, professors or subject matter, then only the most recent syllabus was included in the analysis. The sample database also included syllabi from schools in the 2014 Gartner Top 25 rankings if the syllabi were from the base period (20132014) used for the 2014 analysis and rankings.

\section{How were the syllabi selected?}

The syllabi were collected in a combination of sampling methods. The syllabi sampling and collection plan followed this protocol:

Sampling strategy 1: The initial start point was an internet search using the search criteria using:

- "Supply Chain Management Syllabus" and

- "Supply Chain Management Course."

This provided a variety of available syllabi from a wide range of schools throughout the US and Internationally. The international syllabi may prove to be of interest in future research and while they showed up under this search criteria, they were not used in this research project and were eliminated from the sample set as detailed below. While not a scientific methodology for capturing syllabi, this method provided a large number of syllabi while at the same time realizing that all of the syllabi collected in this sampling strategy may not meet the research needs. 
Sampling strategy 2: The second method for collecting syllabi was a direct contact method, a form of convenience sampling. In this sampling strategy for capturing data, peer faculty at business schools that have supply chain management programs or legacy operations management programs were contacted to ask for a copy of their syllabi. The goal of this strategy was to capture data from schools that may not have their syllabi online or may have old syllabi but not current ones online.

Sampling strategy 3: Snow balling sampling. I provided the executive summary of my pilot study to other faculty in academia, on their request based on their discussions with some of the faculty in sampling strategy 2 . This resulted in a number of faculty offering up their current and past syllabi to be part of the research database.

Sampling strategy 4: Reaching out to supply chain management programs listed in the Gartner Top 25 Programs rankings. Every two years Gartner, a research firm in business, operations and supply chain management, conducts a data call on supply chain management programs and then prepares a listing of the Top 25 Academic Programs in the US. Based on the 2016 rankings, I contacted faculty at the Top 25 schools to ask for a copy of their syllabi if they had not already provided copies via the first three sampling strategies. The rationale for this sampling strategy is that the Gartner Top 25 rankings are considered the premier rankings of supply chain programs as determined by the Gartner Research Firm, an independent business research and consulting company. By asking these programs to provide their syllabi it also helped provide insights into what the top supply chain programs in the country believe to be important. Twenty-four of the 2016 top twenty-five programs are represented in the sample set via one of these sampling strategies. This sampling strategy also looked at programs listed in the 
2014 Gartner rankings that were not in the 2016 listing but provided syllabi from the 2013-2014 time frame.

Sampling strategy 5: This strategy is also a snow ball sampling technique. Based on a series of blogs on supply chain education that I have written over the past year, other educators have commented on the blogs and volunteered their syllabi for use in the study.

Sampling strategy 6: This is also a sampling of convenience. As part of my responsibilities for the School of Business, I review syllabi from other schools, both US and International, which students have taken to determine if they meet the academic criteria of our supply chain management classes. This allowed me to collect approximately six to eight syllabi a year for analysis and these were added to the sample database. Some of these syllabi came from international schools and therefore do not meet the criteria for this research project and will be eliminated from the sample set as detailed below.

Sampling strategy 7: The website CourseHero.com has a wealth of data available for a small monthly fee. Using a sampling technique similar to strategy 1, I conducted a search of supply chain management syllabi on the website and was able to pull down other syllabi from around the country.

The results of the seven sampling strategies provided a database of two hundred and four syllabi for supply chain management classes to include some international school syllabi. A database this large needed a methodology to reduce the sample set to a workable number that was truly representative of the introductory supply chain management classes being taught. 


\section{Sample Selection Process.}

The total number of syllabi collected as part of the data collection plan using the sampling methods detailed above was two hundred and four. This sample set was reduced using the following methodology (Appendix 1 contains the rationale for inclusion or elimination for each syllabus collected):

a) Each syllabus was carefully reviewed for subject matter and course titles. Some of the syllabi provided and collected were for specific aspects of the supply chain such as transportation, warehousing, or procurement. These syllabi were deemed to be too specific to meet the criteria of an introductory supply chain management course. This determination was confirmed through peer review of the course titles and syllabi specifics. The final list was also reviewed as part of a presentation to the National Business and Economics Society Conference in March 2018.

b) Syllabi were eliminated from the sample set if multiple syllabi were provided for the same school over several semesters with no change in professor, textbook or syllabus topics.

c) Syllabi were eliminated if over seven years old as these were deemed to be not current. The goal was to only use syllabi five years old or newer but in some cases with leading schools this was not possible.

d) Syllabi were added to the original sample set and analysis set to include as many of the Gartner Top 25 Supply Chain Education Program schools as possible. The sample set included twenty-four syllabi from the 2016 rankings and an additional syllabus from the 2014 Top 25 schools. These syllabi were added to assist in comparing what the sample schools were teaching to the job announcement skills 
and a further look at what the Top 25 were teaching compared to the desired skills and knowledge sets of the job announcements.

One of the considerations that may fit into future research is the change in the AACSB requirements for accreditation for a required operations management course approximately three years ago. This future research could analyze changes in curriculum development for introductory supply chain management courses as a result of the regulatory change or if any of the courses in the database were changed to meet the needs of an accreditation review process.

With a study focus on what should be taught in an introductory supply chain management course, the syllabi collected needed to be sorted and analyzed for inclusion in the research project. The total collection of syllabi contained supply chain management courses taught in the US as well as some international courses from Australia, Asia, Europe and non-US North America. Some peers provided numerous syllabi while others offered their most recent syllabi. Figure 3-1 shows the methodology used to right size the syllabi database for analysis of introductory supply chain management classes. 


\section{Syllabi Data Capture and Selection Process}

\section{Syllabi Data Capture Process}

1. Internet search

2. Direct contact with peers

3. Snowballing - peers refer other colleagues

4. Contact with Gartner Top 25 programs

5. Volunteers based on papers and blogs

6. Convenience: use of syllabi provided for review for course credit

7. CourseHero.con website search

\section{Syllabi Selection Protocol}

1. Elimination of personally developed courses to preserve objectivity

2. Elimination of all international syllabi to keep the focus on US taught courses

3. Sort by school and eliminate those syllabi from consecutive semesters/years with same instructor; if instructor changes for course and topics are different, that syllabi will remain in the sample set

4. Masters level courses will be eliminated from the sample (some volunteers provided all syllabi both introductory and masters level classes that they teach)

5. Courses that are specific topics (Inventory Management; Sourcing; Logistics; Warehousing) or require the prerequisite of an introductory supply chain management course will be eliminated from the sample set

\section{Figure 3-1 Syllabi Data Capture and Selection Process}

First cut: Any syllabus that was based on courses that I have developed, taught or consulted on were eliminated to help maintain objectivity. This step may not seem necessary with such a large database. However, the Johnson and Pyke framework was developed using eight syllabi of which part of them were their own. To maintain objectivity and prevent skewing the results, twenty syllabi that met the criteria for inclusion but were either courses that I am teaching, have taught, have developed or consulted on the development were eliminated. Not only will this help maintain objectivity for the analysis but will also ensure that I learn something from the process. From days of conducting quantitative analyses in past jobs, I know that a good, supportable research designer can start with the answer that they want and then work backwards to get the question that provides that answer. By eliminating this batch of syllabi, this potential bias is eliminated. While it would be easier to use my own syllabi for this research, after years of 
conducting quantitative studies for the US Army, I decided to eliminate those syllabi in the name of objectivity and reliability of data.

Second cut: All international syllabi were eliminated from the database to maintain a clear focus on what is being taught in US schools only for this analysis. The international syllabi will be available for future analysis but did not meet the scope of what is being taught in US supply chain management classes.

Third cut: The syllabi were sorted by school. Some schools provided a series of syllabi that covered several semesters; some of those had the same instructors and some had different instructors with different topics covered in the classes. Those syllabi for consecutive semesters at the same school were eliminated when there were no changes from one semester to the next with the most current syllabus remaining in the sample. This helped prevent skewing of the data and topics by eliminating redundancy while ensuring that only the most current syllabus was considered in the analysis.

Fourth cut: All Masters level courses were taken out of the database. The rationale for this cut was that the focus of the study is on introductory undergraduate supply chain management classes. While providing insights into other areas of interest in teaching, the masters' level classes were not in the scope of this project but are available for future research into curriculums.

Fifth cut: Syllabi that were for focused or specific courses within supply chain management or had an introductory course as a prerequisite were excluded from the database. The rationale for this cut was to remove those courses that are not introductory courses. The type of courses that were eliminated in this cut included "Sourcing and Supply chain management," 
"Inventory Management," "Warehousing, Transportation and Distribution," and "Supply chain management Information Management Systems." This helped ensure that the focus of the study remained on introductory supply chain management courses only and helped ensure that specifically focused courses did not skew the distribution of topics in the frequency distributions.

The remaining seventy-eight syllabi formed the representative sample set for the data collection and analysis. The result of the five sample cuts produced a sample set of syllabi based on the course title, course description or course contents. A syllabus course description, topics, introductory paragraphs, definition of supply chain management or the course title provided insights into the focus of the course.

Using the exclusion protocols described above, the sample set included schools from across the US to include the majority of the Gartner Top 25 (only Howard University did not respond to the data collection contacts) as well as some smaller schools that do not have supply chain management programs but do have supply chain management courses. The seventy-eight syllabi that met the criteria of introductory courses made this the largest undergraduate syllabus focused study to date. The syllabi selection process was reviewed by a peer in academia and a peer in business to determine if the sample set met the research criteria and to ensure that syllabi excluded from the initial sample as detailed in the five elimination cuts really did not meet the criteria of this research project and/or identify syllabi that were eliminated but should be added back into the representative sample.

\section{Syllabi Analysis, Coding and Frequency Distribution.}

The syllabi were then analyzed and coded for key topics to develop a qualitative listing of key terms and then a quantitative frequency distribution of the most commonly taught subjects and skills. The APICS Basics of Supply Chain Management certification manual listing of key 
terms served as the foundation for identifying key words in the syllabi. This listing was chosen because the APICS certification is the most recognized and oldest supply chain management certification in the industry. The Certified in Production and Inventory Management (CPIM) Exam Manual (2016) was used for the listing of operations management terms in order to differentiate between supply chain topics and operations management topics in the syllabi, as well as in the job announcements.

Where did the key words come from within a syllabus and what was the foundation of the selection criteria to identify supply chain management topics? Because some syllabi are very detailed and some only list the topic or chapter title for a class, the coding and analysis used the class description, introductory paragraph/course objectives to the syllabus, the course title and the topics listed within the syllabi for class topics. The course description was important to help establish if a course was an introductory course or a more advanced course. For example, based on how the professor described the course in the syllabus introduction helped to indicate that the course was more purchasing focused, operations management focused or manufacturing focused.

The syllabi were carefully analyzed to determine what topics were covered in supply chain management courses. This provided two frequency distributions. The first was for the frequency that a topic is listed or discussed in the syllabi and how many syllabi listed that topic. The second frequency distribution showed the frequency of the type of textbook used in the courses (Operations Management, Supply Chain Management, custom text, or a combination Operations Management/Supply Chain Management text). These frequency distributions provided greater insights into what professors believe to be important in the class and where their priorities were placed in course development. Future research into the development of supply chain management curriculum could possibly focus on what each textbook listed as readings, 
chapters, assignments and critical topics to help shape the development of a total supply chain management curriculum and not the narrower focus of introductory supply chain courses that my research focused on.

Although it is realized that what is actually taught may differ from the syllabi topics, the analysis of the syllabi showed the major topics and concepts covered in the introductory supply chain management classes. These major topics were then analyzed in a quantitative analysis in order to construct the frequency distribution of the common topics and a relative importance of the topics covered in the classroom as demonstrated in the syllabi and the coding of the number of class periods devoted to certain topics. The topics listed in the syllabi may not reflect what is actually taught in the classes may not be inclusive of all of the important supply chain management topics. At the same time it is important to keep in mind that the job announcements may have identified broader content topics than did the syllabi topics that could have been more specific in nature than an introductory supply chain course may include.

While this analysis by itself may not be sufficient to accurately determine what is really being taught as was pointed out in one of the interviews during the pilot study, it at least provided a snapshot in time of what topics were intended to be covered in the classes. One of the professors interviewed during the pilot study explained that at his university the approval process for syllabi took several months. Because of this situation, what was reflected in the syllabi may not be what is actually covered if something new becomes available or if current events had an impact on the discussion of certain supply chain management topics. Therefore, the assumption has to be made that what is detailed in a syllabus is what is considered important enough to be covered. This is a limitation of this methodology of topic analysis and has to be covered by the 
assumption that the topics in a syllabus were at some point considered important by the instructor or the instructor's superior.

Another issue that had to be addressed with the syllabi was that some of the topics covered when later compared to the job announcements may fall into the idea of specified or implied tasks. A specified task may be inventory management. While although not specifically addressed in job announcements, an implied task of inventory management is forecasting, location analysis, customer support levels and demand pattern analysis (what does the customer want, how many do they want, when do they want it and where do they want it). Without an understanding of supply chain management, a course developer may miss some of the foundational issues or implied tasks necessary to fully develop an understanding of a topic.

The frequency distributions helped to identify the most commonly taught topics/skills for inclusion in the recommended curriculum. It is realized that just because a topic is not one of the most commonly taught subjects does not mean it should not be considered for inclusion in the recommended curriculum. This could include newer topics that are identified in the job announcements that may not have made it to the syllabi or into textbooks yet or have been identified through trade magazines and recent research, but are current and relevant to the study of supply chain management.

Are there apparent gaps in the content of supply chain management courses in preparing students for the expectations of industry and the demands of a supply chain management career field? The syllabi analysis revealed what is being taught while the job announcements revealed what is being asked for by industry. The frequency distribution created from the syllabi analysis provided a relative listing of what educators think is important to teach. 


\section{Job Announcement Selection Process.}

To get to the research question of what industry wants, an empirical study of the job announcements was conducted on seven separate sets of announcements captured between 31 August 2017 and 30 November 2017. There was a built-in assumption that the contents of these job announcements accurately reflected what employers need or expect in business and supply chain management graduates. One hundred and forty job announcements were collected with a focus on entry level positions.

\section{Announcement selection.}

How were the job announcements selected for the database for analysis? There are seven sets of data. On the seven different dates, approximately two weeks apart, a search was done from each of the five job sites. Four of the job sites (indeed.com, monster.com, jobsinlogistics.com, and careerbuilder.com) were selected based on popularity of the sites for recruiters and job seekers. The fifth site, USAjobs.gov, was selected to pinpoint government jobs in supply chain and logistics that may not appear on the other four sites and to help explain why some topics were covered in government related job markets.

\section{Search criteria.}

A search was conducted on each of the sites for "Entry Level + Supply chain management." This search produced approximately 400 jobs per search per site with the exception of USAjobs.gov, which was more limited during the search period due to a mandated hiring freeze in the Federal Government. Every fourth job was selected for review with the goal of at least twenty job announcements from the five sites for each data set. A second search parameter was for only jobs posted in the last seven days. This parameter was set to help reduce duplication of jobs in the sample sets. 


\section{Job announcement selection/rejection criteria.}

There was very little duplication of job announcements from site to site. However, if a job announcement appeared on multiple sites, it was only used once to prevent skewing the data. Job announcements were accepted or rejected as described below; the search continued using the every fourth announcement sampling technique. The goal was to get no more than seven job announcements per site to help enhance the diversity of the job announcements.

If the job announcement contained experience levels that appeared to exceed a truly entry level position (i.e., "entry level supply chain manager ....... Experience desired: 10+ years") or if the job requirements included the requirement for a graduate degree, that particular announcement was discarded. If the job announcement was for outside the United States, that announcement was disqualified since the focus of this study was on the US. Another disqualifier for the job announcements was the lack of a requirement for a bachelor's degree. The rationale for this disqualifier was that if a bachelor's degree was not necessary for the job, then the job was not part of the data set of jobs for college graduates. The final disqualifier of the job announcements was the requirement for industry specific experience, i.e., "aviation experience required." The rationale for this disqualifier was that recent college graduates should not be expected to already have industry unique experience and thus the announcement was not truly an entry level position.

\section{Job announcement analysis.}

Once the job announcement data set was complete for each of the seven capture dates, the frequency distribution of topics mentioned was compiled for each date and then consolidated into one job announcement frequency distribution and sorted from most frequent to least frequent to establish the critical knowledge sets and skills for graduates based on what industry is 
asking for. Topics that only appeared in less than five announcements (3.6\% or the announcements) were not considered in the comparison analysis with the syllabi frequencies.

A final lens analysis of the job announcement skills was to use the APICS Dictionary to establish themes or related topic groups. As in the syllabi analysis, this was accomplished by looking up each key word in the APICS Dictionary and linking those key words that were shown as "see also: ..." in the definitions. These themes or topic groups were then compared to the themes or topic groups from the syllabi frequency analysis.

\section{Lens analysis:}

\section{Syllabi.}

As the requirements from the job announcements were analyzed, it was necessary to look for Business School and University common topics such as "team member," "leadership," and “communication skills." These skills are not supply chain management unique but cut across all university and business disciplines. At the same time, the analysis had to look for topics that fell into supply chain management basics, which would be the focus of this study, and supply chain management advanced topics that would be more in line with a full supply chain management curriculum review, which could be a follow-on study to this particular analysis.

The analysis of the necessary job skills per the job announcement analysis was conducted against all the schools in the syllabi sample set for a comparison of what is taught to what is required. A second lens analysis compared the job skills and content knowledge to the leading schools as identified in the Gartner Top 25 Supply Chain Management Programs study from 2014 and 2016. This second lens analysis was used to determine if the leading program schools are focusing more on emerging skill sets and industry job needs. The third lens analysis used the 
same methodology but looked only at the syllabi from the schools that were not included in the Gartner Top 25 Programs. The purpose of this analysis was to determine if the non-Top 25 Schools were teaching different topics than the leading schools.

\section{Job announcements.}

The supply chain management recruiting cycle, while a year round enterprise, can really be separated into two critical cycles. The first cycle starts in early September as companies start the recruiting process for interns for the following summer and full-time hires of December graduates as well as May graduates. This process usually runs from September to mid-November when the supply chain world really turns it full time focus to delivery of holiday season products. The busiest recruiting cycle is the fall recruiting cycle and was the foundation for this study. The sites used were Monster.com, CareerBuilder.com, Jobsinlogistics.com, and Indeed.com. These four job sites attract a wide variety of employers and companies from across the entire supply chain career field from small regional companies to large companies such as Ford, Firestone, Bridgestone, Proctor and Gamble and General Motors.

Although the job announcements varied in specificity of topics, if the assumption that the announcements accurately reflect the needs of that company, then the analysis had a sound foundation looking for the number of times a skill or knowledge set is mentioned in the job announcements to reflect the magnitude of the need for that skill or knowledge set and will enable the creation of a frequency distribution for the number of times a skill or knowledge set appears in the job announcements. The second assumption tied to this analysis was that the more frequently a skill or knowledge set appears, the more importance it has in the industry and should most likely be reflected or at least considered for inclusion in curriculums. 


\section{Announcement selection process.}

The analysis of the job announcements starts with the selection process. The search criteria meant that there was the inclusion of some announcements that did not fit the scope of this research project in that the jobs were be seeking other than new graduates in the "entry level supply chain management" positions.

To align with the selection and exclusion methodology for the syllabi, the job announcements were excluded from the database based on the following rules:

- The requirement is for $\geq 2$ years of experience; Rationale: this does not match the desired jobs for new graduates.

- Requirements for knowledge of a specific industry (i.e., pharmaceutical, healthcare, aviation); Rationale: this would not match the criteria for new graduates or would require a specific course or courses in a certain industry.

- International jobs outside of Continental North America; Rationale: the may require specific country or language knowledge/proficiency.

- The requirement for a Masters/MBA degree; Rationale: this does not meet the criteria for entry level or recent graduates.

\section{Announcement coding/analysis.}

The announcements were coded for key terms, key skill sets and key knowledge areas being requested by the recruiting companies using the APICS Basics of Supply Chain Management Key Word listing and the CPIM Key Terms Listing for operations management topics (the same listings used in coding the syllabi). Much like the analysis of the syllabi, the job announcements analysis also contained a quantitative analysis to determine the most frequently identified topics or assumed skill sets requested by industry.

The job announcements were used to conduct a frequency distribution for all of the announcements of the number of times a topic/skill/knowledge set appears as well as a frequency distribution for each data capture to help identify if there are different skills required at different 
times in the year. Within the frequency distribution one of the key areas that were looked at was whether the job announcement asks for a supply chain management degree or whether the requirement is simply for a bachelor's degree. Those jobs that require a degree in supply chain management would indicate a level of knowledge greater and more detailed than what would be required of simply a business graduate. This frequency distribution shows the most commonly requested skill sets and knowledge areas in the recruiting process. Like the syllabi, there was specified and implied skills that may nest under specific needs. Also, like the syllabi, there was some infrequent skills being requested that fall into the new concept/new skill arena and therefore should not be immediately discounted because of the low frequency. This piece of the analysis also depended on my experiences in the supply chain management career field as well as input from industry leaders on emerging concepts and topics. For example, "understanding of omni-channel distribution" may appear in the job announcements infrequently because of the newness of this concept but should still be considered based on inputs from industry and personal experience as a key topic.

\section{Qualitative and Quantitative Analysis}

The list of industry requirements was compared to the syllabi identified knowledge, skills and abilities to help determine if what is needed by industry is being taught by academia as well as what may be taught in academia that no one is asking for in industry.

The study was a combination of both quantitative and qualitative research. The quantitative analysis included the syllabi and job announcement analysis for the most commonly taught topics based on the frequency distributions created. The topics that should be included in a supply chain management curriculum were rank ordered based on the frequency distribution of the materials covered in the syllabi. When compared to the frequency distribution for the job 
announcements the result shows what could be included in an introductory supply chain management curriculum to better prepare students for the needs of industry as identified in the job announcements.

The qualitative research involved the sampling, data collection, and coding of the key terms, knowledge areas, topics and skill sets in both the syllabi and the job announcements. With seventy-eight syllabi that met the research criteria and a collection of one hundred and forty job announcements covering the recruiting cycle for supply chain management talent, the databases are sufficiently large enough to provide the insights needed for this study and to provide and support solid conclusions and recommendations.

The data collected and analyzed from the syllabi and job announcements were also compared to the original framework presented by Johnson and Pyke in 2000 to determine if that framework is dated, obsolete or still applicable. The ten categories from Johnson and Pyke were looked at for validity as topic groupings or subject matter groups for arranging the key topics identified in the analysis.

The analysis was a combination of looking at the differences and similarities and then applying a critical view of the key topics and skill sets from a supply chain practitioner perspective using my experiences from over forty years in the supply chain career field as a Soldier, practitioner, training developer, consultant and educator coupled with a panel of experts to validate the similarities and differences. Will my experiences be sufficient to analyze the data critically? The answer is yes, my background includes leading a supply chain organization with over $\$ 1$ billion in annual budget and over two thousand employees providing support across the entire supply chain to a constantly changing customer base. In addition, I was selected by name by the Vice Chief of Staff of the US Army (the US Army's Chief Operating Officer) to develop 
the distribution plan and the four million square foot distribution center with over $\$ 2$ billion in average daily assets in an active theater of war to support operations throughout the Middle East. I have been certified by two of the largest supply chain and logistics professional organizations, which led to me being the lead author for the logistics and supply chain contents for the APICS Body of Knowledge (the foundation document for all APICS certification programs).

The first cut of the analysis was briefed to the University of Kansas Supply chain management Board of Advisors to get their feedback on the methodology and preliminary data as well as a validation of the coding and classification processes. The Board of Advisors also provided additional insights to the needs of industry and the need to add emerging trends (defined as topics used by business but not yet in syllabi or textbooks) and basic SCM concepts to the curriculum. The methodology and preliminary findings were then briefed to the National Business and Economics Society at their 2018 conference and the management faculty at Middle Tennessee State University.

\section{What Did All of This Provide?}

The job announcements and syllabi provided a broad view of what is being taught, what should be taught and what should comprise a supply chain management curriculum framework using a balanced approach of industry experience and academic theory. The syllabi analysis identified the top skills and knowledge that seemingly are being taught to undergraduates while the job announcements helped to identify the top skills and knowledge required by industry. These two lists were then compared and analyzed to determine similarities and differences.

The key analysis phase compared and contrasted the key themes, categories and topics in the syllabi to the key themes, categories and topics in the job announcements. When coupled with the themes from the literature review, this helped to establish the foundation for what 
should be included in the recommended curriculum based on what industry needs and the supporting topics that are necessary to understand those needs. This was accomplished by looking for the topics/themes identified and then determining if there is a relationship between the topics/themes in the syllabi and the topics/themes in the job announcements.

\section{Limitations}

\section{Syllabi limitations.}

The first limitation was the assumption that what is reflected in a supply chain management introductory course syllabus is an accurate reflection of all of the topics being covered in the class. For example, if a major disaster occurs (terrorist attack, cyber-attack, hurricane, or tornado) does this provide topics of discussion on security or preparedness that may not be reflected in the syllabus? If the syllabus is a standard syllabus for the program, the instructor may modify the amount of class time devoted to a particular topic based on his/her background and experience.

The second limitation with regards to the syllabi analysis was the assumption that because it is on the syllabus it is important to the learning experience. This goes back to the development of the syllabus and the experience of the instructor. It may not be important to industry but is an area of interest of the instructor or an area of expertise and may then get more class time allocated than topics that the professor is not familiar with.

A third limitation to the syllabi analysis was lumping all of the syllabi from across the US into one database. If a regionally unique topic is included in a syllabus it may not be mentioned enough to be part of the primary topics in the frequency distribution even though it is important to that school's customers. 
A final limitation with the syllabi analysis was that some syllabi go into detail in the course descriptions and discussion topics while many syllabi simply list the topics to be discussed each week with little or no discussion of what the topic discussion will include.

\section{Job announcement limitations.}

The first limitation to the job announcement analysis was the assumption that what is in the announcements is what industry hiring officials are looking for as opposed to a generic job announcement for all corporate vacancies. This assumption was necessary in order to conduct that analysis of what industry thinks is important and is linked to the assumption that job announcements are updated as new skill sets and knowledge are needed.

A second job announcement limitation was that the skill sets needed may differ from one recruiting cycle to the next. This then mandates the assumption that the demand for skills/knowledge is standard across the major recruiting cycles. 


\section{Chapter 4 - Findings and Analysis}

"As consumers we love supply chains, because they deliver us all sorts of goods"

(Friedman, 2007, p. 155).

"The supply chain management field is broad, so it's understandably difficult to structure a collegiate undergraduate curriculum to cover everything an incoming hire should know" (Kaplan, 2017). Despite the complexity and difficulty of covering supply chain management in an undergraduate curriculum, other than the Johnson and Pyke (2000) study, little is known about the content of undergraduate supply chain management courses. This proves particularly problematic given the changes in supply chain management since the framework of Johnson and Pyke was developed. In order to set the conditions for developing a new or updated framework for supply chain management introductory courses, it is necessary to look at these changes in supply chain management since 2000. Analyzing what colleges, particularly the 25 leading schools, now offer in their introductory supply chain management courses and what major companies desire of job candidates helped to determine how well the curriculum aligns with the needs of employers, served to answer the research questions and to provide insight into the creation of a new curricular framework. Following the methodology established in Chapter 3, the analysis started first with the syllabi looking at frequency of topics and the type of textbook being used in the course, then looked at the job announcements and finally compared the frequency distributions for the syllabi to the frequency distribution for the job announcements for similarities and differences to help determine if a new framework is needed and if so, what should be in the new framework to best prepare our students to meet the needs of industry upon graduation. 


\section{Syllabi Analysis}

The syllabi database started as two hundred and four syllabi and was narrowed down to seventy-eight syllabi that met the selection criteria. One of the assumptions built into this analysis was that introductory supply chain management courses would most likely reflect the curriculum as a whole. The narrowing/selection process for the syllabi consisted of eliminating those syllabi that were for international courses, MBA or other graduate programs, syllabi that were from consecutive semesters/quarters from the same school with no changes to the curriculum, and the elimination of syllabi for higher level or specific topic courses such as Warehousing/Distribution/Supplier Relationships.

An automated approach was attempted using nVivo and a word cloud program as well as a concordance creation program. The automated processes proved to take more time to establish search constraints and parameters than a manual process would take. Upon completion of this manual process, each key word from the syllabi and its corresponding frequency within each syllabus was loaded into a spread sheet. When all of the frequencies across all syllabi were recorded in the spreadsheet, the cumulative frequency for each key word was calculated and then the key words were sorted from the most to least numerous to help identify the perceived importance of the topics/key words. This frequency distribution was used to show what is reflected in the written curriculums in the introductory undergraduate supply chain management courses. Initial coding of the syllabi was a qualitative approach. The seventy-eight syllabi were analyzed in three ways. The first analysis compiled the key words from the APICS Basics of Supply chain management certification manual that were reflected in the syllabi. The listing of syllabi key words/terms/topics is shown below. One hundred and tten key terms were identified from the syllabi as shown in Figure 4-1. 


\begin{tabular}{|c|c|c|}
\hline KEY TERMS & & \\
\hline $\begin{array}{l}\text { post sale" } \\
\text { processes }\end{array}$ & informal economy & resource planning \\
\hline $3 \mathrm{PL}$ & information flow/systems & responsiveness \\
\hline $\begin{array}{l}\text { aggregate } \\
\text { planning }\end{array}$ & innovation & revenue management \\
\hline Analyze & Intermodal & reverse logistics \\
\hline APICS & inventory management & RFID \\
\hline $\begin{array}{l}\text { balanced } \\
\text { scorecard }\end{array}$ & inventory turns & risk \\
\hline best practices & ISM & S\&OP \\
\hline Bullwhip effect & JIT & $\mathrm{SC}$ as a career \\
\hline $\begin{array}{l}\text { business process } \\
\text { management }\end{array}$ & layout analysis & SC Best Practices \\
\hline Capacity & lead time & SC technology \\
\hline collaboration & Lean & scheduling \\
\hline $\begin{array}{l}\text { Communication } \\
\text { skills }\end{array}$ & Location analysis & SCM design \\
\hline Competitiveness & logistics & SCM integration \\
\hline Complexity & manufacturing & SCM Network \\
\hline Contracting & materials & SCM Operations \\
\hline controlling & $\begin{array}{l}\text { metrics/performance } \\
\text { management }\end{array}$ & SCM systems \\
\hline cross docking & Modeling & SCM transformation \\
\hline CSCMP & $\begin{array}{l}\text { Materials Requirements } \\
\text { Planning/Enterprise } \\
\text { Resource Planning }\end{array}$ & SCOR model \\
\hline $\begin{array}{l}\text { customer service } \\
\text { management }\end{array}$ & Negotiation & Security \\
\hline Cycle time & network design & Services \\
\hline decision making & operations & Six Sigma \\
\hline Delivery & Operations Strategy & Software as a Service \\
\hline demand & order processing & strategy \\
\hline design & outsourcing & suppliers \\
\hline distribution & Packaging & supply management \\
\hline DRP & Planning & $\begin{array}{l}\text { supply chain } \\
\text { management }\end{array}$ \\
\hline e-commerce & Pricing & Sustainability \\
\hline
\end{tabular}




\begin{tabular}{|l|l|l|} 
Effectiveness & problem solving & $\begin{array}{l}\text { Transportation } \\
\text { Management Systems } \\
(\mathrm{TMS})\end{array}$ \\
\hline Efficiency & process design & Theory of Constraints \\
\hline $\begin{array}{l}\text { Economic Order } \\
\text { Quantity }\end{array}$ & process improvement & transportation \\
\hline Ethics & procurement/sourcing & Utilization \\
\hline Facility & product design/production & value chain \\
\hline forecasting & Productivity & vertical integration \\
\hline fulfillment & Project Management & $\begin{array}{l}\text { Vendor Managed } \\
\text { Inventory }\end{array}$ \\
\hline global SCM & quality/TQM & warehousing \\
\hline Improve & queueing theory & \multicolumn{1}{|l}{} \\
\cline { 1 - 2 } INCO terms & raw materials &
\end{tabular}

Figure 4-1: Key Words from Syllabi

\section{Gartner Top 25 Schools syllabi analysis.}

The second analysis was conducted using the initial coding of the syllabi but limited the analysis to the Gartner Top 25 Supply Chain Program schools. Every school from the 2016 Gartner Top 25 Supply Chain Programs is represented with the exception of Howard University (Howard did not respond at all to the data call or requests for assistance) and representatives from the 2014 Top 25 were included as well if the syllabi that they provided were from the 20132014 time frame used for the 2014 rankings. The rationale for looking at the Top 25 Schools was to determine what the leading schools were teaching when compared to those schools not in the Top 25 Schools' list. A total of seventy-eight key words were identified in this subset of syllabi as shown in Figure 4-2.

\begin{tabular}{|c|c|c|}
\hline $\begin{array}{l}\text { KEY TERMS TOP } 25 \\
\text { SCHOOLS }\end{array}$ & & \\
\hline "post sale" processes & Just in Time & queueing theory \\
\hline aggregate planning & layout analysis & raw materials \\
\hline APICS & lead time & resource planning \\
\hline balanced scorecard & Lean & reverse logistics \\
\hline
\end{tabular}




\begin{tabular}{|l|l|l|} 
Bullwhip effect & Location analysis & Risk \\
\hline business process management & Logistics & Sales \&Operations Planning \\
\hline Capacity & Manufacturing & scheduling \\
\hline collaboration & Materials & SCM design \\
\hline controlling & $\begin{array}{l}\text { Materials Requirements } \\
\text { Planning/Enterprise Resource } \\
\text { Planning }\end{array}$ & SCM integration \\
\hline CSCMP & $\begin{array}{l}\text { metrics/performance } \\
\text { management }\end{array}$ & SCM Network \\
\hline customer service management & Negotiation & SCM technology \\
\hline Cycle time & network design & SCM transformation \\
\hline demand & Operations & SCOR model \\
\hline design & Operations Strategy & Services \\
\hline distribution & order processing & Six Sigma \\
\hline $\begin{array}{l}\text { Distribution Requirements } \\
\text { Planning }\end{array}$ & Outsourcing & strategy \\
\hline Economic Order Quantity & Packaging & suppliers \\
\hline Efficiency & Planning & supply chain management \\
\hline Ethics & problem solving & supply management \\
\hline forecasting & process design & Sustainability \\
\hline fulfillment & process improvement & Theory of Constraints \\
\hline global SCM & procurement/sourcing & transportation \\
\hline information flow/systems & product design/production & utilization \\
\hline inventory management & Productivity & value chain \\
\hline inventory turns & Project Management & Vendor Managed Inventory \\
\hline ISM & quality/Total Quality & warehousing \\
\hline & Management (TQM) & \\
\hline
\end{tabular}

Figure 4-2: Top 25 Syllabi Key Words

What I was looking for here was basically, "what are the leading schools teaching in their introductory supply chain management courses compared to the other schools?" The ninety key words from the schools that were not in the T op 25 schools are shown in the listing in Figure 43.

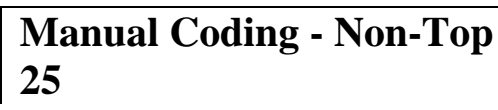




\begin{tabular}{|c|c|c|}
\hline aggregate planning & innovation & revenue management \\
\hline analyze & intermodal & reverse logistics \\
\hline APICS & inventory management & RFID \\
\hline best practices & ISM & risk \\
\hline bullwhip effect & Just in time & $\begin{array}{l}\text { Sales and Operations } \\
\text { Planning }\end{array}$ \\
\hline capacity & lead time & scheduling \\
\hline communication skills & lean & SCM design \\
\hline competitiveness & location analysis & SCM integration \\
\hline complexity & logistics & SCM network \\
\hline contracting & manufacturing & SCM systems \\
\hline cross docking & materials & SCM technology \\
\hline CSCMP & $\begin{array}{l}\text { metrics/performance } \\
\text { management }\end{array}$ & SCM transformation \\
\hline customer service management & modeling & SCOR model \\
\hline decision making & MRP/ERP & security \\
\hline delivery & negotiation & services \\
\hline demand & network design & six sigma \\
\hline design & operations strategy & software as a service \\
\hline distribution & order processing & strategy \\
\hline e-commerce & outsourcing & suppliers \\
\hline effectiveness & packaging & supply chain management \\
\hline efficiency & planning & supply management \\
\hline EOQ & pricing & sustainability \\
\hline ethics & problem solving & Theory of Constraints \\
\hline facility & process design & TMS \\
\hline forecasting & procurement/sourcing & transportation \\
\hline fulfillment & product design/production & value chain \\
\hline global SCM & productivity & vertical integration \\
\hline improve & project management & warehousing \\
\hline INCO terms & quality/TQM & \\
\hline informal economy & queueing theory & \\
\hline information flow/systems & responsiveness & \\
\hline
\end{tabular}

Figure 4-3: Syllabi Key Words from Schools not in the Top 25

The comparison of the Top 25 syllabi to the non-Top 25 syllabi revealed that the terms in Figure 4-4 were not covered in the non-Top 25 syllabi but referenced in the Top 25 schools' syllabi. 


\begin{tabular}{|l|l|}
\hline "post sale" processes & inventory turns \\
\hline $\begin{array}{l}3^{\text {rd }} \text { Party Logistics Providers } \\
(3 \mathrm{PL})\end{array}$ & process improvement \\
\hline balanced scorecard & raw materials \\
\hline business process management & resource planning \\
\hline collaboration & SCM Future \\
\hline controlling & SCM relationships \\
\hline Cycle time & utilization \\
\hline DRP & VMI \\
\hline
\end{tabular}

\section{Figure 4-4: Topics in Top 25 Schools not Covered in non-Top 25 Schools}

The comparison also showed that the nineteen topics reflected in Figure 4-5 are in the syllabi of the non-Top 25 but not in the Top 25 Schools' syllabi. The majority of these topics are either operations topics or generic topics such as analyze and improve.

\begin{tabular}{|c|c|}
\hline Analyze & effectiveness \\
\hline best practices & facility \\
\hline bull whip effect & improve \\
\hline communication skills & innovation \\
\hline competitiveness & pricing \\
\hline complexity & INCO terms \\
\hline cross docking & responsiveness \\
\hline contracting & $\begin{array}{l}\text { software as a } \\
\text { service }\end{array}$ \\
\hline delivery & vertical integration \\
\hline e-commerce & \\
\hline
\end{tabular}

\section{Figure 4-5: Topics in non-Top 25 Syllabi and not in the Top 25 Syllabi}

\section{Textbook Analysis}

The second coding of all three sets of syllabi was to determine what textbooks are being used to teach the courses and to determine if schools are simply changing their programs from 
operations to supply chain management. This was done to determine if the focus of the course was still operations management as opposed to supply chain management.

The coding process looked at the textbooks used in the courses. In analyzing the textbooks, the initial plan was to only identify what type of textbook was being used simply based on the title of the textbook (the titles of the textbooks were used as the first differentiator between operations management textbooks and supply chain management textbooks). However, as this did not provide the level of detail needed for a good analysis, the analysis of the textbooks was expanded to include not just the titles of the textbooks, but an analysis of the topics as contained in the table of contents and chapter descriptions in the books to identify operations versus supply chain management topics in line with the definitions of operations and supply chain provided in Chapter 3.

When looking at the coding of the textbooks, fourteen of the seventy-eight course syllabi reflected the use of an operations management titled textbook even though the course was titled supply chain management. Nine of the courses were using an operations and supply chain management text. These numbers would indicate that Akalin, et al., (2016) may be correct in their claim that the only real change from operations management to supply chain management was the course name. The most commonly used operations management textbooks by title are shown in Figure 4-6 while the most frequently used supply chain management textbooks are shown in Figure 4-7.

\begin{tabular}{|l|l|}
\hline $\begin{array}{l}\text { Operations } \\
\text { Textbooks }\end{array}$ & \\
\hline Introduction to & \\
Operations and Supply & \\
Chain Management & Jacobs and Chase \\
\hline
\end{tabular}




\begin{tabular}{|l|l|}
\cline { 2 - 2 } $\begin{array}{l}\text { Operations } \\
\text { Management }\end{array}$ & Stevenson \\
\hline $\begin{array}{l}\text { Operations } \\
\text { Management }\end{array}$ & Krajewski \\
\hline $\begin{array}{l}\text { Operations and Supply } \\
\text { Chain Management }\end{array}$ & $\begin{array}{l}\text { Heizer and } \\
\text { Render }\end{array}$ \\
\hline Operations & Meredith \\
\hline $\begin{array}{l}\text { Operations } \\
\text { Management }\end{array}$ & Reid and Sanders \\
\hline
\end{tabular}

Figure 4-6: Operations Management Textbooks Most Frequently Used in Syllabi

Supply Chain
Textbooks
\begin{tabular}{|l|l|}
\hline $\begin{array}{l}\text { Supply Chain } \\
\text { Management }\end{array}$ & Ballou \\
\hline $\begin{array}{l}\text { Supply Chain } \\
\text { Management }\end{array}$ & Chopra and Meindl \\
\hline $\begin{array}{l}\text { Supply Chain } \\
\text { Management: A } \\
\text { logistics perspective }\end{array}$ & Coyle and Langley \\
\hline $\begin{array}{l}\text { Supply Chain } \\
\text { Management: A } \\
\text { global perspective }\end{array}$ & Sanders \\
\hline $\begin{array}{l}\text { Purchasing and } \\
\text { Supply Chain } \\
\text { Management }\end{array}$ & Monczka and \\
\hline $\begin{array}{l}\text { Logistics and Supply } \\
\text { Chain Management }\end{array}$ & Chandfield \\
\hline $\begin{array}{l}\text { Supply Chain } \\
\text { Logistics } \\
\text { Management }\end{array}$ & Bowersox and Closs \\
\hline $\begin{array}{l}\text { Managing Operations } \\
\text { Across the Supply } \\
\text { Chain }\end{array}$ & \\
\hline $\begin{array}{l}\text { Introduction to } \\
\text { Supply Chain } \\
\text { Management }\end{array}$ & Swink and Melnyk \\
\hline
\end{tabular}

\section{Figure 24-7: Supply Chain Management Textbooks Most Frequently Used in Syllabi}

What the textbook analysis showed is that there are some commonalities between supply chain management topics and operations management topics as shown in Figure 4-8. This analysis shows that even if the course was changed from operations to supply chain, some of the 
legacy operations topics are still applicable. This dichotomy between operations topics and supply chain management topics was also necessary to determine what should be included in a supply chain management course as opposed to a pure operations management course. What this phase of the analysis shows is that some universities continue to teach operations management although the course title has been changed to supply chain management.

While the coding and analysis revealed terms unique to operations management and supply chain management, it also revealed that there are some common topics shared by both disciplines. This could lead credence to the idea that you cannot teach supply chain management without an understanding of how some operations impact the supply chain. Until recently, the AACSB required an operations management course for business students. Even though that requirement has been removed, it is still important to cover some operations management topics such as manufacturing as a foundation for teaching supply chain management as pointed out in the analysis by Halldorsson \& Arlbjorn in their book on supply chain management (2005).

\begin{tabular}{|l|l|}
\hline OM/SCM common topics & Rationale \\
\hline Forecasting & $\begin{array}{l}\text { ties to manufacturing and inventory } \\
\text { management; necessary for meeting needs of } \\
\text { customers }\end{array}$ \\
\hline inventory & $\begin{array}{l}\text { ties to manufacturing and forecasting; } \\
\text { necessary for meeting needs of customers }\end{array}$ \\
\hline lean/JIT/6 Sigma & $\begin{array}{l}\text { continuous process improvement programs } \\
\text { manpacts on quality as well as inventory } \\
\text { managemt }\end{array}$ \\
\hline project management & impacts customer satisfaction \\
\hline performance measurement & necessary for both disciplines \\
\hline
\end{tabular}




\begin{tabular}{|l|l|} 
capacity & necessary for both disciplines \\
\hline layout design & $\begin{array}{l}\text { necessary for both disciplines: important for } \\
\text { operations layouts as well as supply chain } \\
\text { activities such as distribution center layouts }\end{array}$ \\
\hline $\begin{array}{l}\text { Materials Requirements } \\
\text { Planning }\end{array}$ & ties to inventory as well as manufacturing \\
\hline manufacturing & ties to inventory and quality \\
\hline sales and operations planning & $\begin{array}{l}\text { what needs to be done, what quantities } \\
\text { (inventory) and what needs to be } \\
\text { manufactured }\end{array}$ \\
\hline producing goods and services & impacts customer satisfaction and quality \\
\hline
\end{tabular}

\section{Figure 4-8: Common Terms in Both Operations and Supply Chain Management Textbooks} and Key Word Listings

\section{Thematic Analysis/Topic Groups}

In the preface to his latest book on supply chain management, Christopher (the author of the first book to include the term supply chain management in 1992), stated, "Supply chains today operate in a world where the rate of change continues to increase. As we enter an era that some have termed 'The New Industrial Revolution' much of the conventional wisdom that has been the basis for supply chain design and thinking will have to be questioned" (2016, p. xiii). Because of these rapid changes in supply chain management, a coding was necessary to group topics into related themes or modules, to include emerging concepts or topics that may not be routinely contained in syllabi but may be needed to reflect the changes in supply chain management.

The coding of all three sets of the syllabi terms was to create themes or related topics for comparison to the themes/related topics listing from the job announcements. The use of topic groups or themes was based on the methodology used by Johnson and Pyke in the formation of their framework into ten distinct topic groups or themes of related topics. Included in this listing 
of themes or related topic groupings is a separate grouping of emerging topics that have not reached the textbooks or APICS terminology lists because of the changing dynamics of supply chain management. One of the reasons for these topics not appearing in syllabi could be that there is a multi-year time lag between the introduction of a new industry term and its appearance in textbooks and syllabi.

The plan for this round of coding was to use the APICS Dictionary and APICS Body of Knowledge manuals and expand the key terms into themes by using the relationships established by looking up each of the key terms and then linking the terms found in the definitions to the "see also ..." references. The topic groups are based on the supply chain management topics and chapters from the textbook analysis. All of the topics that could be linked to a common theme were then placed into thematic groups of related topics. Some topics such as the different professional organizations were grouped based on their relationship as professional development organizations. Newer topics that showed up in the syllabi such as Radio Frequency Identification (RFID), supply chain security, and reverse logistics were grouped under emerging concepts/topics.

Of note here are the ideas of $21^{\text {st }}$ Century supply chains, transportation, global supply chain management and supply chain management challenges, which would include supply chain security. These are topics not fully addressed in the original Johnson and Pyke framework. The continued expansion of supply chains globally in the e-commerce society of the $21^{\text {st }}$ Century coupled with the increased dependence on international transportation assets has led to a greater focus on supply chain security, especially in light of the September 11, 2001 terrorists' attacks , Until the impacts on supply chain operations were felt immediately following the 9/11 attacks (when nothing moved in this country for five days by rail, truck or plane), many within the 
industry were not too concerned about security issues as is evident by the fact that the first legal mandate to control access to US ports was in the SAFE Port Act of 2006. It was not until 2012 that the US adopted a National Global Supply Chain Security Strategy (Obama, 2012).

Globalization of supply chains and the resultant increase in international commerce has contributed to greater security issues and increasing cyber security issues with major companies such as Target, FedEx, and Maersk. Each of these topics are described and justified in more detail below and were considered in the further coding of the data, such as the topics addressed in each syllabus.

\section{Globalization.}

“The world is becoming smaller. Supply chains of today's companies have globalized due to increasing efficiency in transport and logistics" (Ruske \& Kauschke, 2012, p. 3). This global view is very similar to the viewpoint of Friedman. Friedman wrote The World is Flat in 2004 and updated his "Brief History of the $21^{\text {st }}$ Century" in 2007. In this seminal work, he defines supply chain management as "a method of collaborating horizontally among suppliers, retailers, and customers - to create value" (p. 152). His definition is not significantly different from the other previous definitions of supply chain management; however, he sees supply chains as one of his ten flatteners of the earth in that supply chains are global in nature with suppliers worldwide and customers worldwide being able to access the supply chain through the internet. "In this world, a smart and fast global supply chain is becoming one of the most important ways for a company to distinguish itself from its competitors" (Friedman, 2007, p. 155). This globalization can be tied to the expanded use of the internet after the initial dot-com bust in the late 1990s. It can also be tied to the growing e-commerce use by consumers. From a curriculum development perspective, students need to understand the impacts of globalization on supply 
chain operations, even for domestic companies that may be competing with global supply chain companies such as Wal-Mart, Amazon or Alibaba. The demand for global supply chain management as a topic appears in the key word listing and frequency distributions for the job announcements. Tied to the impacts of the globalization of supply chains is the idea of securing the supply chain.

\section{Security/preparedness.}

"As the number of man-made attacks on supply chains increases, how will companies need to react? How can companies make sure their people and technology are up to the task of securing the supply chain over the next two decades? Total direct costs of piracy in 2010 are estimated to be between US\$ 7 billion and US\$ 12 billion” (Ruske \& Kauschke, 2012, p. 7). Security in supply chains includes piracy, theft, counterfeit products and cybersecurity. However, security is not a new issue in the supply chain and logistics world. In 512 BC, Sun Tzu (1993) discussed the costs of logistics and the need to have the right materials in the right place and the need to secure the supplies and logistics operations. My ancestors understood the concept of interrupting supply chains when they tried to stop the encroachment and movement of white settlers moving west by attacking the wagon trains carrying supplies. The Native Americans understood that if you could interdict the supply chain you could disrupt the operations and impact success.

Jumping forward to the $21^{\text {st }}$ Century, the World Shipping Council estimated that the number of twenty-foot containers shipped in 2016 was 130,000,000 with a value exceeding \$4 trillion (2017). The sheer number of containers shipped as a result of the globalized supply chain creates a large security issue as each container is a potential dirty bomb or human smuggling operation such as the one when Osama Bin Laden's relative tried to sneak into the US in 2007. 
This security issue is not just the physical security of the containers. It has to include both physical and cyber security measures. Physical security is the focus of the Container Security Initiative as part of the Security and Accountability For Every (SAFE) Port Act of 2006.

Security concerns and a need to focus on security in supply chain programs include securing the supply chain against theft. Cargo theft was estimated at $\$ 30$ billion in the US in 2016 according to PLS Logistics Services and the FBI (2016). This security concern now has to add a focus on cyber security. The failure to focus on supply chain cyber security has resulted in a couple of major incidents involving supply chain companies in the past month. Last month a cyberattack against a FedEx subsidiary in Europe resulted in "significant delays" (Moise, 2017) and the company having to use manual practices in lieu of the normal automated processing of packages. The same week, Maersk, the largest container shipping company in the world, was hit by a cyberattack that crippled their operations at their ports for several days (Kostav \& Paris, 2017).

Supply chain preparedness and security includes planning for any contingency that may impact the flow of products through the supply chain. Hurricane Katrina impacted the flow of coffee in the supply chain among other items. In 2017, Hurricane Harvey hit the Gulf Coast of the US and closed the sixth largest port (Houston) and shut down for over a week approximately $20 \%$ of the petroleum refining operations of the US resulting in area shortages of gasoline and drastic price increases just before the busy Labor Day weekend.

Supply chain security is linked to the increased transportation requirements as a result of e-commerce and globalized supply chains. 


\section{Transportation today.}

The modes of transportation have not really changed in 100 years. We still have water, rail, road and intermodal (the use of more than one mode of transportation). Then why discuss it as a change from 2000? The continued shift of manufacturing to low cost countries has increased the need for water transportation. Not only has this resulted in a need for increased ship sizes but the ripple effect of larger ships is the need for greater infrastructure to berth and off-load the ships. According to the World Shipping Council and Alphaliner, there are currently 5,993 active ships moving cargo weekly (Alphaliner, 2017). The largest of these ships can carry in excess of 20,000 twenty-foot equivalent International Standards Organization containers. The larger ship sizes led to the expansion of the Panama Canal in 2015. The ripple effect on infrastructure from the expansion of the canal was on the depth and berth lengths at the major ports such as Miami, Charleston and New York/New Jersey.

\section{Track and trace.}

The ability to track and trace items in the supply chain has grown with the expansion and globalization of supply chains. Companies need to know where their products are in the supply chain and customers want the same information. One of the newer ways of gaining visibility in the supply chain is through the use of Radio Identification (RFID) tags. As more companies have followed Walmart, Target and the Department of Defense in this initiative, it is imperative that students understand this technology and its uses in order to be prepared for the use of RFID in their future jobs.

\section{Additional Thematic Groupings.}

In addition to the emerging concepts theme, the common themes or topic groupings shown in Figure 4-9 reflect the key words from the APICS key words references as reflected in 
the syllabi that when compared to the APICS Dictionary and APICS Body of Knowledge for "see also...". Johnson and Pyke placed their topics into common groupings; the attempt here was to do the same for comparison against the original framework for changes and commonality. Like Johnson and Pyke, this thematic or "see also" analysis produced ten groups/themes/modules of related terms and topics. These ten groupings are shown in Figure 4-9. Figures 4-10 through 4-18 show the topics that were related by thematic grouping.

\begin{tabular}{|l|l|}
\hline Inventory management & Information Systems \\
\hline Procurement/sourcing & $\begin{array}{l}\text { customer service } \\
\text { management }\end{array}$ \\
\hline $\begin{array}{l}\text { Supply chain management } \\
\text { Basics }\end{array}$ & $\begin{array}{l}\text { Professional Organizations/ } \\
\text { Professional Development }\end{array}$ \\
\hline Operations Topics & $\begin{array}{l}\text { Supply chain management } \\
\text { Emerging Concepts }\end{array}$ \\
\hline Quality/Metrics & \multicolumn{1}{|l}{} \\
\hline University Generic &
\end{tabular}

Figure 4-9: Thematic Analysis Topics

\section{Topics in the inventory management theme group.}

Based on the syllabi topics and the textbook analysis, a discussion of inventory management should consider the topics shown in Figure 4-10 to introduce inventory management to students in an introductory supply chain management course. Forecasting is related to the inventory levels while the Economic Order Quantity calculations related to how many items are ordered at a time which is also related to the inventory levels to meet the customer demands for products.

\begin{tabular}{|l|l|}
\hline Inventory management & Rationale \\
\hline Forecasting & $\begin{array}{l}\text { Necessary to estimate inventory } \\
\text { levels }\end{array}$ \\
\hline Just in Time/Lean & $\begin{array}{l}\text { Can be viewed as an inventory } \\
\text { methodology }\end{array}$ \\
\hline
\end{tabular}




\begin{tabular}{|c|c|}
\hline Demand & $\begin{array}{l}\text { forecasting demand for a product is } \\
\text { critical to inventory levels }\end{array}$ \\
\hline Bullwhip effect & $\begin{array}{l}\text { This is a description of the } \\
\text { distortion in a supply chain when } \\
\text { good information flow is not } \\
\text { present. Inventory levels have to be } \\
\text { adjusted to meet fluctuations in } \\
\text { demand patterns }\end{array}$ \\
\hline Materials & $\begin{array}{l}\text { The inventory level of raw materials } \\
\text { is driven by the forecast for finished } \\
\text { goods }\end{array}$ \\
\hline inventory turns & $\begin{array}{l}\text { This is a metric of how well the } \\
\text { inventory on hand is meeting the } \\
\text { needs of the customers }\end{array}$ \\
\hline Economic Order Quantity & $\begin{array}{l}\text { This is an inventory planning } \\
\text { methodology }\end{array}$ \\
\hline cross docking & $\begin{array}{l}\text { Cross docking is a method of } \\
\text { preplanning inbound and outbound } \\
\text { shipments to reduce inventory on } \\
\text { the shelf }\end{array}$ \\
\hline Pricing & $\begin{array}{l}\text { Important to valuation of inventory } \\
\text { on hand }\end{array}$ \\
\hline Vendor Managed Inventory & $\begin{array}{l}\text { This is an inventory method that } \\
\text { places the onus for on hand } \\
\text { inventory on the vendor }\end{array}$ \\
\hline
\end{tabular}

Figure 4-10: Inventory Management Topics

\section{Topics in the procurement theme group.}

Procurement is a fancy supply chain term for buying things. Procuring the right products at the right price and the right quality sets the stage for manufacturing success and customer satisfaction, both of which are critical to supply chain management success. The topics related to procurement from the syllabi are shown in Figure 4-11. Within this grouping, sustainability is 
related to the idea of future availability of products which in turn ties back to the inventory levels and meeting customer demands. Outsourcing is methodologies of having someone else produce the product in the quantities forecasted under the inventory management theme topics.

\begin{tabular}{|c|c|c|c|}
\hline procurement/sourcing & Rationale & procurement/sourcing & Rationale \\
\hline Sustainability & $\begin{array}{l}\text { Growing area of } \\
\text { interest in } \\
\text { procurement as a } \\
\text { consideration of } \\
\text { impacts on the } \\
\text { environment }\end{array}$ & Contracting & $\begin{array}{l}\text { The result of the } \\
\text { procurement } \\
\text { negotiations }\end{array}$ \\
\hline Just in Time & $\begin{array}{l}\text { A methodology for } \\
\text { procuring and } \\
\text { delivering products } \\
\text { just in time to meet } \\
\text { the company's } \\
\text { needs }\end{array}$ & $3 \mathrm{PL}$ & $\begin{array}{l}\text { 3rd Party Logistics } \\
\text { Providers are part } \\
\text { of the outsourcing } \\
\text { process }\end{array}$ \\
\hline supply management & $\begin{array}{l}\text { Usually viewed as a } \\
\text { subset of } \\
\text { procurement }\end{array}$ & Collaboration & $\begin{array}{l}\text { Important to } \\
\text { procurement } \\
\text { success is the } \\
\text { collaboration with } \\
\text { suppliers and } \\
\text { customers }\end{array}$ \\
\hline outsourcing & $\begin{array}{l}\text { A distinct part of } \\
\text { procurement and } \\
\text { sourcing }\end{array}$ & Delivery & $\begin{array}{l}\text { Getting the product } \\
\text { from the suppliers } \\
\text { and to the } \\
\text { customers }\end{array}$ \\
\hline Negotiation & $\begin{array}{l}\text { A critical skill to } \\
\text { ensure proper } \\
\text { delivery and best } \\
\text { price/quality }\end{array}$ & Pricing & $\begin{array}{l}\text { Critical to getting } \\
\text { the best terms from } \\
\text { a procurement or } \\
\text { outsourcing }\end{array}$ \\
\hline Suppliers & $\begin{array}{l}\text { Critical relationship } \\
\text { to procurement and } \\
\text { sourcing }\end{array}$ & raw materials & $\begin{array}{l}\text { the procurement of } \\
\text { the right quality } \\
\text { and specification } \\
\text { for raw materials is } \\
\text { critical to } \\
\text { operational success }\end{array}$ \\
\hline
\end{tabular}




\begin{tabular}{|l|l|l|l|}
\hline & $\begin{array}{l}\text { The time between } \\
\text { ordering a product } \\
\text { and the receipt of } \\
\text { the product. Part of } \\
\text { the negotiation and } \\
\text { customer service } \\
\text { functions }\end{array}$ & Cycle time & $\begin{array}{l}\text { How long does it } \\
\text { take to make a } \\
\text { product and have it } \\
\text { ready for delivery } \\
\text { from the suppliers? } \\
\text { Related to lead } \\
\text { time }\end{array}$ \\
\hline
\end{tabular}

Figure 4-11: Procurement and Sourcing Topics

\section{Topics in the operations management theme group.}

The previous discussion of common topics between operations management and supply chain management showed that based on these common terms some operations management topics are necessary to establish a foundation in operations as part of a supply chain curriculum. While a course in operations management and a course in supply chain management may be a good idea, the AACSB eliminated the need for a required operations management course in the latest accreditation guidelines. Although no explanation was given by the AACSB for their decision, it does leave the door open to have both an operations management course and a supply chain management course or just a supply chain course. If only a supply chain management course is offered, then students would need exposure to some operations management topics to help establish a foundation for understanding the relationship between the two disciplines. The relationship between these two disciplines can be seen in the topics are similar to both disciplines based on the textbook analysis along with other topics from the syllabi and are shown Figure 412. The concepts of the Theory of Constraints, utilization and efficiency are related to the supply chain management concepts of warehousing and the operations management of capacity management. 


\begin{tabular}{|l|l|}
\hline $\begin{array}{l}\text { Operations Topics } \\
\text { Necessary to Establish a } \\
\text { Foundation for Supply } \\
\text { Chain Education }\end{array}$ & \\
\hline process design & queueing theory \\
\hline Lean & vertical integration \\
\hline Strategy & $\begin{array}{l}\text { business process } \\
\text { management }\end{array}$ \\
\hline product design/production & Competitiveness \\
\hline Capacity & Improve \\
\hline Project Management & Innovation \\
\hline Location analysis & Utilization \\
\hline Risk & balanced scorecard \\
\hline S\&OP & best practices \\
\hline Productivity & Complexity \\
\hline Services & Controlling \\
\hline Theory of Constraints & informal economy \\
\hline value chain & Modeling \\
\hline Efficiency & Software as a Service \\
\hline Effectiveness & \multicolumn{1}{|l}{} \\
\cline { 1 - 2 } &
\end{tabular}

Figure 4-12: Operations Management Topics

\section{Topics in the supply chain management basics and terminology theme group.}

An introductory course in supply chain management should have a set of topics that, like the operations management topics, help establish a foundation in the theory of supply chain management to provide a balance between academic theory and practical business skills. These topics from the syllabi align with the introductory topics found in the supply chain management textbooks. As a minimum the topics in this theme would include the terms and the rationale for these terms as shown in Figure 4-13.While warehousing is also related to the operations management topics of capacity, layout planning and the Theory of Constraints, it is also linked to distribution, customer service and transportation. At the same time customer service 
measurement in the supply chain management theme group is related to performance measurement in the metrics theme group.

\begin{tabular}{|c|c|c|c|}
\hline $\begin{array}{l}\text { Supply chain } \\
\text { management }\end{array}$ & Rationale & $\begin{array}{l}\text { Supply chain } \\
\text { management }\end{array}$ & Rationale \\
\hline logistics & $\begin{array}{l}\text { This is a subset of } \\
\text { supply chain } \\
\text { management that needs } \\
\text { to be understood as part } \\
\text { of the supply chain } \\
\text { education }\end{array}$ & SCM Trends & $\begin{array}{l}\text { Students should have a } \\
\text { grasp of what is } \\
\text { developing in the supply } \\
\text { chain field }\end{array}$ \\
\hline customer service & $\begin{array}{l}\text { Critical to supply chain } \\
\text { success }\end{array}$ & track and trace & $\begin{array}{l}\text { Related to supply chain } \\
\text { security - ensuring } \\
\text { visibility in the supply } \\
\text { chain of products }\end{array}$ \\
\hline warehousing & $\begin{array}{l}\text { Part of distribution and } \\
\text { logistics and necessary } \\
\text { to understand as part of } \\
\text { the supply chain } \\
\text { concept }\end{array}$ & Fulfillment & Related to delivery \\
\hline distribution & $\begin{array}{l}\text { Moving products and } \\
\text { people from point A to } \\
\text { point B; part of logistics }\end{array}$ & $\begin{array}{l}\text { on time } \\
\text { delivery }\end{array}$ & $\begin{array}{l}\text { A critical metric of the } \\
\text { supply chain related to } \\
\text { getting the product to the } \\
\text { customer when promised }\end{array}$ \\
\hline Delivery & $\begin{array}{l}\text { Getting the product to } \\
\text { the customer as } \\
\text { efficiently and } \\
\text { effectively as possible }\end{array}$ & $\begin{array}{l}\text { reverse } \\
\text { logistics }\end{array}$ & $\begin{array}{l}\text { Getting products back if } \\
\text { defective or unwanted }\end{array}$ \\
\hline transportation & $\begin{array}{l}\text { Necessary aspect of } \\
\text { supply chain } \\
\text { management that ties } \\
\text { delivery to distribution }\end{array}$ & receiving & $\begin{array}{l}\text { Critical to warehousing } \\
\text { success and fulfillment } \\
\text { of customer orders }\end{array}$ \\
\hline SCM Security & $\begin{array}{l}\text { Emerging trend that } \\
\text { needs to be understood } \\
\text { to ensure delivery of } \\
\text { products to customers }\end{array}$ & global SCM & $\begin{array}{l}\text { As supply chains } \\
\text { continue to expand } \\
\text { globally, students need } \\
\text { to understand the } \\
\text { impacts of global issues, } \\
\text { security and } \\
\text { transportation modes }\end{array}$ \\
\hline
\end{tabular}

Figure 4-13: Supply Chain Management Basics 


\section{Topics in the quality/metrics theme group.}

Understanding quality is critical to not only procurement and sourcing operations but to all other supply chain operations from manufacturing to the delivery of the right product in the right condition to the customer. The topics of quality also include performance management and the rapidly growing area of metrics and data analysis. The quality/metrics related terms are shown in Figure 4-14. Total Quality Management is not only related to producing quality products in the manufacturing theme but ties to the customer satisfaction measurement within the supply chain management theme. At the same time Lean and Six Sigma can be viewed as quality management systems as well as methodologies to improve operations and could also be linked to inventory management.

\begin{tabular}{|l|l|}
\hline Quality & Rationale \\
\hline Total Quality Management & $\begin{array}{l}\text { Understanding quality is critical to } \\
\text { delivering a quality product to the } \\
\text { customer }\end{array}$ \\
\hline Six Sigma & $\begin{array}{l}\text { A quality initiative that has become } \\
\text { popular and widely used in } \\
\text { business }\end{array}$ \\
\hline Lean & $\begin{array}{l}\text { A quality initiative focused on } \\
\text { improving quality while reducing } \\
\text { costs }\end{array}$ \\
\hline Performance Management & $\begin{array}{l}\text { How well are we doing compared } \\
\text { to the competition? }\end{array}$ \\
\hline Metrics & $\begin{array}{l}\text { A widely growing area of data } \\
\text { mining and analyzing the data }\end{array}$ \\
\hline
\end{tabular}

Figure 4-14: Quality and Metrics Topics 


\section{Topics in the information systems theme group.}

The goal of this set of topics is not to make the students experts in the supply chain management information systems but simply to expose the students to the systems and what their functions are in the supply chain as well as how the systems are interrelated. The information systems related terms needed in an introductory supply chain management class are shown in Figure 4-15. Information systems are critical to the operations of any supply chain and understanding these systems is critical to understanding the flow of information in a company's supply chain.

\begin{tabular}{|l|l|}
\hline Information Systems & Rationale \\
\hline information flow & $\begin{array}{l}\text { Understanding the flow } \\
\text { of information is critical } \\
\text { to reducing distortion in } \\
\text { the supply chain }\end{array}$ \\
\hline Material Requirements Planning & $\begin{array}{l}\text { This is a system related } \\
\text { to both planning and } \\
\text { inventory management }\end{array}$ \\
\hline Enterprise Resource Planning & $\begin{array}{l}\text { ERP systems cover all } \\
\text { aspects of the supply } \\
\text { chain from forecasting to } \\
\text { procurement to storage } \\
\text { to delivery of the } \\
\text { product }\end{array}$ \\
\hline Distribution Requirements Planning & $\begin{array}{l}\text { An understanding of the } \\
\text { interrelationships of the } \\
\text { systems and what each } \\
\text { system does and how it } \\
\text { is linked to the overall } \\
\text { supply chain operations }\end{array}$ \\
\hline SCM Networks and network design & $\begin{array}{l}\text { How many assets are } \\
\text { needed to move the } \\
\text { product? Critical to } \\
\text { supply chain distribution }\end{array}$ \\
\hline
\end{tabular}


Transportation Management Systems

Managing the

transportation modes and assets

\section{Figure 4-15: Information Systems Topics}

\section{Topics in the customer service management theme group.}

Taking care of the customer is the main focus of supply chain management. If a company does not take care of its customers, another company will be happy to do so. How the company takes care of the customer and measures that performance is critical to supply chain success and the success of a company. While customer service could be a course of its own, the supply chain management student needs an understanding of this critical area and the related topics as shown in Figure 4-16. Customer service management is not only a stand-alone theme, but is related to performance measurement in that a company has to measure how well their supply chain is taking care of their customers and is also tied to inventory management and having the right products in the right quantity to meet customer demands.

\begin{tabular}{|l|l|}
\hline Customer Service Management & Rationale \\
\hline order processing & $\begin{array}{l}\text { Properly processing an } \\
\text { order is critical to customer } \\
\text { satisfaction }\end{array}$ \\
\hline lead time & $\begin{array}{l}\text { Understanding the time } \\
\text { from the placement of an } \\
\text { order until the customer has } \\
\text { the product }\end{array}$ \\
\hline e-commerce & $\begin{array}{l}\text { A growing area of } \\
\text { commerce impacting } \\
\text { supply chain operations to } \\
\text { meet the needs of online } \\
\text { customers }\end{array}$ \\
\hline Responsiveness & $\begin{array}{l}\text { How quickly does the } \\
\text { company respond to the } \\
\text { needs of the customers? }\end{array}$ \\
\hline
\end{tabular}




\begin{tabular}{|l|l|} 
"post sale" processes & $\begin{array}{l}\text { Taking care of the customer } \\
\text { after the sale; ay include } \\
\text { reverse logistics }\end{array}$ \\
\hline Delivery & $\begin{array}{l}\text { Getting the product to the } \\
\text { customer on time }\end{array}$ \\
\hline
\end{tabular}

Figure 4-16: Customer Service Topics

\section{Topics in the supply chain emerging concepts theme group.}

The topics in this theme grouping are topics that may not have made it to the textbooks yet but are being taught in some courses and should be considered important enough from the practical experience perspective to be included in this theme. Students in a supply chain introductory course should at least be exposed to the topics in Figure 4-17. While not a complete list of emerging topics, the terms showing up in syllabi that are related to this theme are shown in Figure 4-16 along with the rationale for including them in this theme grouping. While emerging topics only showed up in a few syllabi, this is an interesting way to get students aware of newer topics and how the concepts are being used in business. For example, RFID as part of the digital tracking and tracing of items in the supply chain appeared in eleven Top 25 program syllabi. Blockchain could be viewed as the next generation of visibility and track and trace in the supply chain. Risk showed up in twenty-two syllabi or less than one third of the total sample of seventyeight syllabi. Reverse logistics is a growing area of interest in the supply chain and only showed up in seven syllabi, six of the seven were from Top 25 schools. It is important to keep in mind that the emerging topics list is a moving target that may change from year to year.

\begin{tabular}{|l|l|}
\hline Emerging Supply Chain Topics & Rationale \\
\hline Risk & $\begin{array}{l}\text { Related to the concept of supply } \\
\text { chain security which has garnered } \\
\text { more attention worldwide since the } \\
\text { attacks of September 11, 2001 and } \\
\text { the growth in international piracy }\end{array}$ \\
\hline
\end{tabular}




\begin{tabular}{|c|c|}
\hline Visibility and Tracking & $\begin{array}{l}\text { A relatively new topic that it tied to } \\
\text { visibility and track and trace within } \\
\text { the supply chain to include the } \\
\text { discussion of RFID tags }\end{array}$ \\
\hline Security and Preparedness & $\begin{array}{l}\text { While not really an emerging } \\
\text { concept, protecting the flow of } \\
\text { products in the supply chain has } \\
\text { become a very important issue that is } \\
\text { not covered in many textbooks. } \\
\text { Discussion of this topics includes } \\
\text { not only man-made events such as } \\
\text { piracy or terrorism but also natural } \\
\text { events such as hurricanes }\end{array}$ \\
\hline Reverse Logistics & $\begin{array}{l}\text { A growing multi-trillion dollar a } \\
\text { year aspect of supply chain } \\
\text { management dealing with returns for } \\
\text { defective products, seasonal items } \\
\text { and unwanted products }\end{array}$ \\
\hline Block Chain & $\begin{array}{l}\text { A very new concept that is growing } \\
\text { in importance as a way to make the } \\
\text { visibility and transparency of the } \\
\text { supply chain more viable }\end{array}$ \\
\hline Omni-Channel & $\begin{array}{l}\text { The number of ways that a customer } \\
\text { can order from the supply chain and } \\
\text { have products delivered - includes } \\
\text { tablets, phones, computers, and in } \\
\text { store purchases }\end{array}$ \\
\hline
\end{tabular}

Figure 4-17: Emerging Trends Topics

\section{Topics in the professional development theme group.}

In an introductory supply chain management course, students need to learn not only what supply chain management is but also what they can do in a profession in supply chain management. From that aspect, they need to learn about the different professional organizations that will offer them networking and professional development seminars, meetings and conferences. The topics in this theme, found in Figure 4-17, are necessary to accomplish the goals of preparing the students for the job market and better help them fit the needs of the 
growing talent gap in supply chain management. Supply chain management as a career only showed up in eleven syllabi, but all eleven of them were from the 2016 Gartner Top 25 rankings.

\begin{tabular}{|l|l|}
\hline $\begin{array}{l}\text { Professional Organizations/Professional } \\
\text { Development }\end{array}$ & Rationale \\
\hline APICS & $\begin{array}{l}\text { Offers free student membership } \\
\text { and professional certification } \\
\text { listed in job announcements }\end{array}$ \\
\hline $\begin{array}{l}\text { Council of Supply chain management } \\
\text { Professionals (CSCMP) }\end{array}$ & $\begin{array}{l}\text { One of the largest professional } \\
\text { supply chain organizations }\end{array}$ \\
\hline Institute for Supply Management (ISM) & $\begin{array}{l}\text { Offers free student membership } \\
\text { and professional certification } \\
\text { listed in job announcements }\end{array}$ \\
\hline SCM Future & $\begin{array}{l}\text { Students need to have an } \\
\text { understanding of where the } \\
\text { profession is headed }\end{array}$ \\
\hline SCM and Society & $\begin{array}{l}\text { How do the functions of supply } \\
\text { chain management impact } \\
\text { society and how does society } \\
\text { needs impact supply chains? }\end{array}$ \\
\hline SCM as a Career & $\begin{array}{l}\text { What are the options and career } \\
\text { paths available for supply chain } \\
\text { professionals? }\end{array}$ \\
\hline
\end{tabular}

Figure 4-17: Professional Development Topics

Upon completion of the syllabi analysis and groupings, the job announcements had to be analyzed using the APICS key words lists before a comparison of the job announcements could be made against the syllabi results and a complete framework recommended.

\section{Job Announcement Analysis}

The final piece of the analysis of the data was the analysis of the one hundred and forty job announcements. Like the syllabi analysis, the job announcements were coded for key terms 
and topics using the same APICS Basics of Supply Chain Management Certification Manual and the CPIM Exam Manual. Of the four hundred plus supply chain topics in the APICS Manual, eighty-four key words appeared in the job announcements.

How were the job announcements analyzed? What did they tell us? The job announcements were analyzed the same way the syllabi were analyzed. The first coding of the job announcements was a manual process of identifying the key words from the APICS Basics of Supply Chain certification manual. The basic assumption of the job announcement analysis was that the key words in the job announcements reflect a current picture of what recruiters and companies feel are important areas of mastery in order to be qualified for the jobs available. The use of the seven different data capture time frames helped to smooth the data while providing a good cross section of the job market throughout the critical fall recruiting cycle. While not trying to minimize the importance of any industry desired knowledge, a threshold of at least five occurrences in the job announcements was used to help narrow the analysis to the most commonly requested terms. Key terms that showed up in less than five of the one hundred and forty job announcements appeared to fall into two categories: generic topics that were not really supply chain unique such as team work and communications or were considered outliers since they appeared in less than four percent of the announcements. The job announcements analysis revealed the following fifty-three key words and topics that recruiters are looking for. The key words in the job announcements listed in rank order are shown in Figure 4-19. 


\begin{tabular}{|l|l|l|}
\hline key term & \multicolumn{2}{l|}{} \\
\hline Inventory & Services & Efficiency \\
\hline procurement/sourcing/contracting & Team & engineering \\
\hline Processes & distribution & reports \\
\hline materials & & $\begin{array}{l}\text { SCM Systems (Warehouse } \\
\text { Management } \\
\text { Systems/Transportation } \\
\text { Management Systems/Order } \\
\text { MGT) }\end{array}$ \\
\hline logistics & Delivery & Strategy \\
\hline planning & & global SCM \\
\hline product & performance management/metrics & Negotiation \\
\hline customer service & communication skills & MRP \\
\hline Suppliers & Microsoft & receiving \\
\hline Operations & information systems & reverse logistics \\
\hline manufacturing & forecasting & best practices \\
\hline production & APICS Certification & inventory turns \\
\hline environment & Scheduling & on time delivery \\
\hline quality & ERP/SAP/Oracle & problem solving/resolution \\
\hline process improvement & lean & S\&OP \\
\hline leadership & Demand & \\
\hline data analysis & transportation & \\
\hline warehousing & Parts & \\
\hline project management & Shipping & \\
\hline & location analysis & \\
\hline & orders & \\
\hline
\end{tabular}

Figure 4-19: Job Announcement Key Terms in rank order

The job announcement key terms were also analyzed for themes in the same manner as the syllabi key terms. The job announcement key terms were divided into the same themes or groupings of related topics using the textbook tables of contents and the APICS Dictionary and Body of Knowledge to establish the themes or groupings as the key words from the syllabi.

The inventory management theme included the topics from the syllabi announcement but also added the terms of ABC Analysis, Work in Process and Maintenance, Repair and Operations parts inventory. The procurement/sourcing theme additions from the job announcements were the make or buy decision and customs requirements. Additions to the theme topics for supply chain management basics included planning and best practices. There 
were no additional topics added to quality, information systems, customer service management, or professional development.

The job announcement analysis also revealed some changes to Supply chain management understanding and skills requirements since the writings of Johnson and Pyke. These changes include trends such as Omni-channel distribution, fulfillment centers and advances in information processing and data analytics. Why are these topics important? Just like the emerging concepts or concepts gaining in importance from the syllabi analysis, industry requirements as reflected in the job announcements demonstrate the need for students to understand or at least know what these concepts are and the impacts that these newer concepts have or will have on supply chain operations as a result of the rapid rate of change in the supply chain management field as pointed out by Christopher (2016). These changes and new concepts include omni-channel distribution and fulfillment centers, both emerging with the continued growth of e-commerce. What are these new concepts and changes in supply chain management that appeared in job announcements but not in the syllabi?

\section{Omni-channel distribution.}

While e-commerce is not a new term in business, the ways that a consumer can now order products and have them delivered has changed since the days of Johnson and Pyke. Omnichannel is one of those emerging terms. "Omni-channel is a multichannel approach to sales that seeks to provide the customer with a seamless shopping experience whether the customer is shopping online from a desktop or mobile device, by telephone or in a bricks and mortar store" (Rouse, 2014). In lay terms, Omni-channel is simply providing the customer the opportunity to buy my product from the store, online via the computer/tablet/smart phone, using an Amazon Dash button or phoning in an order via telephone. While not really a new topic - we used to have 
the opportunity to buy products in the store, via catalog mail in orders or via faxed orders (the option of using a catalog goes back to 1894 with the Montgomery Ward's catalog) - the concept of bundling all of the customer experiences together has gotten a lot of attention as consumers continue to make the move from strictly brick and mortar stores to more online purchases.

So why is this concept, if it is critical to retail supply chains, not in business school curriculums? Most likely the answer to this question is because of its newness. As business continues to change and new concepts arrive, the time lag between concept arrival and textbook/classroom coverage may account for the lack of discussions around omni-channel distribution. However, a lack of understanding as to what omni-channel is may also account for the lack of coverage in the curriculums.

\section{Fulfillment centers.}

A fulfillment center is a distribution center that only supports e-commerce as opposed to the traditional warehouse or distribution center that supported stores and online sales. A center that only supports e-commerce was not even considered at the time of the Johnson and Pyke framework as e-commerce was in its infancy at the time. The US Census Bureau (Bureau, 2017) shows a $14.1 \%$ increase in e-commerce sales from the first quarter of 2016 compared to the first quarter of 2017 bringing online sales to approximately $8.5 \%$ of all retail transactions. With the growth in electronic commerce and consumer demand for speedy deliveries comes a need for more distribution centers. Amazon's goal, for example, is to have a facility within one hour of each major city to speed delivery of products. As distribution centers have shifted focus to individual online sales, the need to morph the traditional distribution center away from supporting stores to support individual customers has resulted in fulfillment centers. 
Students need to be aware of the differences in physical operations between a distribution center that supports store orders and a fulfillment center that only supports individual item picking and shipping. While the principles for operations are very similar, the mix of products may be much greater in a fulfillment center and the number of orders processed much higher than those of a traditional distribution center that supports store orders and the shift to fulfillment centers impacts inventory levels, location analysis and site selection processes.

\section{Comparison of Job Announcements to Syllabi}

At this point the data is much like the line from The Sound of Music when Maria is trying to teach the von Trapp children to sing and one of the children remarks "But it doesn't mean anything." Data alone mean nothing, especially in a research project such as this one. The critical piece to any research is the analysis or the turning of the data into information that can be used to make a better-informed decision or recommendation. So far, I have documented what I said I was going to do in Chapter 3 and what I have done as far as a data capture to support that methodology. Now it is time to turn all of the data into information through the quantitative analysis process to produce conclusions and recommendations from the data for future use.

When comparing the frequency of the key words from the job announcements to the frequency of the key words from the total set of seventy-eight syllabi, the data provided a good start point for analyzing what industry is asking for to what academia is teaching as shown in the frequency distributions in Figure 4-20 that show the top fifty terms and their frequencies. The top two topics in both distributions are the same and then the differences start showing up. 
Job announcements

\section{KEY TERMS}

Inventory

procurement/sourcing/contracting

Processes

materials

logistics

planning

product

customer service

Suppliers

Operations

manufacturing

production

environment

quality

process improvement

leadership

data analysis

warehousing

project management

Services

Team

distribution

Delivery

performance management/metrics

communication skills

Microsoft

information systems

forecasting

APICS Certification

Scheduling

ERP/SAP/Oracle

lean

Demand

transportation

Parts

Shipping

location analysis

orders

Efficiency
FREQUENCY

422

287

250

225

219

213

211

177

171

170

150

147

136

132

121

120

105

105

100

87

87

85

80

78

66

64

56

44

41

41

39

34

26

22

20

19

17

17

16

\begin{tabular}{|c|c|}
\hline Syllabi & \\
\hline KEY TERMS & FREQUENCY \\
\hline inventory management & 114 \\
\hline procurement/sourcing & 91 \\
\hline global SCM & 87 \\
\hline operations & 75 \\
\hline logistics & 71 \\
\hline supply chain management & 70 \\
\hline forecasting & 65 \\
\hline process design & 62 \\
\hline strategy & 62 \\
\hline quality/TQM & 55 \\
\hline product design/production & 52 \\
\hline SCM Concepts & 49 \\
\hline distribution & 41 \\
\hline transportation & 41 \\
\hline lean & 36 \\
\hline Capacity & 35 \\
\hline metrics/performance management & 35 \\
\hline information flow/systems & 34 \\
\hline sustainability & 33 \\
\hline Project Management & 30 \\
\hline MRP/ERP & 27 \\
\hline Location analysis & 26 \\
\hline JIT & 24 \\
\hline planning & 23 \\
\hline demand & 22 \\
\hline risk & 22 \\
\hline customer service management & 21 \\
\hline supply management & 21 \\
\hline manufacturing & 20 \\
\hline warehousing & 19 \\
\hline SCM integration & 18 \\
\hline S\&OP & 17 \\
\hline APICS & 16 \\
\hline productivity & 16 \\
\hline services & 15 \\
\hline SCM integration & 14 \\
\hline TOC & 13 \\
\hline SCM Network & 12 \\
\hline Bullwhip effect & 11 \\
\hline
\end{tabular}




\begin{tabular}{|c|c|c|c|}
\hline engineering & 15 & outsourcing & 11 \\
\hline reports & 15 & RFID & 11 \\
\hline $\begin{array}{l}\text { SCM Systems (WMS/TMS/Order } \\
\text { MGT) }\end{array}$ & 12 & Six Sigma & 11 \\
\hline Strategy & 12 & SCM Basics & 10 \\
\hline global SCM & 11 & SCM transformation & 10 \\
\hline Negotiation & 11 & suppliers & 10 \\
\hline MRP & 9 & efficiency & 9 \\
\hline receiving & 7 & scheduling & 9 \\
\hline reverse logistics & 7 & fulfillment & 8 \\
\hline best practices & 6 & layout analysis & 8 \\
\hline inventory turns & 6 & materials & 8 \\
\hline on time delivery & 5 & Negotiation & 8 \\
\hline
\end{tabular}

Figure 4-20: Top Terms in Job Announcements and Syllabi

The syllabi from the schools that have not appeared in the Gartner Top 25 rankings in the past two ranking periods were compared to the job announcements to create the same analysis as the comparison of all of the syllabi to the job announcements and the Top 25 Schools syllabi to the job announcements. The first analysis looked at the syllabi of the Gartner Top 25 Schools compared to the job announcements.

\section{Top 25 school syllabi compared to the job announcements.}

The number of topics/key words in the Top 25 Schools' syllabi that matched the key words within the job announcements was thirty-eight out of the fifty-three key words in the job announcements. This shows a 71.7\% match between the leading schools and the job announcement requirements. Nine of the syllabi key words (outsourcing, bull whip effect, "postsale" processes, collaboration, Distribution Requirements Planning, Economic Order Quantity, raw materials, and Vendor Managed Inventory, Just in Time) are subsets of other key topics contained in job announcements. When these subset words are included in the calculation, this puts sixty-five of the eighty-four job announcement key words as a match between the syllabi of the Top 25 Schools and the job announcement; this reveals a $88.7 \%$ match between the 
curriculums of the Top 25 Schools and the needs of industry as reflected in the job announcements.

When the key words from the syllabi were compared to the job announcement key words, the nineteen topics shown in Figure 4-21 were listed in the Top 25 syllabi but not in the job announcements. One of the limitations of the syllabi review was that a syllabus may not reflect the mastery of a topic or the acquisition of a referenced skill related to a topic but only the inference that the student was exposed to the topic and hopefully learned the materials related to the topic. Simply discussing a topic in class does not imply that the topic was mastered by the student or that an accompanying skill was acquired. For example, listing collaboration in a syllabus may suggest that the students learned about collaboration but not necessarily learned how to collaborate as asked for in the job announcement.

\begin{tabular}{|l|l|}
\hline Key word/topic & Analysis/Justification \\
\hline aggregate planning & $\begin{array}{l}\text { common to operations } \\
\text { management but has supply } \\
\text { chain implications }\end{array}$ \\
\hline balanced scorecard & operations management topic \\
\hline business process management & operations management topic \\
\hline collaboration & $\begin{array}{l}\text { necessary when doing global } \\
\text { supply chain operations }\end{array}$ \\
\hline $\begin{array}{l}\text { Council of Supply chain management } \\
\text { Professionals }\end{array}$ & $\begin{array}{l}\text { supply chain professional } \\
\text { organization - usually taught } \\
\text { as part of student professional } \\
\text { development and networking }\end{array}$ \\
\hline history of supply chain management & $\begin{array}{l}\text { necessary to understand how } \\
\text { SCM got to where it is today }\end{array}$ \\
\hline
\end{tabular}




\begin{tabular}{|c|c|}
\hline Institute of Supply Management & $\begin{array}{l}\text { supply chain professional } \\
\text { organization - usually taught } \\
\text { as part of student professional } \\
\text { development and networking }\end{array}$ \\
\hline process design & operations management topic \\
\hline queueing theory & operations management topic \\
\hline resource planning & operations management topic \\
\hline $\begin{array}{l}\text { Supply chain operations reference } \\
\text { (SCOR) Model }\end{array}$ & $\begin{array}{l}\text { gaining acceptance in } \\
\text { business as the depiction of a } \\
\text { supply chain and SCM best } \\
\text { practices }\end{array}$ \\
\hline supply chain management as a career & $\begin{array}{l}\text { to help students understand } \\
\text { potentials of choosing a SCM } \\
\text { degree and profession }\end{array}$ \\
\hline supply chain management future & $\begin{array}{l}\text { to help students understand } \\
\text { potentials of choosing a SCM } \\
\text { degree and profession }\end{array}$ \\
\hline supply chain management integration & $\begin{array}{l}\text { to help students understand } \\
\text { the link between different } \\
\text { supply chain management } \\
\text { functions }\end{array}$ \\
\hline supply chain management networks & $\begin{array}{l}\text { help students understand the } \\
\text { flow of information between } \\
\text { different aspects of the supply } \\
\text { chain }\end{array}$ \\
\hline $\begin{array}{l}\text { supply chain management } \\
\text { relationships }\end{array}$ & $\begin{array}{l}\text { necessary topic as all of } \\
\text { supply chain management is } \\
\text { based on relationships with } \\
\text { customers and suppliers }\end{array}$ \\
\hline Utilization & operations management topic \\
\hline value chain & operations management topic \\
\hline vendor managed inventory & part of inventory management \\
\hline
\end{tabular}

Figure 4-21 Top 25 Schools Syllabi Key Words Not in Job Announcements 
When comparing the syllabi key words to the job announcement key words, what does this tell us about what is in the introductory supply chain management curriculum in the leading schools? What does this mean when analyzing the curriculums of these courses in the leading schools? Eight of the topics being taught but not asked for by the job announcements fall in the category of operations management terms per the textbook analysis (aggregate planning, balanced scorecard, business process management, process design, queueing theory, resource planning, utilization, and value chain). This would indicate that some operations management understanding is critical to the introduction to supply chain management course curriculum.

Two of the nineteen topics the syllabi are supply chain professional organizations that offer valuable student experiences and resources (Council of Supply chain management Professionals (CSCMP) and Institute of Supply Management (ISM)). The remaining nine of the nineteen topics (collaboration, history of supply chain management, Supply Chain Operations Reference Model, supply chain management as a career, supply chain management future, supply chain management integration, supply chain management networks, supply chain management relationships, and Vendor Managed Inventory) in the Top 25 curriculums are topics that leading schools are using to better prepare their graduates. Included in this list of leading schools is Michigan State, which had over four-hundred graduates in 2017 with supply chain degrees and the average graduate had six job offers before graduation and the University of Tennessee with over nine-hundred students in their supply chain program. The leading schools appear to be placing a greater emphasis on a more rounded curriculum that helps establish a solid foundation in the necessary topics while adding topics to help better prepare the students for the real world as seen in topics such as the future of supply chain management, supply chain as a 
career and teaching the Supply Chain Operations Reference Model (SCOR model) which is being adopted by more companies as a tool to define and benchmark supply chain performance.

When analyzing the topics that are specifically asked for in the job announcements, it is critical to consider if some of these topics may be imbedded in other topics but not specified in the syllabi. These would include on time delivery, which could be and probably should be covered as a subset of performance management and metrics; shipping, receiving and order management, which may be covered under distribution or customer service management; $\mathrm{ABC}$ Analysis and Bills of Material, which could be covered under inventory management; and life cycle management, which may be a subset of product design or sustainability as shown in the thematic analysis above.

\section{Non-top 25 school syllabi compared to the job announcements.}

The next phase of the comparison and analysis looked at the schools in the sample set that were not part of the Top 25 rankings. The first comparison was the topics taught by the Top 25 Schools that were not taught in the other schools in the sample set.

The results of the comparison revealed that there were sixteen topics requested in the job announcements that were taught in the leading schools but were not addressed in the other syllabi. These topics include operations management topics (resource planning, business process management, and balanced scorecard) that help establish a foundation for understanding supply chain management. Figure 4-23 shows the terms that are reflected in the syllabi of the Top 25 Schools but not in the syllabi of the non-Top 25.

\begin{tabular}{|l|}
\hline process improvement \\
\hline resource planning \\
\hline business process \\
management \\
\hline
\end{tabular}




\begin{tabular}{|l|} 
inventory turns \\
\hline SCM Future \\
\hline SCM relationships \\
\hline Utilization \\
\hline "post sale" processes \\
\hline 3PL \\
\hline balanced scorecard \\
\hline collaboration \\
\hline controlling \\
\hline $\begin{array}{l}\text { Distribution Requirements } \\
\text { Planning }\end{array}$ \\
\hline raw materials \\
\hline $\begin{array}{l}\text { Vendor Management } \\
\text { Inventory }\end{array}$ \\
\hline Cycle time \\
\hline
\end{tabular}

\section{Figure 4-23: Topics Taught in Top 25 Missing From Non-Top 25 Syllabi}

The comparison and analysis of the non-Top 25 Schools set of syllabi revealed sixteen topics or key words that while not requested in the job announcements could be taught as subsets of other topics (these topics may fall under the idea of implied tasks - those tasks that have to be understood and mastered in order to master the specified concepts) that are requested in the job announcements. One of the limitations of this study is that some of the syllabi were not detailed enough to determine if these particular topics are included in the curriculums or not. However, these topics could possibly be linked to other concepts. While this may show that the topics are not necessary when compared to the job announcements, it could also show a greater detail of what is being taught in the corresponding courses. The listing of these topics and the potential related areas are shown Figure 4-24.

\begin{tabular}{|l|l|}
\hline $\begin{array}{l}\text { Topics that could be } \\
\text { considered a subset of } \\
\text { other topics in SCM }\end{array}$ & \\
\hline Sustainability & $\begin{array}{l}\text { could be a subset of } \\
\text { environment }\end{array}$ \\
\hline lead time & $\begin{array}{l}\text { could be subset of customer } \\
\text { service and distribution }\end{array}$ \\
\hline
\end{tabular}




\begin{tabular}{|c|c|}
\hline Bullwhip effect & $\begin{array}{l}\text { could be subset of } \\
\text { information flow or } \\
\text { inventory management }\end{array}$ \\
\hline supply management & $\begin{array}{l}\text { could be subset of } \\
\text { inventory or procurement }\end{array}$ \\
\hline process design & $\begin{array}{l}\text { could be subset of process } \\
\text { improvements }\end{array}$ \\
\hline Pricing & $\begin{array}{l}\text { could be subset of } \\
\text { procurement }\end{array}$ \\
\hline $\begin{array}{l}\text { Digital Track and Trace } \\
\text { (RFID) }\end{array}$ & $\begin{array}{l}\text { could be subset of track and } \\
\text { trace }\end{array}$ \\
\hline order processing & $\begin{array}{l}\text { Could be a subset of } \\
\text { customer service }\end{array}$ \\
\hline responsiveness & part of customer service \\
\hline outsourcing & part of procurement \\
\hline contracting & part of procurement \\
\hline packaging & part of shipping \\
\hline e-commerce & $\begin{array}{l}\text { subset of customer service, } \\
\text { delivery, inventory, } \\
\text { distribution }\end{array}$ \\
\hline Six Sigma & $\begin{array}{l}\text { subset of quality or process } \\
\text { improvement }\end{array}$ \\
\hline intermodal & subset of transportation \\
\hline SCM transformation & $\begin{array}{l}\text { synonymous with SCM } \\
\text { trends }\end{array}$ \\
\hline
\end{tabular}

\section{Figure 4-24: Topics That Could Be Subsets of Other Specified Topics}

There was a match between twenty-two of the one hundred and twenty-one key terms in non-Top 25 syllabi to the fifty-three key terms/topics in the job announcements. This shows a $41.5 \%$ match between the syllabi topics and the job announcement topics compared to the $88.7 \%$ match in the Top 25 Schools' syllabi. Another way of looking at this is that only $18.2 \%$ of the topics listed in the non-Top 25 Schools' syllabi are in the key word listing for the job announcements. This could indicate that these schools are not adequately preparing their students for what industry needs in supply chain management graduates. Figure 4-25 shows the topics asked for in the job announcements and reflected in the syllabi of the non-Top 25 Schools. 


\begin{tabular}{|c|c|}
\hline asked and taught & \\
\hline inventory management & distribution \\
\hline procurement/sourcing & $\begin{array}{l}\text { Project } \\
\text { Management }\end{array}$ \\
\hline supply chain management & MRP/ERP \\
\hline operations & risk \\
\hline logistics & Location analysis \\
\hline forecasting & JIT \\
\hline strategy & APICS \\
\hline quality/TQM & warehousing \\
\hline transportation & demand \\
\hline $\begin{array}{l}\text { metrics/performance } \\
\text { management }\end{array}$ & S\&OP \\
\hline information flow/systems & \\
\hline lean & \\
\hline
\end{tabular}

Figure 4-25: Match between Syllabi and Job Announcements for Schools not in the Gartner Top 25 Schools

There are three topics taught in the introductory supply chain management classes of the non-Top 25 Schools that are advanced topics that would be a better fit in upper level courses within a supply chain management curriculum. These "advanced" topics are contained in the syllabi of the higher level undergraduate courses and graduate level supply chain management courses per the syllabi that were eliminated from the sample set during the initial syllabi selection process. While not a long list of topics, this is further evidence that what is needed in an introductory course is not being presented to the students. Although these are important concepts for a greater understanding of supply chain management, if the necessary topics are included in the curriculum there is not sufficient time to address these advanced topics. These topics are reflected in Figure 4-26. 


\begin{tabular}{|l|l|}
\hline Advanced Topics & \\
\hline $\begin{array}{l}\text { International Commerce } \\
\text { (INCO) terms }\end{array}$ & $\begin{array}{l}\text { advanced global } \\
\text { concept }\end{array}$ \\
\hline $\begin{array}{l}\text { Transportation Management } \\
\text { System }\end{array}$ & $\begin{array}{l}\text { advanced } \\
\text { transportation topic }\end{array}$ \\
\hline & $\begin{array}{l}\text { advanced } \\
\text { warehousing topic }\end{array}$ \\
\hline
\end{tabular}

Figure 4-26: Advanced Topics in Introductory Courses

\section{Is there a correlation between the two sets of data?}

When comparing the top thirty topics in the job announcements and syllabi, as shown in Figure 4-27a, it is possible to determine a correlation between the two sets of data. There are several topics as shown in Figure 4-27b that are in the top thirty topics in the syllabi but not in the top thirty topics in the job announcements or are in the top thirty topics in the job announcements but not in the top thirty topics in the syllabi. The topics are shown in frequency order in these figures but rather in alphabetical order to calculate the correlation coefficient between the syllabi topics and the job announcement topics.

Syllabi Job announcements

\begin{tabular}{|l|r|r|l|}
\hline Capacity & 24 & 11 & Capacity \\
\hline distribution & 36 & 11 & distribution \\
\hline forecasting & 32 & 14 & forecasting \\
\hline global SCM & 28 & 11 & global SCM \\
\hline information flow/systems & 26 & 6 & information flow/systems \\
\hline inventory management & 35 & 18 & inventory management \\
\hline JIT & 19 & 6 & JIT \\
\hline lean & 19 & 12 & lean \\
\hline Location analysis & 19 & 6 & Location analysis \\
\hline logistics & 31 & 13 & logistics \\
\hline
\end{tabular}




\begin{tabular}{|l|r|r|l|}
$\begin{array}{l}\text { metrics/performance } \\
\text { management }\end{array}$ & 26 & 8 & $\begin{array}{l}\text { metrics/performance } \\
\text { management }\end{array}$ \\
\hline MRP/ERP & 21 & 7 & MRP/ERP \\
\hline operations & 22 & 14 & operations \\
\hline planning & 20 & 8 & planning \\
\hline process design & 56 & 13 & process design \\
\hline procurement/sourcing & 36 & 12 & procurement/sourcing \\
\hline product design/production & 40 & 9 & $\begin{array}{l}\text { product } \\
\text { design/production }\end{array}$ \\
\hline Project Management & 19 & 8 & Project Management \\
\hline quality/TQM & 34 & 12 & quality/TQM \\
\hline S\&OP & 16 & 7 & S\&OP \\
\hline SCM Concepts & 20 & 5 & SCM Basics \\
\hline strategy & 42 & 15 & strategy \\
\hline supply management & 16 & 7 & supply management \\
\hline sustainability & 24 & 6 & sustainability \\
\hline transportation & 32 & 6 & transportation \\
\hline
\end{tabular}

Figure 4-27a: Matching Topics from Top 30 Syllabi and Job Announcements Terms

\begin{tabular}{|l|r|r|l|}
\hline $\begin{array}{l}\text { Syllabi terms with no } \\
\text { correlation to job } \\
\text { announcements }\end{array}$ & Frequency & Frequency & $\begin{array}{l}\text { Job } \\
\text { announcement } \\
\text { terms with no } \\
\text { correlation to } \\
\text { syllabi }\end{array}$ \\
\hline warehousing & 15 & 5 & Six Sigma \\
\hline $\begin{array}{l}\text { customer service } \\
\text { management }\end{array}$ & 16 & 7 & manufacturing \\
\hline demand & 18 & 7 & $\begin{array}{l}\text { process } \\
\text { improvement }\end{array}$ \\
\hline risk & 18 & 6 & productivity \\
\hline & 5 & services \\
\hline
\end{tabular}

Figure 4-27b: Non-matching Topics from Top 30 Syllabi and Job Announcements Terms 
While there is no assumed causation between what is represented in the syllabi and the key topics in the job announcements, there is a correlation coefficient of 0.566 between the some of the top thirty topics in the job announcements and the top thirty topics in the syllabi as shown in Table 4-1 below. A correlation coefficient of only 0.566 does not indicate a strong relationship between the syllabi terms and the job announcement terms; this would seem to point to a gap between what is being asked for in the job announcements and what is being taught according to the syllabi.

\begin{tabular}{lrr}
\hline & syllabi & job announcements \\
\hline syllabi & 1 & \\
job announcements & 0.56607 & 1
\end{tabular}

\section{Table 4-1: Correlation between Job Announcement Key Words and Syllabi Key Words for Top 25 Topics}

Another way of looking at the data to determine the relationship between the most common job announcement key words and the syllabi key words was to compare the percentage of the number of syllabi containing the key words and the percentage of job announcements asking for the key words. The comparison of the percentages of appearance in the job announcements and syllabi revealed that some of the topics are being taught in much greater percentages than the terms are appearing in the job announcements as job requirements. The comparison of the terms frequency of appearance is shown in Figure 4-28. 


\begin{tabular}{|l|l|l|l|}
\hline $\begin{array}{l}\text { Top Categories by percentage of } \\
\text { appearance }\end{array}$ & $\begin{array}{l}\text { percentage of } \\
\text { syllabi }\end{array}$ & Jobs & $\begin{array}{l}\text { percentage of } \\
\text { appearance }\end{array}$ \\
\hline Jobs & $44.87 \%$ & $\begin{array}{l}\text { inventory } \\
\text { management }\end{array}$ & $12.86 \%$ \\
\hline $\begin{array}{l}\text { inventory } \\
\text { management }\end{array}$ & $53.85 \%$ & strategy & $10.71 \%$ \\
\hline strategy & $41.03 \%$ & forecasting & $10.00 \%$ \\
\hline forecasting & $35.90 \%$ & global supply chain & $7.86 \%$ \\
\hline global supply chain & $46.15 \%$ & procurement & $8.57 \%$ \\
\hline procurement & $51.28 \%$ & product design & $5.00 \%$ \\
\hline product design & $46.15 \%$ & distribution & $7.86 \%$ \\
\hline distribution & Tern & Percentage of Apparance Syllabiand Job
\end{tabular}

Figure 4-28: Comparison of Key Terms by Percentage of Appearance in Syllabi and Job Announcements

The comparison of the key terms in respect to their appearance in the job announcements and syllabi would seem to confirm the correlation analysis that there is not a strong relationship between what is being asked for and what is being taught in the introductory supply chain management courses in the sample set.

\section{What does all of this mean?}

The analysis of the data is critical to making conclusions and recommendations for a structured framework for teaching supply chain management to ensure that our students are best prepared for entering the supply chain management workforce. The conclusions and a recommended framework are contained in Chapter 5. 


\section{Chapter 5: Conclusions and Recommendations}

The literature review established that a talent gap exists in the supply chain management industry. It also raised questions about what topics are taught in the introductory supply chain management courses and how these topics align with what industry desires in its job candidates. The new Chancellor of the University of Kansas, Dr. Douglas Girod, stated in his inauguration speech that faculty needs to consider what they are doing for the good of the students and what faculty should consider to improve the student experience and learning. One of the ways that faculty can improve the student learning experience is through the development of the curriculum to expose the students to a combination of theory and real world practices.

The methodology described in Chapter 3 produced the analysis discussed in Chapter 4. This analysis identified some similarities and some gaps between what is reflected in the written curriculum as shown in the seventy-eight syllabi and what industry is asking for in the recruitment process as reflected in the one hundred and forty job announcements. This chapter uses those similarities and gaps to recommend a framework for what supply chain management topics to include in a supply chain management introductory course. This chapter also makes recommendations for future research into the development of the supply chain management curriculum across all course levels.

Anderson, Britt and Farve (1997) listed one of the principles of supply chain management as "Listen to market signals and align demand planning accordingly." If the market for supply chain graduates is agreed to be the companies that are hiring the graduates to fill the talent gap, then universities need to listen to what their customers want and align the curriculum to the 
needs of the market. This may mean frequent curriculum reviews or adjustments to course offerings. Anderson, Britt and Farve also stated the need to "adapt the supply chain to serve" the market and the customers. This supports the need to keep supply chain programs current and relevant and adapting new technologies and new concepts rapidly into the curriculum in order to better prepare the students for positions of responsibility in the commercial world. When taken in conjunction with the data from Chapter 4, this would point to the need to have a frequent curriculum review to ensure that the customers, the students and the employers, are being best served by the academic community.

\section{Comparison of Chapter 4 Analysis to Johnson and Pyke and Follow-on Frameworks}

\begin{tabular}{|c|c|}
\hline Johnson and Pyke & Bandyopadhyay \\
\hline$(2000)$ & $(2004)$ \\
\hline Location & Location \\
\hline $\begin{array}{l}\text { Transportation and } \\
\text { Logistics }\end{array}$ & $\begin{array}{l}\text { Transportation and } \\
\text { Logistics }\end{array}$ \\
\hline $\begin{array}{l}\text { Forecasting/Inventory } \\
\text { Planning }\end{array}$ & $\begin{array}{l}\text { Forecasting/Inventory } \\
\text { Planning }\end{array}$ \\
\hline marketing & marketing \\
\hline $\begin{array}{l}\text { sourcing/supplier } \\
\text { management }\end{array}$ & $\begin{array}{l}\text { sourcing/supplier } \\
\text { management }\end{array}$ \\
\hline information & information \\
\hline product design & product design \\
\hline $\begin{array}{l}\text { service and after sales } \\
\text { support }\end{array}$ & $\begin{array}{l}\text { service and after sales } \\
\text { support }\end{array}$ \\
\hline reverse logistics/green & reverse logistics/green \\
\hline outsourcing & outsourcing \\
\hline metrics/incentives & metrics/incentives \\
\hline \multirow[t]{3}{*}{ global issues } & global issues \\
\hline & just-in-time \\
\hline & total quality \\
\hline
\end{tabular}

Figure 5-1: Johnson and Pyke/Bandyopadhyay 
The original framework of Johnson and Pyke and the updated framework from Bandyopadhyay are shown in Figure 5-1.Is this framework still current or does it need to be updated? As was pointed out in Chapters 2 and 4, supply chain management as a discipline and as a career has changed dramatically since the works published by Johnson and Pyke (2000) and Bandyopadhyay (2004) The changes of the past eighteen years have not made the original framework or its subsequent revisions obsolete, but the changes in supply chain management have mandated a revision or update to the framework.

\section{Exclusions from original frameworks}

If the original framework and its subsequent revisions need to be updated, what should be excluded and what should be added and why? The first criterion for excluding a topic in the original and subsequent updates of the framework is if a topic or topic set is a separate discipline then it should not be considered as part of the supply chain framework. For example, when looking at Johnson and Pyke it is apparent that the topics associated with marketing, while important to supply chain management, are part of a separate discipline and separate course work from supply chain management. Marketing is defined as, "the design, pricing, promotion and distribution of goods to create transactions with businesses and consumer" (Blackstone, 2013, p. 100); while the supply chain is defined as "the design, planning, execution, control, and monitoring of supply chain activities with the objective of creating net value, leveraging worldwide logistics, synchronizing supply with demand, and measuring performance globally" (Blackstone, 2013, p. 171). The link between marketing and supply chain from these definitions is the distribution of the products. While students need to understand this linkage and relationship of marketing to supply chain, a detailed discussion of marketing needs to be in a separate course. 
Another rationale for exclusion from the original framework and the 2004 update as separate topics or modules are the topics generally associated with operations management as demonstrated in in Chapter 4.

A final rationale for exclusion from the previous frameworks in my proposed framework was if a topic was a subset of another listed topic based on the syllabi and textbook analyses. Outsourcing is a subset of sourcing and supplier management and therefore should not be a separate category within supply chain management.

\section{Other Modifications from Previous Frameworks}

While information is critical in supply chains the category should be updated to include not just information but the flow of information and the varied supply chain information systems such as Distribution Requirements Planning programs, Transportation Management Systems and Supply Chain Optimization programs. Some of these programs and systems did not exist or were in their infantile stages at the time of Johnson and Pyke or during the time of research by Bandyopadhyay.

Transportation and Logistics were traditionally discussed together in legacy operations management programs but have risen in importance in $21^{\text {st }}$ Century supply chains. Transportation has morphed over the past eighteen years since the initial framework study by Johnson and Pyke as discussed in chapter 4. Transportation has become the focus of getting the product to the customer as quickly as possible which has led to the use of Uber drivers to deliver Amazon packages to homes and the research into the use of drones and unmanned vehicles to help reduce the shortage of truck drivers while improving customer support and reducing customer wait times. Logistics is that supply chain function that is also known as distribution. The logistics function of the supply chain has morphed to include warehousing, distribution and 
the processes to move products from one point in the supply chain to another. Because of these changes to transportation and logistics, these two supply chain management functions should be covered as separate but related topics and not as a joint topic. Similarly, there is more to inventory planning than just forecasting. Traditionally, inventory planning has focused on what to order, when to order, and how much to order. In the Amazon economy of 2018, inventory management also must consider where to stock items to best meet the needs of the customer while minimizing the lead time from customer order to delivery of the product. As such, forecasting, a traditional operations management topic, should be separated from inventory planning to enable a more thorough discussion of inventory and its importance in the supply chain.

Sourcing and supplier management also includes the Johnson and Pyke topic of outsourcing and could very well include the support necessary to the company after the sale or procurement of goods or services. Product design while still important to the supply chain curriculum since it impacts inventory and reverse logistics, is really an operations management topic and should be part of the operations management framework rather than part of the supply chain framework.

Reverse logistics is critical and gaining more importance as the problem continues to grow. LL Bean recently changed their $100 \%$ guarantee to limit returns to one year. The company has lost over $\$ 250$ million over the past five years as a result of fraud in the reverse logistics operations (Sharp, 2018). Walmart announced in February 2018 that they were starting a program to offer lower prices online to customers that waived the right to return products. There is more to reverse logistics than just the "green" movement. These two issues point to the increased focus by industry to the importance of reverse logistics. While Johnson and Pyke were 
obviously ahead of their time with the inclusion of reverse logistics in their framework, the needs of industry for a better understanding of sustainability as a topic can be seen in the frequency of appearance in the job announcement for both reverse logistics and sustainability as separate topics.

The other issue with the categories of topics in today's supply chains is the two new topics of just in time and total quality added by Bandyopadhyay in 2004. These two areas are related issues as just in time seeks to improve quality by reducing variability much like six sigma and the Theory of Constraints. All of these continuous process improvement programs could be rolled into one category of quality, which is more of an operations management topic than a supply chain management topic and therefore not necessarily needed as separate categories in a supply chain management curriculum framework.

\section{Johnson and Pyke Conclusions and Recommended Changes}

The analysis and conclusions from looking at the Johnson and Pyke framework is that the framework was a great start for teaching supply chain management in the early days of supply chain management as a discipline. However, it is not current when compared to the demands of industry in 2018. This leads back to the need for a new framework for developing supply chain management curriculum and how academia can best meet the needs of its customer base

\section{New Supply Chain Framework for Introductory Supply Chain Management Undergraduate Courses}

The goal is not to develop a prescriptive framework but rather a descriptive framework that can serve as the foundation for a designing or revising the introductory supply chain management class. This new or updated framework will help introduce the topics that industry believes are important while setting the conditions for revising more advance courses in supply 
chain management for those students that want more detailed knowledge of supply chain. This framework is a blend of some operations management topics related to supply chain management, traditional supply chain topics with professional development and the introduction of newer or emerging topics in supply chain management to help prepare students to better fill the growing talent gap in supply chain management. The new framework will contain the items shown in Figure 5-2. The topics under the heading of emerging concepts under the supply chain management basics and terminology are driven by the leading schools' syllabi, newer demands from the job announcements and the discussions of emerging concepts in recent supply chain management industry publications over the past five months (Inbound Logistics Staff, 2017; Chapman, 2017; Trent, 2018; Frantz, 2018; Melnyk, Voorhees, \& Little, 2018; Monahan \& Gott, 2018; Monahan \& Zimmerman, 2017). While realizing that everything that a student needs to know can't be covered in a one semester introduction to supply chain management, the following topics should be covered in the modules of a supply chain management course. The built in assumption here is that the introduction to supply chain management course will be where students start to learn these topics and that the topics will be covered in greater detail in later, more advanced courses. 


\begin{tabular}{|c|}
\hline $\begin{array}{l}\text { Supply chain management Basics and } \\
\text { Terminology }\end{array}$ \\
\hline Inventory management \\
\hline Procurement/sourcing/contracting \\
\hline $\begin{array}{l}\text { Operations as they relate to Supply chain } \\
\text { management }\end{array}$ \\
\hline Quality \\
\hline Metrics \\
\hline Supply Chain Information Systems \\
\hline Customer service management \\
\hline $\begin{array}{l}\text { Manufacturing as it relates to Supply chain } \\
\text { management }\end{array}$ \\
\hline Emerging Supply Chain Topics \\
\hline $\begin{array}{l}\text { Professional Organizations/Professional } \\
\text { Development }\end{array}$ \\
\hline
\end{tabular}

Figure 5-2: Recommended New Framework

The thematic analysis of the topics required by industry and the topics contained in the syllabi can be arranged into these basic modules as compared to the original ten modules of Johnson and Pyke and the twelve modules or thematic groupings put forth by Bandyopadhyay. As discussed, some of the original modules fall under the categories of operations management the new modules are:

- Inventory management (the most requested topic from the job announcements).

- Procurement/Sourcing/Contracting (the second most requested skill set in the job announcements).

- Supply Chain Management foundational topics and terminology.

- Operations (to provide the link and understanding between supply chain management and operations management). 
- Quality (while primarily an operations topic, quality is also important from a perfect order fulfillment, customer support and reverse logistics perspective).

- Metrics/Analytics/Performance Management (the APICS definition of supply chain management includes the measuring of performance (Blackstone, 2013, p. 172).

- Supply Chain Information Systems (includes supply chain networks, ERP, SAP, Oracle, WMS, TMS, DRP; Customer Service Management (links the supply chain to the needs and support of the customer)).

- Professional Organizations/Professional Development (this could include networking, internships, guest lecturers and discussions of supply chain management trends and the link between current events and supply chain management).

- Manufacturing and the link to supply chain management.

- Emerging supply chain topics (with the rapid rate of change identified in supply chain management, not all new concepts can be addressed in detail, however, the students should at least hear about these topics in the classroom.

The topics in Figures 5-3 through 5-12 reflect the combination of terms from the syllabi analysis, job announcement analysis and recommendations from industry groups on what should be included in the introductory supply chain management framework. The topics in each category is by no means comprehensive as this would take away any latitude of the instructors and would change the framework from descriptive to prescriptive. The goal of the framework is to provide a foundation for the development of the introductory supply chain management course. 


\section{Supply chain management topics for a new framework.}

The supply chain management topics that should be included in the introductory supply chain course are shown here. The level of detail of the coverage of these topics is dependent on the level of expertise of the faculty members teaching the course but should at least be addressed in the introductory course. The topics that should be considered as part of the supply chain management foundations and terminology are shown in Figure 5-3.

\begin{tabular}{|c|c|}
\hline $\begin{array}{l}\text { CATEGORY: Supply } \\
\text { Chain Management Basics } \\
\text { and Terminology }\end{array}$ & \\
\hline best practices & $\begin{array}{l}\text { Supply chain } \\
\text { management } \\
\text { Basics }\end{array}$ \\
\hline $\begin{array}{l}\text { Supply chain management } \\
\text { relationships }\end{array}$ & $\begin{array}{l}\text { Supply chain } \\
\text { management } \\
\text { Concepts }\end{array}$ \\
\hline $\begin{array}{l}\text { Supply chain management } \\
\text { as a career }\end{array}$ & $\begin{array}{l}\text { Supply chain } \\
\text { management } \\
\text { design }\end{array}$ \\
\hline Project Management & $\begin{array}{l}\text { Supply chain } \\
\text { management } \\
\text { Future }\end{array}$ \\
\hline $\begin{array}{l}\text { Supply chain management } \\
\text { trends }\end{array}$ & $\begin{array}{l}\text { Supply chain } \\
\text { management } \\
\text { integration }\end{array}$ \\
\hline distribution & $\begin{array}{l}\text { Supply chain } \\
\text { management } \\
\text { Operations }\end{array}$ \\
\hline fulfillment & $\begin{array}{l}\text { Supply chain } \\
\text { management } \\
\text { terminology }\end{array}$ \\
\hline $\begin{array}{l}\text { global Supply chain } \\
\text { management }\end{array}$ & SCOR model \\
\hline $\begin{array}{l}\text { history of Supply chain } \\
\text { management }\end{array}$ & transportation \\
\hline
\end{tabular}




\begin{tabular}{|l|l|} 
Just in Time Logistics & planning \\
\hline logistics & $\begin{array}{l}\text { Supply Chain } \\
\text { Security }\end{array}$ \\
\hline sustainability/environment & track and trace \\
\hline
\end{tabular}

Figure 5-3: Supply Chain Management Topics

\section{Inventory management topics for a new framework.}

Inventory management is the most requested topic in the job announcements and the most commonly taught item in the syllabi. Inventory management contains enough complexity that it could be an advanced topic course of its own. However, an introductory supply chain course should at least cover the topics of inventory management shown in Figure 5-4 to expose the students to the concepts necessary for professional success.

\begin{tabular}{|l|}
\hline $\begin{array}{l}\text { CATEGORY: Inventory } \\
\text { Management }\end{array}$ \\
\hline $\begin{array}{l}\text { Inventory } \\
\text { techniques/planning/control }\end{array}$ \\
\hline inventory turns \\
\hline forecasting \\
\hline $\begin{array}{l}\text { Economic Order Quantity } \\
\text { (EOQ) }\end{array}$ \\
\hline ABC Analysis \\
\hline
\end{tabular}

\section{Figure 5-4: Inventory Management Topics}

\section{Procurement topics for a new framework.}

The number two ranked topic in both the job announcements and syllabi was procurement. Like inventory management, procurement could and probably should be a standalone course. However, even if procurement or supplier relationships are taught as a stand-alone course, the introductory supply chain course should at least discuss the topics shown in Figure 5- 
5. Some topics such as risk analysis actually cut across several topic areas since there are multiple reasons for conducting a risk analysis from product development as part of procurement to risk analysis for the outcome of operations. Knowing what a risk analysis is and the actual conduct of a risk analysis are not the same. Therefore, an ideal supply chain curriculum would include classroom instruction on what a risk analysis is, why it is important and how to conduct a risk analysis using the commonly accepted steps of identifying the risk, determining the probability of the risk, determining the magnitude of the impacts if the risk occurs and then putting steps in place to minimize, mitigate or eliminate the risk in a product or process. The curriculum should also include activities that allow the students to conduct a risk analysis using a case study or simulated activity or product. This will help combine classroom instruction with hands on experience with real world applications.

\begin{tabular}{|l|}
\hline $\begin{array}{l}\text { CATEGORY: } \\
\text { Procurement/Sourcing }\end{array}$ \\
\hline purchasing/contracting \\
\hline Delivery \\
\hline Product risk analysis \\
\hline lead time \\
\hline Outsourcing \\
\hline Suppliers and supplier relationships \\
\hline
\end{tabular}

Figure 5-5: Procurement Topics

\section{Operations management topics that should be part of a new framework.}

Teaching supply chain management should include a foundation of operations management topics especially in light of the recent change by the AACSB that eliminated the requirement for business students to have an operations management course as part of the general business requirements. With the elimination of the requirement for an operations course, 
students in any aspect of business, especially in supply chain management still need exposure to and understanding of some operations management topics. This means that the topics shown in Figure 5-6 should be included in an introductory supply chain management course to help establish a solid foundation and background in the aspects of operations that impact supply chain management.

\begin{tabular}{|c|c|c|c|}
\hline $\begin{array}{l}\text { CATEGORY: Operations } \\
\text { Topics as they relate to } \\
\text { supply chain management }\end{array}$ & $\begin{array}{l}\text { Relationship to } \\
\text { Supply chain } \\
\text { management }\end{array}$ & $\begin{array}{l}\text { CATEGORY: } \\
\text { Operations Topics } \\
\text { as they relate to } \\
\text { supply chain } \\
\text { management }\end{array}$ & $\begin{array}{l}\text { Relationship to } \\
\text { Supply chain } \\
\text { management }\end{array}$ \\
\hline bills of materials & $\begin{array}{l}\text { Critical to } \\
\text { manufacturing } \\
\text { planning and } \\
\text { inventory } \\
\text { management }\end{array}$ & processes & $\begin{array}{l}\text { This term could } \\
\text { be related to } \\
\text { planning and } \\
\text { execution of } \\
\text { supply chain } \\
\text { operations }\end{array}$ \\
\hline capacity & $\begin{array}{l}\text { Facility and } \\
\text { transportation } \\
\text { impacts }\end{array}$ & quality & $\begin{array}{l}\text { Related to product } \\
\text { development and } \\
\text { reverse logistics } \\
\text { operations }\end{array}$ \\
\hline Environment/sustainability & $\begin{array}{l}\text { Related to product } \\
\text { development and } \\
\text { reverse logistics } \\
\text { operations }\end{array}$ & risk analysis & $\begin{array}{l}\text { All aspects of } \\
\text { supply chain } \\
\text { management need } \\
\text { a risk analysis for } \\
\text { completion risks, } \\
\text { product risks and } \\
\text { supply chain } \\
\text { security }\end{array}$ \\
\hline $\begin{array}{l}\text { Lean/JIT/Kaizen/TOC/Six } \\
\text { Sigma/process improvement }\end{array}$ & $\begin{array}{l}\text { Not only related } \\
\text { to quality but to } \\
\text { process } \\
\text { improvement }\end{array}$ & $\begin{array}{l}\text { life cycle } \\
\text { management }\end{array}$ & $\begin{array}{l}\text { Related to the } \\
\text { development of } \\
\text { products and to } \\
\text { reverse logistics }\end{array}$ \\
\hline planning & $\begin{array}{l}\text { Related to } \\
\text { transportation } \\
\text { operations and } \\
\text { facility layout }\end{array}$ & & \\
\hline
\end{tabular}

Figure 5-6: Operations Topics 
Supply chain management and operations management are not the same discipline but in order to establish a foundation in Supply chain management, an understanding of operations management is necessary. Although, not to the degree that the non-Top 25 Schools are teaching operations management at the expense of supply chain management, but some operations management topics are needed. The Bill of Materials is a fancy operations management term for the list of ingredients in a product as such that it ties to the concept of inventory management. Capacity management is necessary for understanding transportation constraints, distribution constraints and warehousing constraints.

The environment is tied to production planning and product design as well as reverse logistics and life cycle management. Lean/Just-in-Time/Kaizen/Theory of Constraints/Six Sigma are all process improvement programs and while considered operations management topics by the textbook authors, they all have applications to solving problems and improving operations in the supply chain. Risk analysis is critical for all supply chain operations and not just operations management.

\section{Metrics and performance management topics for a new framework.}

Metrics and performance management should be added to the supply chain management framework to ensure that students have an exposure to the concepts of metrics calculations and the use of metrics to help solve problems and identify what needs to be improved in order to improve customer service while eliminating non-value adding activities. Like risk analysis, the inclusion of metrics in the supply chain framework should include not only classroom instruction but the actual computation of metrics using supply chain cases or real world data. The topics of metrics and performance management are shown in Figure 5-7. 


\begin{tabular}{|l|}
\hline $\begin{array}{l}\text { CATEGORY: } \\
\text { Metrics }\end{array}$ \\
\hline $\begin{array}{l}\text { problem } \\
\text { solving/resolution }\end{array}$ \\
\hline data analysis \\
\hline $\begin{array}{l}\text { performance } \\
\text { management/metrics }\end{array}$ \\
\hline $\begin{array}{l}\text { Perfect order } \\
\text { fulfillment }\end{array}$ \\
\hline on time delivery \\
\hline customer support \\
\hline
\end{tabular}

\section{Figure 5-7: Metrics and Performance Management Topics}

One of the fastest growing areas of business is business analytics. The need to understand not only how the supply chain metrics are calculated but what they actually mean is critical to success in the supply chain world. Like inventory management and operations, business analytics and metrics could and probably should be a course of its own, but supply chain students need to have a basic understanding of the most important supply chain metrics.

\section{Information systems topics for a new framework.}

Some of the data necessary to understanding metrics come from the information systems used to manage supply chains. Like other topics in the framework, supply chain information systems could very well be a semester long course in and of itself. However, since the goal of the introductory course in supply chain management is to build the foundation for the future courses of study in business or supply chain management, students in the introductory course should be exposed to the different information systems used in managing supply chains. These topics are reflected in Figure 5-8. 


\begin{tabular}{|c|}
\hline $\begin{array}{l}\text { CATEGORY: Information } \\
\text { Systems }\end{array}$ \\
\hline $\begin{array}{l}\text { Material Requirements } \\
\text { Planning }\end{array}$ \\
\hline $\begin{array}{l}\text { Supply chain information } \\
\text { systems }\end{array}$ \\
\hline $\begin{array}{l}\text { Enterprise Resource Planning } \\
\text { Programs/SAP/Oracle }\end{array}$ \\
\hline $\begin{array}{l}\text { Supply chain management } \\
\text { Systems (Warehouse } \\
\text { Management } \\
\text { System/Transportation } \\
\text { Management System/Order } \\
\text { Management } \\
\text { System/Distribution } \\
\text { Management System) }\end{array}$ \\
\hline $\begin{array}{l}\text { RFID (Radio Frequency } \\
\text { Identification Tags) }\end{array}$ \\
\hline
\end{tabular}

\section{Figure 5-8: Information Systems Topics}

Like many other supply chain management topics, this could and probably should be a full blown semester course or even a separate major. However, every supply chain student needs to have a working knowledge of supply chain information systems. While most of the syllabi touch on SAP (the largest provider of Enterprise Resource Planning programs), students that want to succeed in supply chain management need to understand all of the other systems that are used in managing the supply chain activities.

\section{Customer service topics for a new framework.}

Everything in a supply chain should be customer focused. Therefore, a good supply chain management curriculum has to be customer focused as well. The topics in this module include the aspects of supply chain management that are related to customer service. Inventory turns also relates to metrics and performance management as this metric measures how well the company is 
doing in having the right items in the right quantity to meet the needs of the customers. On time delivery measures how well the company is doing in delivering the products to the customer at the time the customer states that they need the products. Figure 5-9 shows the topics that should be included in the discussions of customer service in the supply chain.

\begin{tabular}{|l|}
\hline $\begin{array}{l}\text { CATEGORY: Customer } \\
\text { service management }\end{array}$ \\
\hline customer service \\
\hline delivery \\
\hline demand \\
\hline shipping \\
\hline orders \\
\hline inventory turns \\
\hline on time delivery \\
\hline fulfillment \\
\hline
\end{tabular}

Figure 5-9: Customer Service Topics

\section{Manufacturing topics for a new framework.}

The Supply Chain Operations Reference (SCOR) Model is one of the foundations of the analysis in Gartner analysis. The SCOR Model contains six functions that are inherent in every supply chain: Plan, Source, Make, Deliver, Return, and Enable. The function of "Make" is simply what products will be made or bought, where they will be made and how they will be made, which is basically manufacturing. Inherent to manufacturing is continuous process improvement. Process improvement is linked to the topics of Six Sigma/Theory of Constraints/JIT/Lean discussed earlier. As pointed out earlier, scheduling is critical but under served in the syllabi in the database. The manufacturing topics that should be considered for inclusion in a supply chain management framework are shown in Figure 5-10. 


\begin{tabular}{|l|}
\hline $\begin{array}{l}\text { CATEGORY: } \\
\text { Manufacturing }\end{array}$ \\
\hline $\begin{array}{l}\text { process } \\
\text { improvement }\end{array}$ \\
\hline layout analysis \\
\hline cycle time \\
\hline environment \\
\hline quality \\
\hline $\begin{array}{l}\text { process } \\
\text { improvement }\end{array}$ \\
\hline scheduling \\
\hline materials \\
\hline
\end{tabular}

Figure 5-10: Manufacturing Topics

\section{Quality topics for a new framework.}

Although quality can be linked to manufacturing, it can also be linked to product design, reverse logistics and sustainment discussed in earlier modules. Risk analysis should be a component of every aspect of a supply chain curriculum. Previously we discussed lean and Six Sigma as continuous process improvement programs, but they are also considered quality topics and an understanding of these topics will help round out the supply chain curriculum and preparation of students for jobs in the supply chain industry as shown in Figure 5-11. 


\begin{tabular}{|c|}
\hline $\begin{array}{l}\text { CATEGORY: } \\
\text { Quality }\end{array}$ \\
\hline risk analysis \\
\hline Kaizen \\
\hline quality \\
\hline lean \\
\hline Six Sigma \\
\hline
\end{tabular}

\section{Figure 5-11: Quality Topics}

\section{Emerging concepts topics for a new framework.}

Emerging concepts is a moving target and may change from year to year or even from semester to semester. While this may be a moving target as new topics emerge, it is incumbent on the supply chain faculty to expose the students to these new concepts and how they interact and impact other aspects of businesses. For example, the inability to remain resilient after the hurricanes of 2017 resulted in a shortage of flu vaccines due to the impacts to manufacturing operations in Puerto Rico and this then led to a shortage of medical bags for fluids to help treat the patients of the resulting flu epidemic and other illnesses across the United States. The goal of this category is not to make the students emerging concepts experts but to simply bring the new concepts into the classroom to expose the students to the new and emerging concepts. This list is not comprehensive and with the rapid rate of change in technology and supply chain management may change continually, but at this point in time, the topics in Figure 5-12 are the hot topics that industry is implementing or considering. 


\begin{tabular}{|c|c|}
\hline $\begin{array}{l}\text { CATEGORY: } \\
\text { Emerging Supply } \\
\text { Chain Tonics }\end{array}$ & Rationale \\
\hline Visibility and Tracking & $\begin{array}{l}\text { A relatively new topic that it tied to } \\
\text { visibility and track and trace within the } \\
\text { supply chain to include the discussion of } \\
\text { RFID tags and tied to the implementation } \\
\text { of block chain technologies }\end{array}$ \\
\hline $\begin{array}{l}\text { Security and } \\
\text { Preparedness }\end{array}$ & $\begin{array}{l}\text { While not really an emerging concept, } \\
\text { protecting the flow of products in the } \\
\text { supply chain has become a very important } \\
\text { issue that is not covered in many textbooks. } \\
\text { Discussion of this topic includes not only } \\
\text { man-made events such as piracy or } \\
\text { terrorism but also natural events such as } \\
\text { hurricanes. The focus on resiliency in the } \\
\text { supply chain from natural disasters has } \\
\text { gained exposure as the result of major } \\
\text { storms such as Super Storm Sandy and the } \\
\text { impacts from Hurricanes Harvey, Irma and } \\
\text { Maria in } 2017 \text {. }\end{array}$ \\
\hline Reverse Logistics & $\begin{array}{l}\text { A growing multi-trillion dollar a year } \\
\text { aspect of supply chain management dealing } \\
\text { with returns for defective products, } \\
\text { seasonal items and unwanted products. This } \\
\text { could potentially be a semester long course } \\
\text { but all business students in a supply chain } \\
\text { class need to understand the impacts on } \\
\text { other business functions as a result of the } \\
\text { growth in reverse logistics. }\end{array}$ \\
\hline Block Chain & $\begin{array}{l}\text { A very new concept that is growing in } \\
\text { importance as a way to make the visibility } \\
\text { and transparency of the supply chain more } \\
\text { viable. Students need to at least be familiar } \\
\text { with this topic and how it impacts all } \\
\text { business functions. }\end{array}$ \\
\hline Omni-Channel & $\begin{array}{l}\text { The number of ways that a customer can } \\
\text { order from the supply chain and have } \\
\text { products delivered - includes tablets, } \\
\text { phones, computers, and in store purchases. } \\
\text { Students also need to understand the } \\
\text { different channels available to companies to } \\
\text { get the products to the customers. }\end{array}$ \\
\hline
\end{tabular}

Figure 5-12: Emerging Concepts 
The topics for the emerging concepts thematic group will not only expose the students to these critical and emerging concepts and topics before the ideas are captured in textbooks, but will also help benefit the students' professional development by seeing these concepts in the classroom before entering the workforce.

\section{Professional Development topics for a new framework.}

The final category or module of the new framework is professional development. While professional development should be the goal of any professional school program, with the changes in the requirements for supply chain management, this category of topics should be a part of the introductory supply chain management course. Included in this module is not only teaching students about what their options are as far as jobs and career progression. Included in this module is the discussion of supply chain professional organizations, the professional development opportunities and networking opportunities of the organizations. In addition, ISM and APICS provide free membership for students.

Supply chain management is based on relationships between customers and suppliers. Project management is a critical skill that while not necessarily a supply chain management unique topic, supply chain managers use project teams on a regular basis to solve problems. A job candidate with an understanding of project management will be better postured for success. Somewhere in an introductory course in supply chain management there has to be a discussion of professional development for supply chain managers. This discussion of professional development should include jobs, professional organizations, and discussions of what a supply chain manager needs to do to remain current in their profession as well as trends in supply chain management and the link between current events and supply chain implications to help get the 
students to start thinking critically about the ripple effect of current events on the supply chain. These topics are shown in Figure 5-13.

\begin{tabular}{|l|}
\hline $\begin{array}{l}\text { CATEGORY: } \\
\text { Professional } \\
\text { development }\end{array}$ \\
\hline best practices \\
\hline SCM relationships \\
\hline SC as a career \\
\hline Project Management \\
\hline SCM trends \\
\hline APICS \\
\hline CSCMP \\
\hline ISM \\
\hline
\end{tabular}

\section{Figure 5-13: Professional Development}

The combination of these modules into a well-rounded curriculum will help prepare students for a better understanding of supply chain management and can also serve as the foundation for developing a supply chain management program in those schools that do not currently have a program.

\section{Recommendations}

One of the limitations of this study is that it is only looking at the introductory supply chain management classes. A future study should focus on the entire supply chain management curriculum for those schools that offer a supply chain major, minor or concentration. This could be accomplished by adding the other syllabi back into the sample set to broaden the scope of the analysis and by conducting both a survey of course authors to determine the rationale for including or not including certain topics and face to face interviews with faculty members to 
develop greater insights into subject matter selection. A broader scoped project would enable the development of a recommended curriculum for the entire supply chain management education process and assist schools in curriculum reviews and curriculum development.

Future research is also needed in the area of student involvement in extracurricular activities such as supply chain management clubs, industry visits, guest speakers, and study abroad programs and the impacts of these activities on placement rates. Another area for future research is to look at what schools are doing (with a focus on the Top 25 Schools) to remain current with the changes in industry expectations and what industry is doing to pass the new requirements on to academia.

\section{Conclusions}

The syllabi and textbook analyses showed that students may still be getting a large percentage of operations management topics in their supply chain management classes based on the topics covered in the syllabi and the textbooks being used. While it is necessary to address some operations management concepts to help better understand where supply chain management fits in the holistic view of business, the gap in the non-Top 25 Schools is a bit excessive and could be a contributing factor to not having the students properly prepared to meet the needs of industry.

A related conclusion is that if we are going to teach supply chain management as a critical topic in the business curriculum, even if we are not offering a supply chain management major, we need to use a supply chain management textbook not an operations management textbook. Using an operations management text and a syllabus that is filled with operations management topics has its merits in an operations management course but if we are claiming to 
be teaching supply chain management, we need to coordinate and collaborate with industry to ensure we are teaching what industry needs.

The literature review showed that there is a talent gap in the supply chain world. This supply chain talent gap is a combination of increased job requirements coupled with potentially ill prepared graduates. The issue of better preparing students to help fill the talent gap is dependent on faculty presenting a wide variety of topics in the introductory supply chain management classes. Although the American Association of Universities makes it very clear that it is the primary responsibility of faculty to set curriculum (AAU, 2013), there should be some guidelines to help faculty coordinate with industry to help develop current and relevant supply chain curriculums. Failure to expose the students to these concepts is, in the words of Freire (1970), doing an injustice to the students. 


\section{APPENDIX 1 Syllabi Listing}

\begin{tabular}{|c|c|c|c|c|}
\hline $\begin{array}{l}\text { Database of } \\
\text { Selected Syllabi }\end{array}$ & & & $\begin{array}{l}\text { Course } \\
\text { Title }\end{array}$ & $\begin{array}{l}\text { comments/rationale } \\
\text { for inclusion }\end{array}$ \\
\hline MGMT S-5033 & Harvard & 2014 & $\begin{array}{l}\text { Supply } \\
\text { chain } \\
\text { management }\end{array}$ & undergraduate course \\
\hline Bus 0017 & NYU & 2015 & $\begin{array}{l}\text { Operations } \\
\text { Management }\end{array}$ & SCM in description \\
\hline IDS 3163 & FIU & 2015 & $\begin{array}{l}\text { Global } \\
\text { Supply } \\
\text { Chains \& } \\
\text { Logistics }\end{array}$ & \\
\hline Bus 0017 & $\begin{array}{l}\text { Stern School of } \\
\text { Business }\end{array}$ & 2013 & $\begin{array}{l}\text { Supply } \\
\text { Chain } \\
\text { Management }\end{array}$ & $\begin{array}{l}\text { updated course title }+ \\
\text { different text }\end{array}$ \\
\hline SCM 301 & Penn State & 2012 & $\begin{array}{l}\text { Introduction } \\
\text { to Supply } \\
\text { Chain } \\
\text { Management }\end{array}$ & \\
\hline SCM 301 & Penn State - Erie & 2014 & $\begin{array}{l}\text { Supply } \\
\text { Chain } \\
\text { Management }\end{array}$ & $\begin{array}{l}\text { different instructor; } \\
\text { different text from main } \\
\text { campus }\end{array}$ \\
\hline SCM 301 & $\begin{array}{l}\text { Penn State - } \\
\text { Altoona }\end{array}$ & 2011 & $\begin{array}{l}\text { Supply } \\
\text { Chain } \\
\text { Management }\end{array}$ & $\begin{array}{l}\text { d different instructor; } \\
\text { different text from main } \\
\text { campus }\end{array}$ \\
\hline SCM 08035 & Rutgers & 2017 & $\begin{array}{l}\text { Introduction } \\
\text { to Supply } \\
\text { Chain } \\
\text { Management }\end{array}$ & new course \\
\hline SCM 302 & UNC-G & Summer 2016 & $\begin{array}{l}\text { Operations } \\
\text { and Supply } \\
\text { Chain } \\
\text { Management }\end{array}$ & $\begin{array}{l}\text { foundation course for } \\
\text { SCM program with } \\
\text { SCM text }\end{array}$ \\
\hline SCMS 2610 & Memphis & Spring 2017 & $\begin{array}{l}\text { Introduction } \\
\text { to Supply } \\
\text { Chain } \\
\text { Management }\end{array}$ & \\
\hline MAN 4504 & $\begin{array}{l}\text { University of } \\
\text { Florida }\end{array}$ & Fall 2016 & $\begin{array}{l}\text { Supply } \\
\text { Chain } \\
\text { Management }\end{array}$ & \\
\hline
\end{tabular}




\begin{tabular}{|c|c|c|c|c|}
\hline MAN 4504 & $\begin{array}{l}\text { University of } \\
\text { Florida }\end{array}$ & Summer 2015 & $\begin{array}{l}\text { Operations } \\
\text { and Supply } \\
\text { Chain } \\
\text { Management }\end{array}$ & different text \\
\hline MGMT 4230 & $\begin{array}{l}\text { University of } \\
\text { Georgia }\end{array}$ & 2016 & $\begin{array}{l}\text { Supply } \\
\text { Chain } \\
\text { Management }\end{array}$ & \\
\hline BUS 553G & $\begin{array}{l}\text { Emory } \\
\text { University }\end{array}$ & 2016 & $\begin{array}{l}\text { Supply } \\
\text { Chain } \\
\text { Management }\end{array}$ & undergraduate course \\
\hline MGT 307 & $\begin{array}{l}\text { Northern } \\
\text { Kentucky } \\
\text { University }\end{array}$ & Fall 2012 & $\begin{array}{l}\text { Supply } \\
\text { Chain } \\
\text { Management }\end{array}$ & \\
\hline SCML 3106 & $\begin{array}{l}\text { Clayton } \\
\text { University }\end{array}$ & 2015 & $\begin{array}{l}\text { Principles of } \\
\text { Supply } \\
\text { Chain } \\
\text { Management }\end{array}$ & \\
\hline SCMA 386 & $\begin{array}{l}\text { Virginia } \\
\text { Commonwealth } \\
\text { Univ. }\end{array}$ & Spring 2017 & $\begin{array}{l}\text { Introduction } \\
\text { to Supply } \\
\text { Chain } \\
\text { Management }\end{array}$ & \\
\hline MGT 301 & $\begin{array}{l}\text { Colorado State } \\
\text { University }\end{array}$ & Spring 2018 & $\begin{array}{l}\text { Supply } \\
\text { Chain } \\
\text { Management }\end{array}$ & \\
\hline BU 347 & Washburn & Fall 2016 & $\begin{array}{l}\text { Production } \\
\text { and } \\
\text { Operations } \\
\text { Management }\end{array}$ & $\begin{array}{l}\text { Introduction to supply } \\
\text { chain management in } \\
\text { course description }\end{array}$ \\
\hline BM 3130 & Ohio State & Spring 2016 & $\begin{array}{l}\text { Foundations } \\
\text { of } \\
\text { Operations } \\
\text { Management }\end{array}$ & $\begin{array}{l}\text { Introduction to supply } \\
\text { chain in course } \\
\text { description }\end{array}$ \\
\hline SCM 330 & $\begin{array}{l}\text { University of } \\
\text { Akron }\end{array}$ & Fall 2014 & $\begin{array}{l}\text { Principles of } \\
\text { Supply } \\
\text { chain } \\
\text { management }\end{array}$ & \\
\hline SCM 100 & $\begin{array}{l}\text { Donnelly } \\
\text { College }\end{array}$ & Fall 2014 & $\begin{array}{l}\text { Principles of } \\
\text { Supply } \\
\text { chain } \\
\text { management }\end{array}$ & \\
\hline SCM 3301 & UM - St. Louis & Spring 2017 & $\begin{array}{l}\text { Introduction } \\
\text { to Supply } \\
\text { Chain } \\
\text { Management }\end{array}$ & \\
\hline BUS 370 & $\begin{array}{l}\text { University of } \\
\text { Wisconsin }\end{array}$ & Fall 2016 & $\begin{array}{l}\text { Introduction } \\
\text { to Supply }\end{array}$ & \\
\hline
\end{tabular}




\begin{tabular}{|c|c|c|c|c|}
\hline & & & $\begin{array}{l}\text { Chain } \\
\text { Management }\end{array}$ & \\
\hline MGT 422 & $\begin{array}{l}\text { University of } \\
\text { Wisconsin- } \\
\text { Madison }\end{array}$ & Fall 2011 & Logistics & $\begin{array}{l}\text { supply chain in course } \\
\text { description }\end{array}$ \\
\hline SCM 1 & $\begin{array}{l}\text { Michigan State } \\
\text { University }\end{array}$ & Fall 2016 & $\begin{array}{l}\text { Two } \\
\text { semesters of } \\
\text { Basics }\end{array}$ & \\
\hline SCM 2 & $\begin{array}{l}\text { Michigan State } \\
\text { University }\end{array}$ & Spring 2016 & $\begin{array}{l}\text { Two } \\
\text { semesters of } \\
\text { Basics }\end{array}$ & \\
\hline OM 337 & $\begin{array}{l}\text { University of } \\
\text { Texas - Austin }\end{array}$ & Fall 2015 & $\begin{array}{l}\text { Supply } \\
\text { Chain }\end{array}$ & \\
\hline OM 367 & $\begin{array}{l}\text { University of } \\
\text { Texas }\end{array}$ & Fall 2016 & $\begin{array}{l}\text { Operations } \\
\text { and Supply } \\
\text { Chain } \\
\text { Management }\end{array}$ & \\
\hline OPRE 366 & $\begin{array}{l}\text { University of } \\
\text { Texas - Dallas }\end{array}$ & Fall 2012 & $\begin{array}{l}\text { Supply } \\
\text { Chain } \\
\text { Management }\end{array}$ & \\
\hline OM 335 & $\begin{array}{l}\text { University of } \\
\text { Texas }\end{array}$ & Spring 2016 & $\begin{array}{l}\text { Operations } \\
\text { Management }\end{array}$ & $\begin{array}{l}\text { supply chain in course } \\
\text { description }\end{array}$ \\
\hline $\mathrm{O} 4615$ & $\begin{array}{l}\text { University of } \\
\text { Texas }\end{array}$ & Fall 2016 & $\begin{array}{l}\text { Operations } \\
\text { and Supply } \\
\text { Chain } \\
\text { Management }\end{array}$ & \\
\hline BBA 428 & $\begin{array}{l}\text { Northern } \\
\text { Arizona }\end{array}$ & Fall 2016 & $\begin{array}{l}\text { Global } \\
\text { Supply } \\
\text { Chain \& } \\
\text { Logistics }\end{array}$ & Introductory course \\
\hline BUS 2160 & USNA & Fall 2016 & $\begin{array}{l}\text { Supply } \\
\text { Chain } \\
\text { Management }\end{array}$ & \\
\hline SCM 234 & Weber State & Fall 2015 & $\begin{array}{l}\text { Supply } \\
\text { Chain } \\
\text { Management }\end{array}$ & \\
\hline POM 4375 & $\begin{array}{l}\text { University of } \\
\text { Texas - El Paso }\end{array}$ & Fall 2015 & $\begin{array}{l}\text { Supply } \\
\text { Chain } \\
\text { Management }\end{array}$ & \\
\hline TECH 3355 & $\begin{array}{l}\text { University of } \\
\text { Texas - Tyler }\end{array}$ & Fall 2016 & $\begin{array}{l}\text { Supply } \\
\text { Chain } \\
\text { Management }\end{array}$ & \\
\hline BUS 361 & BYU & Fall 2011 & $\begin{array}{l}\text { Introduction } \\
\text { to Supply }\end{array}$ & \\
\hline
\end{tabular}




\begin{tabular}{|c|c|c|c|c|}
\hline & & & $\begin{array}{l}\text { Chain } \\
\text { Management }\end{array}$ & \\
\hline IOER 4210 & Weber & Fall 2016 & $\begin{array}{l}\text { Supply } \\
\text { Chain } \\
\text { Management }\end{array}$ & \\
\hline MGT 174 & $\begin{array}{l}\text { University of } \\
\text { California - San } \\
\text { Diego }\end{array}$ & Fall 2013 & $\begin{array}{l}\text { Supply } \\
\text { Chain and } \\
\text { Operations } \\
\text { Management }\end{array}$ & \\
\hline IOM 482 & USC & Fall 2011 & $\begin{array}{l}\text { Supply } \\
\text { Chain } \\
\text { Management }\end{array}$ & \\
\hline BA 628 & San Diego State & Spring 2017 & $\begin{array}{l}\text { Operations } \\
\text { and Supply } \\
\text { Chain } \\
\text { Management }\end{array}$ & \\
\hline MS\&E 260 & Stanford & Summer 2013 & $\begin{array}{l}\text { Introduction } \\
\text { to } \\
\text { Operations } \\
\text { Management }\end{array}$ & $\begin{array}{l}\text { supply chain in course } \\
\text { description }\end{array}$ \\
\hline OP 320 & $\begin{array}{l}\text { Ageno School of } \\
\text { Business }\end{array}$ & Spring 2010 & $\begin{array}{l}\text { Purchasing } \\
\text { and Supply } \\
\text { Management }\end{array}$ & $\begin{array}{l}\text { supply chain in course } \\
\text { description }\end{array}$ \\
\hline MGT 282 & UC Davis & Spring 2015 & $\begin{array}{l}\text { Supply } \\
\text { chain } \\
\text { management }\end{array}$ & \\
\hline BM 4261 & Oregon State & Undated & $\begin{array}{l}\text { Supply } \\
\text { chain } \\
\text { management }\end{array}$ & \\
\hline SCM 300 & $\begin{array}{l}\text { Arizona State } \\
\text { University }\end{array}$ & Fall 2016 & $\begin{array}{l}\text { Global } \\
\text { Supply } \\
\text { Chain } \\
\text { Operations }\end{array}$ & \\
\hline POM 3310 & Texas A\&M & Fall 2012 & $\begin{array}{l}\text { Production } \\
\text { and } \\
\text { Operations } \\
\text { Management }\end{array}$ & \\
\hline SCHM 2301 & $\begin{array}{l}\text { Northeastern } \\
\text { University }\end{array}$ & Spring 2017 & $\begin{array}{l}\text { Supply } \\
\text { Chain and } \\
\text { Operations } \\
\text { Management }\end{array}$ & \\
\hline BUS 322 & $\begin{array}{l}\text { University of } \\
\text { Illinois }\end{array}$ & Fall 2016 & $\begin{array}{l}\text { Principles of } \\
\text { Supply } \\
\text { Chain } \\
\text { Management }\end{array}$ & \\
\hline
\end{tabular}




\begin{tabular}{|c|c|c|c|c|}
\hline P371 & $\begin{array}{l}\text { University of } \\
\text { Indiana }\end{array}$ & Fall 2016 & $\begin{array}{l}\text { Operations } \\
\text { and Supply } \\
\text { chain } \\
\text { management }\end{array}$ & \\
\hline SCM 340 & $\begin{array}{l}\text { Lehigh } \\
\text { University }\end{array}$ & Fall 2016 & $\begin{array}{l}\text { Demand and } \\
\text { Supply } \\
\text { Chain } \\
\text { Planning } \\
\end{array}$ & \\
\hline MGMT 3830 & $\begin{array}{l}\text { University of } \\
\text { North Texas }\end{array}$ & Spring 2015 & $\begin{array}{l}\text { Operations } \\
\text { Management }\end{array}$ & \\
\hline SCM 265 & Syracuse & Fall 2013 & $\begin{array}{l}\text { Introduction } \\
\text { to Supply } \\
\text { Chain } \\
\text { Management }\end{array}$ & \\
\hline SCM 301 & Penn State & Fall 2015 & $\begin{array}{l}\text { Introduction } \\
\text { to Supply } \\
\text { Chain } \\
\text { Management }\end{array}$ & \\
\hline SCM 311 & $\begin{array}{l}\text { University of } \\
\text { Tennessee }\end{array}$ & Summer 2017 & $\begin{array}{l}\text { Supply } \\
\text { Chain } \\
\text { Management }\end{array}$ & \\
\hline SCMT 2103 & $\begin{array}{l}\text { University of } \\
\text { Arkansas }\end{array}$ & Spring 2017 & $\begin{array}{l}\text { Introduction } \\
\text { to Supply } \\
\text { Chain } \\
\text { Management }\end{array}$ & \\
\hline SCM 352 & UNLV & Spring 2017 & $\begin{array}{l}\text { Operations } \\
\text { and Supply } \\
\text { Chain } \\
\text { Management }\end{array}$ & \\
\hline MAN 4504 & $\begin{array}{l}\text { University of } \\
\text { Florida }\end{array}$ & Spring 2017 & $\begin{array}{l}\text { Operations } \\
\text { and Supply } \\
\text { Chain } \\
\text { Management }\end{array}$ & $\begin{array}{l}\text { different instructor from } \\
\text { above }+ \text { different text }+ \\
4 \text { CR course }\end{array}$ \\
\hline GSC 3600 & Wayne State & Fall 2016 & $\begin{array}{l}\text { Operations } \\
\text { and Supply } \\
\text { Chain } \\
\text { Management }\end{array}$ & \\
\hline BUS 144 & San Jose State & Spring 2017 & $\begin{array}{l}\text { Supply } \\
\text { Chain } \\
\text { Management }\end{array}$ & \\
\hline SCM 301X & Iowa State & Spring 2016 & $\begin{array}{l}\text { Supply } \\
\text { Chain } \\
\text { Management }\end{array}$ & \\
\hline SCMN 3150 & Auburn & Spring 2015 & $\begin{array}{l}\text { Management } \\
\text { of Supply }\end{array}$ & \\
\hline
\end{tabular}




\begin{tabular}{|c|c|c|c|c|}
\hline & & & $\begin{array}{l}\text { Chain } \\
\text { Processes }\end{array}$ & \\
\hline BUS $370 \mathrm{H}$ & $\begin{array}{l}\text { North Carolina } \\
\text { State University }\end{array}$ & Spring 2017 & $\begin{array}{l}\text { Operations } \\
\text { and Supply } \\
\text { Chain } \\
\text { Management }\end{array}$ & \\
\hline MGO 303 & $\begin{array}{l}\text { State University } \\
\text { of NY - Buffalo }\end{array}$ & Fall 2015 & $\begin{array}{l}\text { Supply } \\
\text { Chain } \\
\text { Management }\end{array}$ & \\
\hline SCHM 2301 & Northeastern & Spring 2017 & $\begin{array}{l}\text { Supply } \\
\text { Chain and } \\
\text { Operations } \\
\text { Management }\end{array}$ & \\
\hline BusM 361 & BYU & Fall 2011 & $\begin{array}{l}\text { Introduction } \\
\text { to Supply } \\
\text { Chain } \\
\text { Management } \\
\end{array}$ & \\
\hline SCM 300 & $\begin{array}{l}\text { Arizona State } \\
\text { University }\end{array}$ & Summer 2017 & $\begin{array}{l}\text { Global } \\
\text { Supply } \\
\text { Operations }\end{array}$ & \\
\hline OPER 3100 & UNC Charlotte & Spring 2017 & $\begin{array}{l}\text { Operations } \\
\text { and Supply } \\
\text { Chain } \\
\text { Management }\end{array}$ & \\
\hline OMGT 3123 & East Carolina & Spring 2016 & $\begin{array}{l}\text { Operations } \\
\text { and Supply } \\
\text { Chain } \\
\text { Management }\end{array}$ & \\
\hline SCM 401 & KU & Fall 2015 & $\begin{array}{l}\text { Introduction } \\
\text { to Supply } \\
\text { Chain } \\
\text { Management }\end{array}$ & \\
\hline BMGT 370 & Maryland & Fall 2015 & $\begin{array}{l}\text { Introduction } \\
\text { to Supply } \\
\text { Chain } \\
\text { Management }\end{array}$ & \\
\hline MGT 302 & Miami of Ohio & Spring 2016 & $\begin{array}{l}\text { Introduction } \\
\text { to } \\
\text { Operations } \\
\text { and Supply } \\
\text { Chain } \\
\text { Management }\end{array}$ & \\
\hline SCM 303 & MSU & Fall 2016 & $\begin{array}{l}\text { Introduction } \\
\text { to Supply } \\
\text { Chain } \\
\text { Management }\end{array}$ & $\begin{array}{l}\text { new professor, new text } \\
\text { from previous offering }\end{array}$ \\
\hline
\end{tabular}




\begin{tabular}{|c|c|c|c|c|}
\hline SCM 352 & UNR & Summer 2017 & $\begin{array}{l}\text { Operations } \\
\text { Management }\end{array}$ & $\begin{array}{l}\text { SCM Course Title with } \\
\text { SCM text }\end{array}$ \\
\hline TLI_21400 & Purdue & & $\begin{array}{l}\text { Introduction } \\
\text { to Supply } \\
\text { Chain } \\
\text { Management }\end{array}$ & \\
\hline MIS 302 & SDSU & Fall 2014 & $\begin{array}{l}\text { Introduction } \\
\text { to } \\
\text { Operations } \\
\text { and Supply } \\
\text { Chain } \\
\text { Management }\end{array}$ & different text \\
\hline SCM 311 & Tennessee & Summer 2017 & $\begin{array}{l}\text { Introduction } \\
\text { to Supply } \\
\text { Chain } \\
\text { Management }\end{array}$ & \\
\hline BUS ADM 370 & Wisconsin & Spring 2015 & $\begin{array}{l}\text { Introduction } \\
\text { to Supply } \\
\text { Chain } \\
\text { Management }\end{array}$ & \\
\hline
\end{tabular}




\begin{tabular}{|c|c|}
\hline Eliminated syllabi & Rationale \\
\hline Logistics and Supply chain management & $\begin{array}{l}\text { Single focus on } \\
\text { warehousing and } \\
\text { inventory; } \\
\text { operations } \\
\text { textbook }\end{array}$ \\
\hline NYU, 2015, Supply chain management & $\begin{array}{l}\text { appears to be } \\
\text { more of a risk } \\
\text { management } \\
\text { focus vice intro } \\
\text { to SCM }\end{array}$ \\
\hline GSU, MBA 8155, Operations Management & $\begin{array}{l}\text { MBA course not } \\
\text { open to } \\
\text { undergrads }\end{array}$ \\
\hline GA Tech, ISyE 3103, SCM Modeling: logistics & $\begin{array}{l}\text { too narrow of a } \\
\text { focus }\end{array}$ \\
\hline UGA, MGMT 4230, Supply chain management & $\begin{array}{l}\text { consecutive } \\
\text { semesters with } \\
\text { no changes }\end{array}$ \\
\hline SCM 305, Rutgers, Global Procurement & $\begin{array}{l}\text { too narrow of a } \\
\text { focus }\end{array}$ \\
\hline SCM 310, Rutgers, Demand Planning and Fulfillment & $\begin{array}{l}\text { too narrow of a } \\
\text { focus }\end{array}$ \\
\hline SCM 380, Rutgers, Intro to Project Management & $\begin{array}{l}\text { too narrow of a } \\
\text { focus }\end{array}$ \\
\hline SCM 420, Rutgers, SCM Industry Client Projects & $\begin{array}{l}\text { too narrow of a } \\
\text { focus }\end{array}$ \\
\hline SCM 330, Rutgers, Business Logistics and Transportation & $\begin{array}{l}\text { too narrow of a } \\
\text { focus }\end{array}$ \\
\hline OAD 30013, Ottawa, Production and Operations Management & international \\
\hline $\begin{array}{l}\text { OPS 257, University of Wollongong, Principles of Supply chain } \\
\text { management }\end{array}$ & international \\
\hline MIT, Logistics and Supply chain management & $\begin{array}{l}\text { too narrow of a } \\
\text { focus - } \\
\text { warehousing }\end{array}$ \\
\hline
\end{tabular}




\begin{tabular}{|c|c|}
\hline SCM 460, Iowa State, Decision Tools for Logistics & $\begin{array}{l}\text { too narrow of a } \\
\text { focus }\end{array}$ \\
\hline SCM 560, Iowa State, Strategic Logistics Management & $\begin{array}{l}\text { MBA course not } \\
\text { open to } \\
\text { undergrads }\end{array}$ \\
\hline BM 4237, Ohio State, Internal Operations & $\begin{array}{l}\text { too narrow of a } \\
\text { focus }\end{array}$ \\
\hline MGT 301, Colorado State, Supply chain management & $\begin{array}{l}\text { consecutive } \\
\text { semesters with } \\
\text { no changes }\end{array}$ \\
\hline SCM 460, Iowa State, Decision Tools for Logistics & $\begin{array}{l}\text { Too narrow of a } \\
\text { focus }\end{array}$ \\
\hline BU 347, Washburn, Production and Operations Management & $\begin{array}{l}\text { consecutive } \\
\text { semesters with } \\
\text { no changes }\end{array}$ \\
\hline BM 4261, Purchasing and Supply Management & $\begin{array}{l}\text { too narrow of a } \\
\text { focus - } \\
\text { procurement bias }\end{array}$ \\
\hline TRA 6157, Logistics/Supply chain management & MBA course \\
\hline SCM 400, Supply Chain Inventory Management & $\begin{array}{l}\text { too narrow of a } \\
\text { focus - inventory } \\
\text { management }\end{array}$ \\
\hline BUS 3230, Ohio State, Introduction to Operations Management & $\begin{array}{l}\text { consecutive } \\
\text { semesters with } \\
\text { no changes }\end{array}$ \\
\hline $\begin{array}{l}\text { SCM 330, Akron, Principles of Supply chain management and } \\
\text { Operations Management }\end{array}$ & $\begin{array}{l}\text { consecutive } \\
\text { semesters with } \\
\text { no changes }\end{array}$ \\
\hline SCM I, Michigan State, Supply chain management & $\begin{array}{l}\text { consecutive } \\
\text { semesters with } \\
\text { no changes }\end{array}$ \\
\hline IEOR 4210, Supply chain management & $\begin{array}{l}\text { not enough } \\
\text { details in } \\
\text { syllabus }\end{array}$ \\
\hline
\end{tabular}




\begin{tabular}{|c|c|}
\hline OM 368, Texas, Logistics and Inventory Management & $\begin{array}{l}\text { too specific - } \\
\text { inventory } \\
\text { management } \\
\text { focus }\end{array}$ \\
\hline OM 337, Texas, Supply Chain Modeling and Optimization & $\begin{array}{l}\text { too specific - } \\
\text { modeling }\end{array}$ \\
\hline MIS 373, Texas, IT for Supply Chains & $\begin{array}{l}\text { too specific - info } \\
\text { systems focus }\end{array}$ \\
\hline OM 337.4, Texas, Supply Chain IT & $\begin{array}{l}\text { too specific - info } \\
\text { systems focus }\end{array}$ \\
\hline OM 337, Texas, Supply Chain Analytics & $\begin{array}{l}\text { too specific - } \\
\text { metrics/analytics } \\
\text { focus }\end{array}$ \\
\hline OM 368, Texas, Logistics and Inventory Management & $\begin{array}{l}\text { consecutive } \\
\text { semesters with } \\
\text { no changes }\end{array}$ \\
\hline OM 337.2, Texas, Supply Chain Modeling & too specific \\
\hline MIS 373, Texas, IT for Supply Chains & $\begin{array}{l}\text { consecutive } \\
\text { semesters with } \\
\text { no changes }\end{array}$ \\
\hline BUSM 361, BYU, Introduction to Supply chain management & $\begin{array}{l}\text { consecutive } \\
\text { semesters with } \\
\text { no changes }\end{array}$ \\
\hline BM 3230, Ohio state, introduction to operations mgmt. & $\begin{array}{l}\text { too specific when } \\
\text { reviewing } \\
\text { syllabus }\end{array}$ \\
\hline Weber State, IEOR 4210 & $\begin{array}{l}\text { not enough info } \\
\text { in syllabus }\end{array}$ \\
\hline OM 337, Texas & $\begin{array}{l}\text { too specific for } \\
\text { intro course }\end{array}$ \\
\hline $\begin{array}{l}\text { Miami, MGT 302, Intro to Operations and Supply chain } \\
\text { management, Fall } 15\end{array}$ & $\begin{array}{l}\text { new professor, } \\
\text { no real changes } \\
\text { from previous } \\
\text { semesters }\end{array}$ \\
\hline $\begin{array}{l}\text { Miami, MGT 302, Intro to Operations and Supply chain } \\
\text { management Spring } 14\end{array}$ & $\begin{array}{l}\text { new professor, } \\
\text { no real changes } \\
\text { from previous } \\
\text { semesters }\end{array}$ \\
\hline
\end{tabular}




\begin{tabular}{|c|c|}
\hline MGMT 3121, CUNY & $\begin{array}{l}\text { too specific - } \\
\text { services based }\end{array}$ \\
\hline MGMT, Logistics Management, Embry-riddle & $\begin{array}{l}\text { too narrow focus } \\
\text { - aviation focus }\end{array}$ \\
\hline $\begin{array}{l}\text { MIS 302, Introduction to Operations and Supply chain } \\
\text { management, San Diego State }\end{array}$ & $\begin{array}{l}\text { no changes from } \\
\text { previous } \\
\text { semester }\end{array}$ \\
\hline BUS 553G - Supply chain management, Emory & $\begin{array}{l}\text { MBA course not } \\
\text { open to } \\
\text { undergrads }\end{array}$ \\
\hline MAN 4504, UF, Supply chain management & $\begin{array}{l}\text { Advanced SCM } \\
\text { Course }\end{array}$ \\
\hline $\begin{array}{l}6500330 \text { 001: Principles of Supply Chain \& Operations } \\
\text { Management }\end{array}$ & $\begin{array}{l}\text { Advanced SCM } \\
\text { Course }\end{array}$ \\
\hline BBA Pune University & international \\
\hline $\begin{array}{l}\text { BUSN 5680/5220 Global Logistics and Supply chain } \\
\text { management }\end{array}$ & $\begin{array}{l}\text { MBA course not } \\
\text { open to } \\
\text { undergrads }\end{array}$ \\
\hline IEOR E4210: Supply chain management, Columbia & $\begin{array}{l}\text { Inventory } \\
\text { Management }\end{array}$ \\
\hline Dirección de Operaciones, Universidad Pontifica de Salamanca & international \\
\hline MGT 3510 - Management of Technology, GA Tech & Too narrow focus \\
\hline $\begin{array}{l}\text { MGT } 3744 \text { - Managing Products, Service, and Technology } \\
\text { Development, GA Tech }\end{array}$ & Too narrow focus \\
\hline MGT 4352 - Operations Resource Planning, GA Tech & Too narrow focus \\
\hline MGT 4353 - Operations Strategy, GA Tech & Too narrow focus \\
\hline $\begin{array}{l}\text { MGT } 4360 \text { - Global Operations and Supply chain management, } \\
\text { GA Tech }\end{array}$ & Too narrow focus \\
\hline MGT 4366 - Service Operations, GA Tech & Too narrow focus \\
\hline MGT 4401 - Supply Chain Modeling, GA Tech & Too narrow focus \\
\hline ISEY 3103, Supply Chain Modeling, GA Tech & Too narrow focus \\
\hline POM 405, Haskell & self developed \\
\hline SCM 310, KU & self developed \\
\hline
\end{tabular}




\begin{tabular}{|c|c|}
\hline SCM 403, KU & $\begin{array}{l}\text { Too narrow of } \\
\text { focus }\end{array}$ \\
\hline SCM 305, KU & self developed \\
\hline BUSN 6110, Webster & $\begin{array}{l}\text { MBA course not } \\
\text { open to } \\
\text { undergrads }\end{array}$ \\
\hline PROC 5520, Webster & $\begin{array}{l}\text { MBA course not } \\
\text { open to } \\
\text { undergrads }\end{array}$ \\
\hline PROC 5530, Webster & $\begin{array}{l}\text { MBA course not } \\
\text { open to } \\
\text { undergrads }\end{array}$ \\
\hline SCM 401, Fall 2016, KU & self developed \\
\hline SCM 311, KU, Spring 2016 & self developed \\
\hline IDS 3163, Global Supply Chains and Logistics & $\begin{array}{l}\text { too specific for } \\
\text { intro course }\end{array}$ \\
\hline BBA 305, KU, Fall 2017 & self developed \\
\hline SCM 703, KU, Spring 2015 & $\begin{array}{l}\text { MBA course not } \\
\text { open to } \\
\text { undergrads }\end{array}$ \\
\hline SCM 701, KU, Spring 2014 & $\begin{array}{l}\text { MBA course not } \\
\text { open to } \\
\text { undergrads }\end{array}$ \\
\hline SCM 710, KU, Spring 2015 & $\begin{array}{l}\text { MBA course not } \\
\text { open to } \\
\text { undergrads }\end{array}$ \\
\hline $\begin{array}{l}\text { GSU ROBINSON COLLEGE OF BUSINESS, MBA } 8155 \text { - } \\
\text { Operations Management }\end{array}$ & $\begin{array}{l}\text { MBA course not } \\
\text { open to } \\
\text { undergrads }\end{array}$ \\
\hline SCMS 2610 - Introduction to Supply chain management & $\begin{array}{l}\text { no changes from } \\
\text { previous } \\
\text { semester }\end{array}$ \\
\hline OMGT 2198, Supply chain management Strategy, RMIT & international \\
\hline OMGT, 2199, Operations. RMIT & international \\
\hline $\begin{array}{l}\text { OMGT, } 8219 \text { Introduction to Logistics and Supply chain } \\
\text { management, RMIT }\end{array}$ & international \\
\hline
\end{tabular}




\begin{tabular}{|c|c|}
\hline OMGT 2267, Business IT and Supply Chain, RMIT & international \\
\hline OMGT 2277, Supply Chain Analysis and Design, RMIT & international \\
\hline OMGT 2279, Transportation and Freight Logistics, RMIT & international \\
\hline OPMA 3306, Information Systems and Operations Management & $\begin{array}{l}\text { too specific for } \\
\text { intro course }\end{array}$ \\
\hline OPS 216: Operations Management, Wollongong & international \\
\hline OPS 257: Principles of Supply chain management, Wollongong & international \\
\hline SCM 301 Supply chain management, Penn State, 2001 & $\begin{array}{l}\text { too old - Spring } \\
2001\end{array}$ \\
\hline $\begin{array}{l}\text { SCMN } 3810 \text { PROFESSIONAL DEVELOPMENT IN SUPPLY } \\
\text { CHAIN - Fall 2014, Auburn }\end{array}$ & $\begin{array}{l}\text { too specific for } \\
\text { intro course }\end{array}$ \\
\hline $\begin{array}{l}\text { Supply Chain Performance Management, SCMN 4700, Fall } \\
\text { 2014, Auburn }\end{array}$ & $\begin{array}{l}\text { too specific for } \\
\text { intro course }\end{array}$ \\
\hline $\begin{array}{l}\text { SCMN } 4800 \text {-Supply Chain Strategy: A Global Perspective, } \\
\text { Auburn }\end{array}$ & $\begin{array}{l}\text { too specific for } \\
\text { intro course }\end{array}$ \\
\hline South University, Logistics & self developed \\
\hline South University, Operations & self developed \\
\hline South University, Supply Chain & self developed \\
\hline OPRE 6371, Purchasing and Sourcing Management, UT Dallas & $\begin{array}{l}\text { too specific for } \\
\text { intro course }\end{array}$ \\
\hline IOM 482, Marshall School, Supply Chain Process Improvement & $\begin{array}{l}\text { too specific for } \\
\text { intro course }\end{array}$ \\
\hline MBA 723-001: Supply chain management, GMU & $\begin{array}{l}\text { MBA course not } \\
\text { open to } \\
\text { undergrads }\end{array}$ \\
\hline $\begin{array}{l}\text { Syllabus: SCML } 3106 \text { - Principles of Supply chain } \\
\text { management, Clayton }\end{array}$ & $\begin{array}{l}\text { consecutive } \\
\text { semesters with } \\
\text { no changes }\end{array}$ \\
\hline $\begin{array}{l}\text { OP 320.C1/SF1 SPRING 2010: PURCHASING AND SUPPLY } \\
\text { MANAGEMENT, Ageno }\end{array}$ & $\begin{array}{l}\text { too specific for } \\
\text { intro course }\end{array}$ \\
\hline IEOR E4210: Supply chain management & $\begin{array}{l}\text { not enough } \\
\text { details in } \\
\text { syllabus }\end{array}$ \\
\hline
\end{tabular}




\begin{tabular}{|l|l|}
$\begin{array}{l}\text { MGMT 622: Strategic Operations and Supply chain } \\
\text { management, Rice }\end{array}$ & $\begin{array}{l}\text { MBA course not } \\
\text { open to } \\
\text { undergrads }\end{array}$ \\
\hline $\begin{array}{l}\text { SCMA 1000 Introduction to Supply chain management, Albany } \\
\text { Tech }\end{array}$ & $\begin{array}{l}\text { too specific for } \\
\text { intro course }\end{array}$ \\
\hline $\begin{array}{l}\text { BMGT370 - Introduction to Transportation and Supply chain } \\
\text { management, Univ of Maryland }\end{array}$ & $\begin{array}{l}\text { too specific for } \\
\text { intro course }\end{array}$ \\
\hline $\begin{array}{l}\text { SCM 301 Introduction to Supply chain management, Rutgers, } \\
\text { 2014 }\end{array}$ & $\begin{array}{l}\text { consecutive } \\
\text { semesters with } \\
\text { no changes }\end{array}$ \\
\hline $\begin{array}{l}\text { SCM 301:01 - Introduction to Supply chain management, } \\
\text { Rutgers, 2015 }\end{array}$ & $\begin{array}{l}\text { consecutive } \\
\text { semesters with } \\
\text { no changes }\end{array}$ \\
\hline & $\begin{array}{l}\text { MBA course not } \\
\text { open to } \\
\text { undergrads }\end{array}$ \\
\hline $\begin{array}{l}\text { Lancaster, MBA Elective Course - Supply chain management } \\
\text { MGMT 3320.300 (F2F): Supply Chain and Operations }\end{array}$ & $\begin{array}{l}\text { too old for } \\
\text { criteria }\end{array}$ \\
\hline Management, 2011, TAMU & $\begin{array}{l}\text { too old for } \\
\text { criteria }\end{array}$ \\
\hline $\begin{array}{l}\text { OPERATIONS STRATEGY \& SUPPLY CHAIN } \\
\text { MANAGEMENT, OM 367, UT }\end{array}$ & $\begin{array}{l}\text { consecutive } \\
\text { semesters with } \\
\text { no changes }\end{array}$ \\
\hline SCMT 2103: Introduction to Supply chain management, \\
Arkansas & $\begin{array}{l}\text { consecutive } \\
\text { semesters with } \\
\text { no changes }\end{array}$ \\
\hline $\begin{array}{l}\text { SCMT 2103, Introduction to Supply chain management, } \\
\text { Arkansas, 2015 } \\
\text { management, SDS, 2016 }\end{array}$ & $\begin{array}{l}\text { consecutive } \\
\text { semesters with } \\
\text { no changes }\end{array}$ \\
\hline $\begin{array}{l}\text { MAMT 2103: Introduction to Supply chain management, } \\
\text { Arkansas, 2016 }\end{array}$ & $\begin{array}{l}\text { consecutive } \\
\text { semesters with } \\
\text { no changes }\end{array}$ \\
\hline intro course \\
intement, Kennesaw
\end{tabular}




\begin{tabular}{|c|c|}
\hline $\begin{array}{l}\text { MGMT } 633 \text { GLOBAL SUPPLY CHAIN MANAGEMENT, } \\
2010\end{array}$ & $\begin{array}{l}\text { too old for } \\
\text { criteria }\end{array}$ \\
\hline $\begin{array}{l}\text { MGT } 4193 \text { - Servant Leadership, Values, and Systems, GA } \\
\text { Tech }\end{array}$ & $\begin{array}{l}\text { too specific for } \\
\text { intro course }\end{array}$ \\
\hline MGT 4309 - Services Marketing, GA Tech & $\begin{array}{l}\text { outside of } \\
\text { research focus }\end{array}$ \\
\hline BUSM 390R - Business Analytics and Big Data, BYU-H, 2017 & $\begin{array}{l}\text { too specific for } \\
\text { intro course }\end{array}$ \\
\hline BUSM 391 - Project Management, BYU-H, 2017 & $\begin{array}{l}\text { too specific for } \\
\text { intro course }\end{array}$ \\
\hline BUSM 461 - Six Sigma Quality Management, BYU-H, 2017 & $\begin{array}{l}\text { too specific for } \\
\text { intro course }\end{array}$ \\
\hline SCM 420, KU, Customer Focused Operations, 2018 & $\begin{array}{l}\text { too specific for } \\
\text { intro course }\end{array}$ \\
\hline
\end{tabular}




\section{APPENDIX 2 Job Announcements}

\begin{tabular}{|l|l|l|} 
Logistics Account Executive (Entry Level) & JEAR Logistics & Charleston, SC \\
\hline Jr. Buyer (Entry Level) & Wesco Aircraft & Valencia, CA \\
\hline Logistics Operator (Entry-Level) & WOONGJIN INC & Doral, FL \\
\hline Supply Chain Manager & CMC Rescue & Goleta, CA \\
\hline Inventory and Supply Chain Manager & Deatschwerks & Oklahoma City, OK \\
\hline Manager, Supply Chain (Operations) & GKN & St. Louis, MO \\
\hline Supply Chain Manager & GKN & Roxboro, NC \\
\hline Supply Chain Manager & AmesburyTruth & Owatonna, MN \\
\hline Zone Manager, Asset Protection Supply Chain & K-MART & Lawrence, KS \\
\hline Supply Chain Assistant Manager & Automotive & \\
\hline Supply Chain Manager & Exhaust Systems & Fort Deposit, AL \\
\hline Logistics Coordinator & Landmark Hospital & Naples, FL \\
\hline Supply Chain Ops Analyst I & Mayo Clinic & La Crosse, WI, US \\
\hline Supply Chain Section Manager & CEVA Logistics & Mt. Juliet, TN \\
\hline & Caterpillar & Seguin, TX \\
\hline Operations Manager - Warehouse & Penske & $\begin{array}{l}\text { Various locations } \\
\text { USA }\end{array}$ \\
\hline Supply Chain Operations Manager & $\begin{array}{l}\text { Ellison Educational } \\
\text { Equipment }\end{array}$ & Lake Forest, CA \\
\hline Logistics Manager & truCore Distributors & Kings Park, NY \\
\hline & Johnson and & $\begin{array}{l}\text { West Chester, PA; } \\
\text { Palm Beach } \\
\text { Gardens, FL or } \\
\text { Bridgewater, NJ. }\end{array}$ \\
\hline Manager, Supply Chain (SC)Business Analyst & Johnson & Saint Paul, MN \\
\hline Logistics Specialist (MN) & Trinity Logistics & St. Louis, MO \\
\hline Supply Chain Manager & GKN & Daily Express, Inc. \\
\hline Management Trainee Transportation \& & - & Milwaukee, WI \\
\hline Logistics & Anheuser Busch & St. Louis, MO \\
\hline Sogistics Trainee Program & Webstaurant Store & US \\
\hline Inventory Supply Chain Manager Trainee & Dot Foods & Mt. Sterling, IL \\
\hline Distribution Center Manager Trainee & Menards & IRON RIDGE, WI \\
\hline Supply Chain Analyst & OpX & Phoenix, AZ \\
\hline Inventory/Supply Chain Manager & Evernex & Brooklyn, NY \\
\hline Entry Level Inventory Manager & $\begin{array}{l}\text { WIS } \\
\text { INTERNATIONAL }\end{array}$ & Sudbury, ON \\
\hline & & \\
\hline
\end{tabular}




\begin{tabular}{|c|c|c|}
\hline Supply Chain Manager & $\begin{array}{l}\text { Swimways } \\
\text { Corporation }\end{array}$ & Tarboro, NC \\
\hline Supply Chain Manager & Superior Group & Euclid, OH \\
\hline Supply Chain Manager & TECT Group & Cleveland, $\mathrm{OH}$ \\
\hline Customer Supply Chain Program Manager & $\begin{array}{l}\text { Federal-Mogul } \\
\text { Powertrain }\end{array}$ & Southfield, MI \\
\hline Supply Chain Manager & Eaton & $\begin{array}{l}\text { Sumter, South } \\
\text { Carolina }\end{array}$ \\
\hline Supply Chain Manager / Production Manager & $\begin{array}{l}\text { Guardian Industries } \\
\text { Corp }\end{array}$ & Carleton, MI \\
\hline Supply Chain Manager & $\begin{array}{l}\text { Plasan Carbon } \\
\text { Composites }\end{array}$ & Walker, MI \\
\hline Supply Chain Manager & $\begin{array}{l}\text { Taco Comfort } \\
\text { Solutions }\end{array}$ & $\begin{array}{l}\text { Cranston, Rhode } \\
\text { Island }\end{array}$ \\
\hline Supply Chain Specialist & Owens \& Minor & Kennesaw, GA \\
\hline $\begin{array}{l}2018 \text { Intern to Leadership Program - Logistics } \\
\text { \& Supply Chain Operations }\end{array}$ & Belk Retail & Charlotte, NC \\
\hline Supply Chain Specialist & Clopay Corporation & Mason, $\mathrm{OH}$ \\
\hline Operations Supervisor (Warehouse / Logistics) & $\begin{array}{l}\text { Capstone Logistics, } \\
\text { LLC }\end{array}$ & Saxonburg, PA \\
\hline Supply Manager- DMC & $\begin{array}{l}\text { Central Garden \& } \\
\text { Pet }\end{array}$ & Dallas, TX \\
\hline Materials Manager & Shiloh Industries & Wellington, $\mathrm{OH}$ \\
\hline Supply Chain Manager & Barry Plastics & Lawrence, KS \\
\hline $\begin{array}{l}\text { Manager- Supply Chain Distribution \& } \\
\text { Logistics }\end{array}$ & $\begin{array}{l}\text { Stanford Health } \\
\text { Care }\end{array}$ & Palo Alto, CA \\
\hline Logistics/Supply Chain Manager & Valmont & Brenham TX \\
\hline Procurement \& Supply Chain Manager & Snap Kitchen & Austin, TX \\
\hline Zone Manager, Asset Protection Supply Chain & Sears Holding & Lawrence, KS \\
\hline Supply Chain/Distribution Operations Manager & $\begin{array}{l}\text { Company } \\
\text { Confidential }\end{array}$ & Richmond, CA \\
\hline Operations Manager & $\begin{array}{l}\text { Mid-Am Building } \\
\text { Supply }\end{array}$ & $\mathrm{KC}, \mathrm{KS}$ \\
\hline Manager, Logistics Process Improvement & $\begin{array}{l}\text { Tractor Supply } \\
\text { Company }\end{array}$ & Brentwood, TN \\
\hline Supply Planner I & K Force & Sarasota, FL \\
\hline PROCUREMENT SUMMER INTERN 2018 & $\begin{array}{l}\text { Direct Energy } \\
\text { Houston, TX }\end{array}$ & Houston, TX \\
\hline Supply Chain Specialist I (Entry Level) & $\begin{array}{l}\text { American } \\
\text { Cybersystems, Inc }\end{array}$ & St. Louis, MO \\
\hline
\end{tabular}




\begin{tabular}{|l|l|l|} 
Category Sourcing Manager, Junior Level & The Squires Group & Springfield, VA \\
\hline Supply Chain Manager & $\begin{array}{l}\text { Company } \\
\text { Confidential }\end{array}$ & SC \\
\hline Supply Chain Manager & $\begin{array}{l}\text { Company } \\
\text { Confidential }\end{array}$ & OH \\
\hline Supply Chain Manager & $\begin{array}{l}\text { Company } \\
\text { Confidential }\end{array}$ & NC \\
\hline Program Manager, Supply Chain & Masco & Livonia, MI \\
\hline Project Manager - Supply Chain & The Judge Group & Lawrenceville, GA \\
\hline Supply Chain Manager & Michael Page USA & Riverside, CA \\
\hline Manager of Supply Chain & K Force & Seymour, CT \\
\hline Supply Chain Manager & Collabera & Wayne, NJ \\
\hline Supply Chain Manager & Plasan Carbon & Walker, MI \\
\hline Supply Chain Manager & Snackoo Inc. & Hayward, CA \\
\hline Supply Chain Manager & General LED, Inc. & San Antonio, TX \\
\hline Supply Chain / Logistics Manager & Siemens & Norwood, Ohio \\
\hline Entry Level Supply Chain & Adecco & Wixom, MI \\
\hline Junior Supply Chain Manager & Page Group & $\begin{array}{l}\text { New York, NY } \\
10017\end{array}$ \\
\hline Supply Chain Specialist I & American & Hazelwood, MO \\
\hline Supply Chain Specialist & The Bartech Group & Racine, WI \\
\hline & $\begin{array}{l}\text { NextGen } \\
\text { Information }\end{array}$ & \\
\hline Jr. Materials Control Specialist & Services, Inc & Golden, CO \\
\hline Jr Supply Chain Analyst & Talent Source & Elkhart, IN \\
\hline Logistics Supervisor & CNH Industrial & Racine, WI \\
\hline Entry Level Inventory Manager & $\begin{array}{l}\text { WIS } \\
\text { INTERNATIONAL }\end{array}$ & Various locations \\
\hline USA
\end{tabular}




\begin{tabular}{|l|l|l|} 
& $\begin{array}{l}\text { Management } \\
\text { Recruiters of } \\
\text { Hudson }\end{array}$ & Cleveland, OH \\
\hline Supply Chain Manager & $\begin{array}{l}\text { Johnson Service } \\
\text { Group }\end{array}$ & Valencia, CA \\
\hline Supply Chain Manager & CTG & Horseheads, NY \\
\hline Supply Chain Manager & $\begin{array}{l}\text { Company } \\
\text { Confidential }\end{array}$ & KY \\
\hline Supply Chain Manager & TalentBridge & Charlotte, NC \\
\hline Supply Chain Manager & Apex Systems & Racine, WI \\
\hline \multicolumn{1}{|c|}{ Chain Specialist - Entry Level } & Talis Group & Louisville, KY \\
\hline Supply Chain Manager & US Tech Solutions & Wisconsin \\
\hline Supply Chain Specialist & TIMKEN & Various locations \\
\hline USA
\end{tabular}




\begin{tabular}{|l|l|l|}
\multirow{2}{*}{ Entry Level Buyer } & $\begin{array}{l}\text { The LaSalle } \\
\text { Network }\end{array}$ & Chicago, IL \\
\hline PLANNER / SCHEDULER & $\begin{array}{l}\text { Benchmark } \\
\text { Electronics, Inc. }\end{array}$ & Phoenix, AZ \\
\hline Supply Chain Inventory Analyst & $\begin{array}{l}\text { CKE Restaurants } \\
\text { Inc. }\end{array}$ & Franklin, TN \\
\hline Customer Program Manager & Celestica Inc & Rochester, MN \\
\hline Account Manager-Supply Chain & Nesco Resource & Ridgefield, NJ \\
\hline Warehouse Operations Manager & $\begin{array}{l}\text { Capstone Logistics, } \\
\text { LLC }\end{array}$ & Elba, AL \\
\hline Operations Supervisor (Warehouse / Logistics) & $\begin{array}{l}\text { Capstone Logistics, } \\
\text { LLC }\end{array}$ & Greenville, SC \\
\hline Supply Chain Business Manager, JR & Superior Group & Livermore, CA \\
\hline Logistics Project Management (Entry Level) & Pantos USA, Inc. & $\begin{array}{l}\text { Englewood Cliffs, } \\
\text { NJ }\end{array}$ \\
\hline Operations Management Trainee & $\begin{array}{l}\text { Worthington } \\
\text { Industries, Inc }\end{array}$ & Rome, NY \\
\hline Operations Leadership Development Program & Siemens Careers & Mishawaka, Indiana \\
\hline Supply Chain Manager Trainee & $\begin{array}{l}\text { Clark and } \\
\text { Associates }\end{array}$ & Leola, PA \\
\hline
\end{tabular}




\section{APPENDIX 3 APICS Supply Chain Industry Terminology}

CPIM Key Terminology

\begin{tabular}{|c|c|c|c|}
\hline (C) APICS 2016 & five whys & on-hand balance & scheduling \\
\hline $\mathrm{ABC}$ classification & $\begin{array}{l}\text { fixed-location } \\
\text { storage }\end{array}$ & $\begin{array}{l}\text { on-time } \\
\text { schedule } \\
\text { performance }\end{array}$ & scrap \\
\hline $\begin{array}{l}\text { advanced planning and } \\
\text { scheduling (APS) }\end{array}$ & $\begin{array}{l}\text { fixed order } \\
\text { quantity }\end{array}$ & open order & seasonal inventory \\
\hline advance ship notice & fixed overhead & $\begin{array}{l}\text { operating } \\
\text { expense }\end{array}$ & seasonality \\
\hline Andon & $\begin{array}{l}\text { fixed-position } \\
\text { manufacturing }\end{array}$ & $\begin{array}{l}\text { operations } \\
\text { management }\end{array}$ & sensei \\
\hline anticipation inventories & flowchart & $\begin{array}{l}\text { operator } \\
\text { flexibility }\end{array}$ & service \\
\hline assemble-to-order & flow processing & order entry & service industry \\
\hline assembly line & flow shop & ordering cost & service parts \\
\hline assignable cause & $\begin{array}{l}\text { fluctuation } \\
\text { inventory }\end{array}$ & order picking & setup \\
\hline available inventory & forecast & order point & setup \\
\hline available-to-promise & forecast error & order promising & Shingo's seven wastes \\
\hline average inventory & $\begin{array}{l}\text { forward } \\
\text { scheduling }\end{array}$ & order qualifiers & shipping manifest \\
\hline back scheduling & four Ps & order winners & $\begin{array}{l}\text { single-level bill of } \\
\text { material }\end{array}$ \\
\hline backflush & $\begin{array}{l}\text { freight } \\
\text { consolidation }\end{array}$ & outsourcing & single-source supplier \\
\hline backhauling & $\begin{array}{l}\text { freight } \\
\text { forwarder }\end{array}$ & overhead & six sigma \\
\hline backlog & $\begin{array}{l}\text { functional } \\
\text { layout }\end{array}$ & $\begin{array}{l}\text { overlapped } \\
\text { schedule }\end{array}$ & SMART \\
\hline backorder & Gantt chart & owner's equity & split lot \\
\hline balance sheet & gemba & pacemaker & spread \\
\hline bar code & $\begin{array}{l}\text { genchi } \\
\text { genbutsu }\end{array}$ & $\begin{array}{l}\text { package to } \\
\text { order }\end{array}$ & standard costs \\
\hline batch & $\begin{array}{l}\text { general and } \\
\text { administrative } \\
\text { expenses } \\
\text { (G\&A) }\end{array}$ & pallet positions & standard time \\
\hline
\end{tabular}




\begin{tabular}{|c|c|c|c|}
\hline batch picking & $\begin{array}{l}\text { generally } \\
\text { accepted } \\
\text { accounting } \\
\text { principles } \\
\text { (GAAP) } \\
\end{array}$ & parent item & start date \\
\hline bias & $\begin{array}{l}\text { green reverse } \\
\text { logistics }\end{array}$ & Pareto's law & $\begin{array}{l}\text { statistical process control } \\
\text { (SPC) }\end{array}$ \\
\hline bill of lading & gross margin & $\begin{array}{l}\text { participative } \\
\text { design engineering }\end{array}$ & $\begin{array}{l}\text { stockkeeping unit } \\
(\mathrm{SKU})\end{array}$ \\
\hline bill of material (BOM) & $\begin{array}{l}\text { gross } \\
\text { requirement }\end{array}$ & pegging & stockout costs \\
\hline bonded warehouse & hansei & $\begin{array}{l}\text { performance } \\
\text { standard }\end{array}$ & stockout percentage \\
\hline bottleneck & hedge inventory & $\begin{array}{l}\text { periodic } \\
\text { replenishment }\end{array}$ & store \\
\hline break-bulk & heijunka & $\begin{array}{l}\text { period order } \\
\text { quantity }\end{array}$ & strategic plan \\
\hline break-even point & histogram & $\begin{array}{l}\text { perpetual inventory } \\
\text { record }\end{array}$ & subcontracting \\
\hline buffer & hoshin & $\begin{array}{l}\text { physical } \\
\text { inventory }\end{array}$ & $\begin{array}{l}\text { summarized bill of } \\
\text { material }\end{array}$ \\
\hline buffer management & hoshin planning & physical supply & supplier \\
\hline bullwhip effect & idle capacity & picking list & supplier certification \\
\hline business plan & $\begin{array}{l}\text { income } \\
\text { statement }\end{array}$ & $\begin{array}{l}\text { pickup and } \\
\text { delivery system }\end{array}$ & supplier lead time \\
\hline capable-to-promise & incoterms & pipeline stock & supplier partnership \\
\hline capacity available & $\begin{array}{l}\text { indented bill } \\
\text { of materials }\end{array}$ & $\begin{array}{l}\text { plan-do-check- } \\
\text { action (PDCA) }\end{array}$ & $\begin{array}{l}\text { supplier relationship } \\
\text { management (SRM) }\end{array}$ \\
\hline capacity management & $\begin{array}{l}\text { independent } \\
\text { demand }\end{array}$ & planned order & supply chain \\
\hline capacity planning & infinite loading & $\begin{array}{l}\text { planned order } \\
\text { receipt }\end{array}$ & $\begin{array}{l}\text { supply chain } \\
\text { management }\end{array}$ \\
\hline carrying cost & $\begin{array}{l}\text { input/output } \\
\text { control }\end{array}$ & $\begin{array}{l}\text { planned order } \\
\text { release }\end{array}$ & sustainability \\
\hline cash flow & $\begin{array}{l}\text { intermittent } \\
\text { production }\end{array}$ & $\begin{array}{l}\text { planning bill of } \\
\text { materials }\end{array}$ & tactical plan(s) \\
\hline cause-and-effect diagram & $\begin{array}{l}\text { intermodal } \\
\text { transport }\end{array}$ & planning horizon & takt time \\
\hline cellular manufacturing & $\begin{array}{l}\text { internal failure } \\
\text { costs }\end{array}$ & $\begin{array}{l}\text { point of sale } \\
(\mathrm{POS})\end{array}$ & tariff \\
\hline
\end{tabular}




\begin{tabular}{|c|c|c|c|}
\hline centralized inventory control & $\begin{array}{l}\text { internal setup } \\
\text { time }\end{array}$ & postponement & terminals \\
\hline certified supplier & $\begin{array}{l}\text { interplant } \\
\text { demand }\end{array}$ & prevention costs & terminal-handling costs \\
\hline chase production method & $\begin{array}{l}\text { in-transit } \\
\text { inventory }\end{array}$ & $\begin{array}{l}\text { preventive } \\
\text { maintenance }\end{array}$ & terms and conditions \\
\hline closed-loop $\quad$ MRP & $\begin{array}{l}\text { intrinsic forecast } \\
\text { method }\end{array}$ & priority control & $\begin{array}{l}\text { theory of constraints } \\
\text { (TOC) }\end{array}$ \\
\hline common carrier & $\begin{array}{l}\text { inventory } \\
\text { accuracy }\end{array}$ & priority planning & $\begin{array}{l}\text { theory of constraints } \\
\text { accounting }\end{array}$ \\
\hline component & $\begin{array}{l}\text { inventory } \\
\text { adjustment }\end{array}$ & private carrier & $\begin{array}{l}\text { third-party logistics } \\
\text { provider }\end{array}$ \\
\hline consignment & $\begin{array}{l}\text { inventory } \\
\text { buffer }\end{array}$ & process batch & throughput \\
\hline constraint & $\begin{array}{l}\text { inventory } \\
\text { control }\end{array}$ & $\begin{array}{l}\text { process } \\
\text { flexibility }\end{array}$ & time bucket \\
\hline $\begin{array}{l}\text { continuous process } \\
\text { improvement }\end{array}$ & $\begin{array}{l}\text { inventory } \\
\text { management }\end{array}$ & $\begin{array}{l}\text { process flow } \\
\text { diagram }\end{array}$ & time buffer \\
\hline continuous production & $\begin{array}{l}\text { inventory } \\
\text { ordering system }\end{array}$ & procurement & time fence \\
\hline continuous replenishment & $\begin{array}{l}\text { inventory } \\
\text { turnover }\end{array}$ & $\begin{array}{l}\text { procurement lead } \\
\text { time }\end{array}$ & $\begin{array}{l}\text { time-phased order point } \\
\text { (TPOP) }\end{array}$ \\
\hline contract carrier & jidoka & product cost & tolerance \\
\hline control chart & jishuken & $\begin{array}{l}\text { product } \\
\text { differentiation }\end{array}$ & total cost curve \\
\hline control limit & job costing & product family & $\begin{array}{l}\text { total cost of ownership } \\
\text { (TCO) }\end{array}$ \\
\hline cost of goods sold & job shop & $\begin{array}{l}\text { production activity } \\
\text { control }\end{array}$ & total costs \\
\hline cost of poor quality & $\begin{array}{l}\text { job shop } \\
\text { scheduling }\end{array}$ & production line & total line-haul cost \\
\hline critical chain method & kaizen & production plan & $\begin{array}{l}\text { total productive } \\
\text { maintenance (TPM) }\end{array}$ \\
\hline critical path method & kanban & $\begin{array}{l}\text { production } \\
\text { planning }\end{array}$ & traceability \\
\hline cross-docking & $\begin{array}{l}\text { key } \\
\text { performance } \\
\text { indicator } \\
(\mathrm{KPI})\end{array}$ & $\begin{array}{l}\text { productive } \\
\text { capacity }\end{array}$ & tracking signal \\
\hline cumulative lead time & landed cost & productivity & traffic \\
\hline
\end{tabular}




\begin{tabular}{|c|c|c|c|}
\hline customs broker & $\begin{array}{l}\text { leading } \\
\text { indicator }\end{array}$ & product layout & transaction channel \\
\hline cycle counting & lead time & $\begin{array}{l}\text { product life } \\
\text { cycle }\end{array}$ & transit inventory \\
\hline cycle stock & lead-time offset & product $\operatorname{mix}$ & transit time \\
\hline cycle time & lean production & profit margin & transportation \\
\hline data governance* & $\begin{array}{l}\text { lean six } \\
\text { sigma* }\end{array}$ & $\begin{array}{l}\text { projected } \\
\text { available balance }\end{array}$ & transportation inventory \\
\hline days of supply & $\begin{array}{l}\text { level of } \\
\text { service }\end{array}$ & $\begin{array}{l}\text { project } \\
\text { management }\end{array}$ & trend \\
\hline $\begin{array}{l}\text { decentralized inventory } \\
\text { control }\end{array}$ & $\begin{array}{l}\text { level } \\
\text { production } \\
\text { method }\end{array}$ & $\begin{array}{l}\text { protective } \\
\text { capacity }\end{array}$ & truckload carriers \\
\hline decoupling inventory & level schedule & $\begin{array}{l}\text { protective } \\
\text { inventory }\end{array}$ & $\begin{array}{l}\text { two-bin inventory } \\
\text { system }\end{array}$ \\
\hline delivery lead time & Liabilities & $\begin{array}{l}\text { protective } \\
\text { packaging }\end{array}$ & $\begin{array}{l}\text { two-card kanban } \\
\text { system }\end{array}$ \\
\hline demand lead time & line haul costs & $\begin{array}{ll}\text { pull } & \text { system } \\
\end{array}$ & U-lines \\
\hline demand management & load & purchase order & uniform plant \\
\hline demand planning & load leveling & $\begin{array}{l}\text { purchase } \\
\text { requisition }\end{array}$ & unit cost \\
\hline demonstrated capacity & logistics & $\begin{array}{l}\text { purchasing lead } \\
\text { time }\end{array}$ & $\begin{array}{l}\text { UN Global Compact } \\
\text { Management Model }\end{array}$ \\
\hline demurrage & lot & push system & $\begin{array}{l}\text { United Nations Global } \\
\text { Compact }\end{array}$ \\
\hline dependent demand & lot control & quality & unitization \\
\hline detention & lot-for-lot & $\begin{array}{l}\text { quality at the } \\
\text { source }\end{array}$ & unit load \\
\hline direct labor & lot size & quality control & unit of measure \\
\hline direct material & $\begin{array}{l}\text { lot-size } \\
\text { inventory }\end{array}$ & quality costs & upstream \\
\hline discrete manufacturing & $\begin{array}{l}\text { maintenance, } \\
\text { repair, operating } \\
\text { (MRO) supplies }\end{array}$ & $\begin{array}{l}\text { quality function } \\
\text { deployment (QFD) }\end{array}$ & utilization \\
\hline discrete order picking & $\begin{array}{l}\text { make-or buy } \\
\text { decision }\end{array}$ & quantity discount & value added \\
\hline dispatching & make-to-order & queue & value analysis \\
\hline distribution & make-to-stock & quick changeover & value chain \\
\hline
\end{tabular}




\begin{tabular}{|c|c|c|c|}
\hline distribution center & $\begin{array}{l}\text { manufacturing } \\
\text { calendar }\end{array}$ & $\begin{array}{l}\text { radio frequency } \\
\text { identification } \\
\text { (RFID) }\end{array}$ & value stream \\
\hline distribution channel & $\begin{array}{l}\text { manufacturing } \\
\text { lead time }\end{array}$ & $\begin{array}{l}\text { random-location } \\
\text { storage }\end{array}$ & value stream mapping \\
\hline distribution inventory & $\begin{array}{l}\text { manufacturing } \\
\text { order }\end{array}$ & random sample & variable cost \\
\hline $\begin{array}{l}\text { distribution requirements } \\
\text { planning (DRP) }\end{array}$ & $\begin{array}{l}\text { manufacturing } \\
\text { philosophy }\end{array}$ & random variation & variance \\
\hline distribution warehouse & $\begin{array}{l}\text { manufacturing } \\
\text { process }\end{array}$ & rated capacity & VATI Analysis \\
\hline dock-to-stock & $\begin{array}{l}\text { manufacturing } \\
\text { resource planning } \\
\left(\begin{array}{ll}\text { MRP } & \text { II) }\end{array}\right.\end{array}$ & raw material & velocity \\
\hline drop ship & market driven & receiving & $\begin{array}{l}\text { vendor-managed } \\
\text { inventory(VMI) }\end{array}$ \\
\hline drum-buffer-rope (DBR) & $\begin{array}{l}\text { marketing } \\
\text { strategy }\end{array}$ & record accuracy & visual review system \\
\hline drum schedule & $\begin{array}{l}\text { mass } \\
\text { customization }\end{array}$ & remanufacturing & voice of the customer \\
\hline duty & master planning & reorder quantity & wait time \\
\hline $\begin{array}{l}\text { economic order quantity } \\
(\mathrm{EOQ})\end{array}$ & $\begin{array}{l}\text { master production } \\
\text { schedule (MPS) }\end{array}$ & $\begin{array}{l}\text { repetitive } \\
\text { manufacturing }\end{array}$ & wall-to-wall inventory \\
\hline efficiency & master schedule & $\begin{array}{l}\text { replenishment } \\
\text { lead time }\end{array}$ & warehousing \\
\hline $\begin{array}{l}\text { electronic data } \\
\text { interchange(EDI) }\end{array}$ & $\begin{array}{l}\text { material } \\
\text { requirements } \\
\text { planning }(\mathrm{MRP})\end{array}$ & $\begin{array}{l}\text { request for } \\
\text { quote (RFQ) }\end{array}$ & waste \\
\hline employee empowerment & $\begin{array}{l}\text { materials } \\
\text { handling }\end{array}$ & $\begin{array}{l}\text { requirements } \\
\text { explosion }\end{array}$ & wave picking \\
\hline employee involvement & $\begin{array}{l}\text { materials } \\
\text { management }\end{array}$ & $\begin{array}{l}\text { resource } \\
\text { planning }\end{array}$ & waybill \\
\hline engineer-to-order & $\begin{array}{l}\text { mean absolute } \\
\text { deviation (MAD) }\end{array}$ & reverse auction & ways \\
\hline $\begin{array}{l}\text { enterprise resources planning } \\
\text { (ERP) }\end{array}$ & milk run & reverse logistics & what-if analysis \\
\hline explode & $\begin{array}{l}\text { min-max } \\
\text { system }\end{array}$ & $\begin{array}{l}\text { risk } \\
\text { management* }\end{array}$ & where-used list \\
\hline
\end{tabular}




\begin{tabular}{|l|l|l|l|} 
external failure costs & $\begin{array}{l}\text { mixed-flow } \\
\text { scheduling }\end{array}$ & $\begin{array}{l}\text { root cause } \\
\text { analysis }\end{array}$ & work cell \\
\hline external setup time & $\begin{array}{l}\text { mixed-model } \\
\text { production }\end{array}$ & $\begin{array}{l}\text { rough-cut capacity } \\
\text { planning (RCCP) }\end{array}$ & work center \\
\hline extrinsic forecasting methods & $\begin{array}{l}\text { mixed-model } \\
\text { scheduling }\end{array}$ & routing & Work in process \\
(WIP)
\end{tabular}




\section{APPENDIX 4 - APICS Operations Industry Terminology}

\section{CPIM Key \\ Operations}

\section{Terminology}

\begin{tabular}{|c|c|c|c|}
\hline (C) APICS 2016 & decomposition & $\begin{array}{l}\text { learning } \\
\text { organization }\end{array}$ & production level \\
\hline 14 Points (Deming's) & decoupling & $\begin{array}{l}\text { least changeover } \\
\text { cost }\end{array}$ & production rate \\
\hline A3 method & dedicated line & least-squares method & production schedule \\
\hline abnormal demand & de-expedite & least total cost & $\begin{array}{l}\text { production } \\
\text { scheduling }\end{array}$ \\
\hline absorption costing & $\begin{array}{l}\text { define, measure, } \\
\text { analyze, improve, } \\
\text { control (DMAIC) } \\
\text { process }\end{array}$ & level loading & product line \\
\hline $\begin{array}{l}\text { acceptable quality level } \\
\text { (AQL) }\end{array}$ & delivery schedule & $\begin{array}{l}\text { life cycle } \\
\text { assessment }\end{array}$ & $\begin{array}{l}\text { product load } \\
\text { profile }\end{array}$ \\
\hline acceptance sampling & Delphi method & lifecycle analysis & $\begin{array}{l}\text { product-mix } \\
\text { flexibility }\end{array}$ \\
\hline action message & demand filter & lifecycle costing & product positioning \\
\hline activation & $\begin{array}{l}\text { demand } \\
\text { forecasting }\end{array}$ & limiting operation & product profiling \\
\hline activity-based cost & $\begin{array}{l}\text { demand time } \\
\text { fence (DTF) }\end{array}$ & line & $\begin{array}{l}\text { product/service } \\
\text { hierarchy }\end{array}$ \\
\hline $\begin{array}{l}\text { activity based management } \\
(\mathrm{ABM})\end{array}$ & $\begin{array}{lr}\text { design for } \\
\text { manufacturing }\end{array}$ & line balancing & project costing \\
\hline actual costs & $\begin{array}{l}\text { design for } \\
\text { manufacture and } \\
\text { assembly } \\
\text { (DFMA) }\end{array}$ & load profile & $\begin{array}{l}\text { project } \\
\text { manufacturing }\end{array}$ \\
\hline actual demand & $\begin{array}{l}\text { design of } \\
\text { experiments }\end{array}$ & load projection & project phase \\
\hline adaptive smoothing & design-to-order & local measures & project plan \\
\hline adjustable capacity & direct costs & lot $\operatorname{cost}$ & prototyping \\
\hline
\end{tabular}




\begin{tabular}{|c|c|c|c|}
\hline $\begin{array}{l}\text { advanced planning } \\
\text { system (APS) }\end{array}$ & $\begin{array}{l}\text { discounted cash } \\
\text { flow }\end{array}$ & lot sizing & pull signal \\
\hline aggregate forecast & $\begin{array}{l}\text { discrete available to } \\
\text { promise }\end{array}$ & lot splitting & pyramid forecasting \\
\hline aggregate plan & disintermediation & lot traceability & QS 9000 \\
\hline Agility & distressed goods & lower control limit & $\begin{array}{l}\text { qualitative forecasting } \\
\text { techniques }\end{array}$ \\
\hline Allocation & $\begin{array}{l}\text { distribution } \\
\text { network planning }\end{array}$ & $\begin{array}{l}\text { lower specification } \\
\text { limit }\end{array}$ & queue time \\
\hline alpha factor & $\begin{array}{l}\text { distribution of } \\
\text { forecast errors }\end{array}$ & low-level code & quick asset ratio \\
\hline alternate operation & divergent point & machine center & random cause \\
\hline alternate routing & downtime & machine hours & random sample \\
\hline analysis of variance & $\begin{array}{l}\text { early } \\
\text { manufacturing } \\
\text { involvement }\end{array}$ & $\begin{array}{l}\text { machine-limited } \\
\text { capacity }\end{array}$ & $\begin{array}{l}\text { rate-based } \\
\text { scheduling }\end{array}$ \\
\hline anticipated delay report & $\begin{array}{l}\text { early supplier } \\
\text { involvement(ESI) }\end{array}$ & machine loading & redundancy \\
\hline appraisal costs & earned hours & $\begin{array}{l}\text { management by } \\
\text { walking (MBWA) }\end{array}$ & regression analysis \\
\hline attribute data & echelon & $\begin{array}{l}\text { managerial } \\
\text { accounting }\end{array}$ & released order \\
\hline availability & e-commerce & $\begin{array}{l}\text { manufacturing } \\
\text { enrichment }\end{array}$ & $\begin{array}{l}\text { preplanning } \\
\text { frequency }\end{array}$ \\
\hline available capacity & $\begin{array}{l}\text { econometric } \\
\text { model }\end{array}$ & $\begin{array}{l}\text { manufacturing } \\
\text { execution systems } \\
\text { (MES) }\end{array}$ & requisition \\
\hline available time & $\begin{array}{l}\text { Environmentally } \\
\text { responsible } \\
\text { business }\end{array}$ & $\begin{array}{l}\text { manufacturing layout } \\
\text { strategies }\end{array}$ & rescheduling \\
\hline average cost per unit & excess capacity & $\begin{array}{l}\text { manufacturing } \\
\text { strategy }\end{array}$ & residual income \\
\hline $\begin{array}{l}\text { average } \\
\text { quality }\end{array}$ & expedite & $\begin{array}{l}\text { master planning of } \\
\text { resources }\end{array}$ & resiliency \\
\hline
\end{tabular}




\begin{tabular}{|c|c|c|c|}
\hline backflush costing & $\begin{array}{l}\text { exponential } \\
\text { smoothing forecast }\end{array}$ & $\begin{array}{l}\text { master schedule } \\
\text { item }\end{array}$ & resource \\
\hline backward integration & extrapolation & master scheduler & $\begin{array}{l}\text { resource-constrained } \\
\text { schedule }\end{array}$ \\
\hline backward scheduling & fabricator & $\begin{array}{l}\text { material-dominated } \\
\text { scheduling (MDS) }\end{array}$ & resource leveling \\
\hline balanced scorecard & $\begin{array}{l}\text { failsafe work } \\
\text { methods }\end{array}$ & $\begin{array}{l}\text { mean absolute percent } \\
\text { error (MAPE) }\end{array}$ & $\begin{array}{l}\text { resource-limited } \\
\text { scheduling }\end{array}$ \\
\hline balancing operations & $\begin{array}{l}\text { failure mode effects } \\
\text { analysis (FMEA) }\end{array}$ & mean squared error & resource profile \\
\hline baseline measures & Feature & $\begin{array}{l}\text { mean time between } \\
\text { failure (MTBF) }\end{array}$ & $\begin{array}{l}\text { responsible } \\
\text { procurement }\end{array}$ \\
\hline base series & Feedback & $\begin{array}{l}\text { mean time to } \\
\text { repair (MTTR) }\end{array}$ & $\begin{array}{l}\text { return on } \\
\text { investment }\end{array}$ \\
\hline basic seven tools of quality & $\begin{array}{l}\text { feeder } \\
\text { workstations }\end{array}$ & measure phase & sales promotion \\
\hline batch processing & fill rate & Median & sample \\
\hline benchmarking & $\begin{array}{l}\text { finishing lead } \\
\text { time }\end{array}$ & $\operatorname{mix}$ forecast & $\begin{array}{l}\text { sampling } \\
\text { distribution }\end{array}$ \\
\hline benchmark measures & $\begin{array}{l}\text { first-article } \\
\text { inspection }\end{array}$ & mode & scheduled downtime \\
\hline bill of distribution & $\begin{array}{l}\text { first in, first } \\
\text { out (FIFO) }\end{array}$ & $\begin{array}{l}\text { modular bill of } \\
\text { materials }\end{array}$ & scheduled load \\
\hline bill of labor & $\begin{array}{l}\text { first-order } \\
\text { smoothing }\end{array}$ & $\begin{array}{l}\text { multilevel master } \\
\text { schedule }\end{array}$ & scrap factor \\
\hline bill of resources & first pass yield & net present value & seasonal index \\
\hline block scheduling & fishbone analysis & network planning & $\begin{array}{l}\text { second-order } \\
\text { smoothing }\end{array}$ \\
\hline bottleneck operation & fitness for use & $\begin{array}{l}\text { nominal group } \\
\text { technique }\end{array}$ & $\begin{array}{l}\text { self-directed work } \\
\text { team }\end{array}$ \\
\hline bottom-up replanning & flexibility & nonconformity & Semi-finished goods \\
\hline bucketed system & $\begin{array}{l}\text { flexible } \\
\text { workforce }\end{array}$ & Non-evident failure & shitsuke \\
\hline budgeted capacity & floor stocks & $\begin{array}{l}\text { Nongovernmental } \\
\text { organization (NGO) }\end{array}$ & shojinka \\
\hline
\end{tabular}




\begin{tabular}{|c|c|c|c|}
\hline buffer stock & focused factory & non-value-added & shrinkage \\
\hline $\begin{array}{l}\text { business process } \\
\text { reengineering }\end{array}$ & focus forecasting & normal distribution & $\begin{array}{l}\text { single-card Kanban } \\
\text { system }\end{array}$ \\
\hline business-to-business & forecast horizon & obsolete inventory & $\begin{array}{l}\text { single exponential } \\
\text { smoothing }\end{array}$ \\
\hline by-product & forecast interval & operation & smoothing constant \\
\hline calculated capacity & $\begin{array}{l}\text { forecast } \\
\text { management }\end{array}$ & $\begin{array}{l}\text { operational } \\
\text { performance } \\
\text { measurements }\end{array}$ & smoothing factor \\
\hline capacity-constrained & form-fit-function & operation costing & social responsibility \\
\hline capacity control & $\begin{array}{l}\text { forward flow } \\
\text { scheduling }\end{array}$ & operation due date & special cause \\
\hline $\begin{array}{l}\text { capacity planning using } \\
\text { overall factors (CPOF) }\end{array}$ & $\begin{array}{l}\text { forward } \\
\text { integration }\end{array}$ & operation duration & specification \\
\hline capacity-related costs & $\begin{array}{l}\text { frequency } \\
\text { distribution }\end{array}$ & $\begin{array}{l}\text { operation } \\
\text { overlapping }\end{array}$ & $\begin{array}{l}\text { specific } \\
\text { identification }\end{array}$ \\
\hline capacity requirements & $\begin{array}{l}\text { functional } \\
\text { product* }\end{array}$ & $\begin{array}{l}\text { operation/process } \\
\text { yield }\end{array}$ & $\begin{array}{l}\text { statistical quality } \\
\text { control (SQC) }\end{array}$ \\
\hline capacity strategy & funnel experiment & operations plan & strategic drivers \\
\hline capacity utilization & $\begin{array}{l}\text { global } \\
\text { measurements }\end{array}$ & $\begin{array}{l}\text { operations } \\
\text { scheduling }\end{array}$ & $\begin{array}{l}\text { strategic performance } \\
\text { measurements }\end{array}$ \\
\hline cash conversion cycle & $\begin{array}{l}\text { global reporting } \\
\text { initiative }(\mathrm{GRI})\end{array}$ & operations sequence & strategic planning \\
\hline cash-to-cash cycle time & $\begin{array}{l}\text { global trade } \\
\text { identification } \\
\text { number }(\mathrm{GTIN}) *\end{array}$ & $\begin{array}{l}\text { operations } \\
\text { sequencing }\end{array}$ & strategic sourcing \\
\hline cell & go/no-go & operation start date & substitution \\
\hline central point scheduling & $\begin{array}{l}\text { green } \\
\text { manufacturing }\end{array}$ & operations strategy & sunk cost \\
\hline certificate of compliance & $\begin{array}{l}\text { group technology } \\
\text { (GT) }\end{array}$ & operation time & $\begin{array}{l}\text { super bill of } \\
\text { material }\end{array}$ \\
\hline certification audits & hazmat & opportunity cost & $\begin{array}{l}\text { supermarket } \\
\text { approach }\end{array}$ \\
\hline
\end{tabular}




\begin{tabular}{|c|c|c|c|}
\hline changeover & hedge & option & $\begin{array}{l}\text { supplier-input-process- } \\
\text { output-customer } \\
\text { (SIPOC) }\end{array}$ \\
\hline changeover costs & $\begin{array}{l}\text { horizontal } \\
\text { dependency }\end{array}$ & option over planning & diagram \\
\hline chase strategy & $\begin{array}{l}\text { horizontally } \\
\text { integrated firm }\end{array}$ & outbound stock point & $\begin{array}{l}\text { supplier } \\
\text { measurement }\end{array}$ \\
\hline check sheet & $\begin{array}{l}\text { house of quality } \\
\text { (HOQ) }\end{array}$ & outlier & supplier scheduling \\
\hline $\begin{array}{l}\text { Collaborative planning } \\
\text { forecasting, and } \\
\text { replenishment (CPFR) }\end{array}$ & hurdle rate & overload & surge capacity \\
\hline common causes & $\begin{array}{l}\text { hybrid production } \\
\text { method }\end{array}$ & $\begin{array}{l}\text { overstated master } \\
\text { production schedule }\end{array}$ & SWOT analysis \\
\hline $\begin{array}{l}\text { common parts bill of } \\
\text { materials }\end{array}$ & hypothesis testing & $\begin{array}{l}\text { participative } \\
\text { management }\end{array}$ & $\begin{array}{l}\text { synchronized } \\
\text { production }\end{array}$ \\
\hline competitive advantage & idle time & payback & tactical planning \\
\hline competitive analysis & inactive inventory & $\mathrm{P}: \mathrm{D}$ ratio & $\begin{array}{l}\text { Taguchi } \\
\text { methodology }\end{array}$ \\
\hline concurrent design & $\begin{array}{l}\text { inbound stock } \\
\text { point }\end{array}$ & people involvement & $\begin{array}{l}\text { target inventory } \\
\text { level }\end{array}$ \\
\hline concurrent engineering & insourcing & perceived quality & throughput time \\
\hline conformance & intangible costs & $\begin{array}{l}\text { performance } \\
\text { measure }\end{array}$ & $\begin{array}{l}\text { time-based } \\
\text { competition }\end{array}$ \\
\hline constraints management & $\begin{array}{l}\text { intellectual } \\
\text { property }\end{array}$ & $\begin{array}{l}\text { performance } \\
\text { measurement system }\end{array}$ & time series \\
\hline consuming the forecast & $\begin{array}{l}\text { inventory } \\
\text { investment }\end{array}$ & $\begin{array}{l}\text { performance } \\
\text { objectives }\end{array}$ & $\begin{array}{l}\text { time series } \\
\text { analysis }\end{array}$ \\
\hline continuous improvement & $\begin{array}{l}\text { inventory } \\
\text { valuation }\end{array}$ & $\begin{array}{l}\text { planning time } \\
\text { fence }\end{array}$ & time standard \\
\hline $\begin{array}{l}\text { continuous } \\
\text { manufacturing }\end{array}$ & Ishikawa diagram & point-of-use delivery & $\begin{array}{l}\text { total quality } \\
\text { control }\end{array}$ \\
\hline $\begin{array}{l}\text { continuous process } \\
\text { control }\end{array}$ & $\begin{array}{l}\text { ISO } 14000 \text { Series } \\
\text { Standards }\end{array}$ & $\begin{array}{l}\text { point-of-use } \\
\text { inventory }\end{array}$ & transfer batch \\
\hline
\end{tabular}




\begin{tabular}{|c|c|c|c|}
\hline contribution & ISO 9000 & $\begin{array}{l}\text { poka-yoke (mistake } \\
\text { proofing) }\end{array}$ & transfer pricing \\
\hline contribution margin & ISO 26000 & $\begin{array}{l}\text { post-deduct inventory } \\
\text { transaction processing }\end{array}$ & transient state \\
\hline control points & $\begin{array}{l}\text { item master } \\
\text { record }\end{array}$ & $\begin{array}{l}\text { pre-deduct inventory } \\
\text { transaction processing }\end{array}$ & $\begin{array}{l}\text { trend forecasting } \\
\text { models }\end{array}$ \\
\hline co-product & job enlargement & $\begin{array}{l}\text { primary work } \\
\text { center }\end{array}$ & $\begin{array}{l}\text { two-level master } \\
\text { schedule }\end{array}$ \\
\hline core competencies & job enrichment & priority & unplanned repair \\
\hline core process & $\begin{array}{l}\text { job sequencing } \\
\text { rules }\end{array}$ & probability & upper control limit \\
\hline corporate culture & job shop & $\begin{array}{l}\text { probability } \\
\text { distribution }\end{array}$ & $\begin{array}{l}\text { upper specification } \\
\text { limit (USL) }\end{array}$ \\
\hline corrective action & $\begin{array}{l}\text { job shop } \\
\text { scheduling }\end{array}$ & probable scheduling & usage variance \\
\hline correlation & job status & $\begin{array}{l}\text { problem-solving } \\
\text { storyboard }\end{array}$ & vertical dependency \\
\hline cost center & $\begin{array}{l}\text { joint } \\
\text { replenishment }\end{array}$ & process capability & vertical integration \\
\hline cost of quality & Juran trilogy & $\begin{array}{l}\text { process capability } \\
\text { index }\end{array}$ & virtual cell \\
\hline cost variance & $\begin{array}{l}\text { Just-in-Time } \\
\text { (JIT) }\end{array}$ & process control & virtual organization \\
\hline cost-volume-profit & kaizen blitz & process costing & visual control \\
\hline count point & kaizen event & process flow & warehouse demand \\
\hline critical characteristics & keiretsu & $\begin{array}{l}\text { process flow } \\
\text { analysis }\end{array}$ & \\
\hline critical point backflush & $\begin{array}{l}\text { key success } \\
\text { factors }\end{array}$ & $\begin{array}{l}\text { process flow } \\
\text { production }\end{array}$ & \\
\hline critical ratio & kit & $\begin{array}{l}\text { process flow } \\
\text { scheduling }\end{array}$ & \\
\hline critical-to-quality & $\begin{array}{l}\text { knowledge-based } \\
\text { system }\end{array}$ & process focused & \\
\hline $\begin{array}{l}\text { cumulative available to } \\
\text { promise }\end{array}$ & labor efficiency & $\begin{array}{l}\text { process } \\
\text { manufacturing }\end{array}$ & \\
\hline
\end{tabular}




\begin{tabular}{|l|l|l|} 
current ratio & labor productivity & $\begin{array}{l}\text { processor-dominated } \\
\text { scheduling }\end{array}$ \\
\hline curve fitting & labor standard & process train \\
\hline customer service level & $\begin{array}{l}\text { lag capacity } \\
\text { strategy }\end{array}$ & product focused \\
\hline $\begin{array}{l}\text { customer-supplier } \\
\text { partnership }\end{array}$ & $\begin{array}{l}\text { last in, first } \\
\text { out (LIFO) }\end{array}$ & $\begin{array}{l}\text { product group } \\
\text { forecast }\end{array}$ \\
\hline decision matrix & $\begin{array}{l}\text { lead capacity } \\
\text { strategy }\end{array}$ & $\begin{array}{l}\text { production } \\
\text { capability }\end{array}$ \\
\hline $\begin{array}{l}\text { decision support } \\
\text { system (DSS) }\end{array}$ & learning curve & production forecast \\
\hline
\end{tabular}




\section{References}

AACSB. (2016). 2016 Business School Data Guide. Retrieved March 15, 2016, from http://www.aacsb.edu/-/media/aacsb/publications/data-trends-booklet/2016.ashx?la=en

AACSB. (2016b). Total Enrollment and Percentages. Retrieved April 14, 2017, from AACSB/data: http://www.aacsb.edu/knowledge/data/frequentlyrequested/enrollment/enrollment-total

AAU. (2013, April). Academic principles: a brief introduction. Retrieved April 1, 2018, from Amerian Association of Universities: https://www.aau.edu/sites/default/files/AAU\%20Files/AAU\%20Documents/AcademicPrinciples.pdf

Ackerman, K. (2016, February 10). The Crisis in Talent Management. Retrieved February 10, 2016, from DC Velocity: http://www.dcvelocity.com/print/article/20160208-the-crisis-intalent-management/

Akalin, G., Huang, Z., \& Willems, J. (2016). Is Supply Chain Management Replacing Operations Management in the Business School Core Curriculum. Operations and Supply Chain Management, 9(2), 119-130. Retrieved November 1, 2016

Alphaliner. (2017). Alphaliner Top 100. Retrieved July 19, 2017, from axsmarine.com: https://alphaliner.axsmarine.com/PublicTop100/index.php

Anderson, D., Britt, F., \& Favre, D. (1997, April 1). The 7 Principles of Supply Chain Management. Supply Chain Management Review. 
APICS 2015. (2015). Best Practices in Teaching Supply Chain Management. Conference Proceedings. Las Vegas: APICS.

APICS. (2016). Basics of Supply Chain Management Exam Manual. Chicago: APICS.

Baehr, J. M. (2018, May 2). Teaching Collaboration. Retrieved May 7, 2018, from Supply chain management review: http://www.scmr.com/article/teaching_collaboration_something_that_should_be_learned _if_it_hasnt_been

Bahouth, S., \& Hartmann, D. W. (2014). Supply chain management: how the curricula of the top ten undergraduate universities meet the practitioners' knowledge set. American Journal of Business Education, 7(4), 285-298.

Ballou, R. (2007). The evolution and future of logistics and supply chain mangement. European Business Review, 19(4), 332-348.

Bandhopadhyay, J. (2004, March). Developing a model for a supply chain management major in a United States university in the new millennium. International Journal of Management, 21(1), 67-76.

Bandyopadhyay, J. (2004, March). Developing a model for a supply chain management major in a United States university in the new millennium. International Journal of Management, 21(1), 67-76.

Bandyopadhyay, J. (2004, March). Developing a model for a supply chain management major in a United States university in the new millennium. International Journal of Management, 21(1), 67-76. 
Bentz, B. (2015, Feb 1). Reverse logistics: time to clean up the mess. Retrieved July 5, 2016, from Logistics Managemetn: http://www.logisticsmgmt.com/article/reverse_logistics_time_to_clean_up_the_mess

Birou, L., Lutz, H., \& Zsidisin, G. (2016). Current state of the art and science: a survey of purchasing and supply chain management courses and teaching approaches. International Journal of Procurement Management, 9(1), 71-85. Retrieved June 13, 2017

Blackstone, J. H. (2013). APICS Dictionary - the essential supply chain reference. Chicago, IL: APICS.

Blackstone, J. H. (2013). APICS Dictionary, 14th ed. . Chicago, IL: APICS.

Blanchard, D. (2011, October 14). Supply Chain Talent Needs to be Spread Around More. Retrieved October 31, 2016, from industry Week: http://www.industryweek.com/recruiting-retention

Blanchard, D. (2014, July 11). Supply Chain \& Logistics: The Competitive Advantage of a Supply Chain. Retrieved October 31, 2016, from Industry Week: http://www.industryweek.com/comptetitive-chain

Bohman, J. (2005). Critical Theory. Retrieved June 29, 2017, from Stanford Encyclopedia of Philosophy: https://plato.stanford.edu/entries/critical-theory/

Bronner, S. E. (2011). Critial theory: a very short introduction. New York: Oxford University Press.

Buffett, J. (1978). Manana [Recorded by J. Buffett]. [Album - Son of a Son of a Sailor]. MCA Records. 
Bureau, C. (2017, May 16). Quarterly retail e-commerce sales. Retrieved July 17, 2017, from US Census Bureau: https://www.census.gov/retail/mrts/www/data/pdf/ec_current.pdf

Burnette, M. (2014). The First Step in Talent Management: Finding the Best Supply Chain Talent. Supply Chain Management Review.

Capar, I., Ulengin, F., \& Reisman, A. (2004). A Taxonomoy for Supply Chain Management Literature. Isatanbul: Istanbul Technical University.

Cappelli, P. (2008, March). Talent Management for the 21st Century. Harvard Business Review. Retrieved July 31, 2017, from https://hbr.org/2008/03/talent-management-for-the-twentyfirst-century

Carlson, G., \& Sosnoski, J. (2017). Conceptiual logistics as a form of critical pedagogy. International Journal of Critical Pedagogy, 8(1), 8-31.

Center, S. C. (2017, April 27). Supply Chain Star. Retrieved from Supply Chain Research: http://supplychainresearch.com/supplychainstar.html

Christopher, M. (1992). Logistics - The Strategic Issues. London: Chapman and Hall.

Christopher, M. (2016). Logistics and Supply Chain Management, 5th ed. Edinburg Gate, Great Britain: Pearson/Financial Times.

Clausewitz, C. v. (1984). On War. (M. E. Howard, Ed.) Princeton, NJ: Princeton Universityy Press.

Collins, J. (2001). Good to great. New York: Harper.

Colvin, G. (2018, Feb 1). Job Market 2018: Ready, Set, Jump. Fortune Magazine, pp. 44-52. 
Cottrill, K. (2010). Are you prepared for the supply chain talent crisis. Massachusetts Institute of Technology. Boston: Center for Transportation and Logistics. Retrieved January 5, 2016

Cousins, P., Lawson, B., \& Squire, B. (2006). Supply Chain Management: theory and practice the emergence of an academic discipline? International Jouran of Operations and Production Management, 26(7), 697-702.

Cowell, ,. D. (1998). A marketing logistics eduational prgramme in action. International Journal of Physical Distribution and Logistics Management, 28(4), pp. 242-250.

Croom, S., Romano, P., \& Giannakis, M. (2000). Supply chain management: an analytical framework for critical literature review. European Journal of Purchasing and Supply Management, 67-83.

CSCMP. (2018). CSCMP supply chain management definitions and glossary. Retrieved May 5, 2018, from CSCMP: https://cscmp.org/CSCMP/Educate/SCM_Definitions_and_Glossary_of_Terms/CSCMP/ Educate/SCM_Definitions_and_Glossary_of_Terms.aspx?hkey=60879588-f65f-4ab5$8 \mathrm{c} 4 \mathrm{~b}-6878815 \mathrm{ef} 921$

Daud, D. (2016, February). Determinants of success in logistics graduates: an exploratory study. Educational Research International, 5(1).

Daughtery, P., \& Closs, D. (2016). Supply chain issues: what's keeping supply chain managers awake at night? Chicago: APICS.

dbpedia. (n.d.). academic disciplline. Retrieved August 21, 2017, from dbpedia: http://dbpedia.org/ontology/academicDiscipline 
Derwik, P., \& Hellstrom, D. (2017). Competence in supply chain management: a systemtic review. Supply Chain Management: An International Journal, 22(2), 200-218.

DHL. (2017). The supply chain talent shortage: from gap to crisis. DHL.

Di, Y. (2016). University-Enterprise Cooperation Is the New Trend of the Reform of Logsitics Universities. Canadian Social Science, 89-92.

Drucker, P. (1999). Management challenges for the 21 st century. New York: Harper Business.

FIT. (2017). MS- Logistics Management. Retrieved January 28, 2017, from FIT:

http://web2.fit.edu/programs/8322/ms-logistics-management

Florida Institute of Technology. (2016, January). Supply Chain Management vs. Values Chain Management. Retrieved February 3, 2016, from Florida Tech Online: www.floridatechonline.com/resources/supply-chain-management

Foster, M. A. (2009, July 15). Critical or Radical Pedagogy: An Application of Critical Theory. Retrieved July 27, 2017, from The Mark Foster.org: http://www.markfoster.net/struc/criticalpedagogy.html

Freire, P. (1970). Pedagogy of the Oppressed (30th Anniversary Edition). New York: Bloomsbury.

Friedman, T. (2007). The world is flat. New York: Picador.

Garcia-Caceres, R. G., \& Escobar, J. W. (2016). Characterization of supply chain problems. DYNA, 83(198), 68-78. doi:http://dx.doi.org/10.15446/dyna.v83n198.44532 
Garrett, R. (2016, June 28). Tackling the talent shortage. Retrieved April 16, 2017, from Supply and Demand Chain Executive: http://www.sdcexec.com/article/12221751/tackling-thetalent-shortage-executive-memo-june-2016

Gartner Research . (2016). Top 25 Supply Chain Schools Undergraduate. Boston: Gartner Research Center.

Gibson, T., Kerr, D., \& Fisher, R. (2016). Accelerating supply chain management learning: identifying enablers from a. Supply Chain Management: An International Journal, 21(4), 470-484. Retrieved April 6, 2017, from http://www.emeraldinsight.com/doi/pdfplus/10.1108/SCM-10-2014-0343

Gilmour, P. (1978). The current status of business logistics education. Transportation Journal, 18(2), 71-78.

Giroux, H. (1988). Teachers as Intellectuals. Westport, CT: Bergin and Garvey.

Giuntini, R., \& Miller, T. (2014, May). Business and Academia: Schooling Each Other. Material Handling and Logistics, pp. 24-26.

Glatthorn, A., Boschee, F., Whitehead, B., \& Boschee, A. (2006). Curriculum Leadership: Development and Implemetation. Thousand Oaks: SAGE.

Glatthorn, A., Boschee, F., Whitehead, B., \& Boschee, B. (2012). Curriculum leadership: trategies for development and mplementation, 3rd ed. Thousand Oaks: Sage.

Glatthorn, A., Boschee, F., Whitehead, B., \& Boschee, B. (2017). Curriculum Leadership (4th ed.). Thousand Oaks: Sage. 
Gonzalez, M., Quesada, G., Gourdin, K., \& Hartley, M. (2008). Designing a supply chain management academic curriculumm using QFD and benchmarking. Quality Assurance in Education, 16(1), 36-60.

Gravier, M. J., \& Farris, M. T. (2008). An analysis of logistics pedgogical literature. The International Journal of Logistics Management, 19(2), 233-253.

Halldorsson, A., \& Arlbjorn, J. S. (2005). Research Methodologies in Supply Chain. Heidelberg, Germany: Physica Verlag.

Harland, C., Lamming, R., Walker, H., Phillips, W., Caldwell, N., Johnsen, T., . . Sheng, J. (2006). Supply management: is it a discipline? International Journal of Operations and Production Management, 26(7), 730-753.

Harland, C., Lamming, R., Walker, H., Phillips, W., Caldwell, N., Johnson, T., . . Zehng, J. (2006). Supply management: is it a discipline? International Journal of Operations and Production Management, 26(7), 730-753.

Harnowo, A., Calhoun, M., \& Monteiro, H. (2016). Sink or Swim: Learning by Doing in a Supply Chain Integration Activity. Decision Sciences Journal of Innovative Education, 14(1), 7-23.

Harrington, L. (2015). Solving the talent crisis. Robert H. Smith School of Business, University of Maryland.

Holcomb, M., Krul, A., \& Thomas, D. (2015, July/August). How business and universities are collaborating to fill the gap. Supply Chain Management Review, 10-18. 
Hudson, S. (2004, June 2). The increasing necessity for reverse logistics. Retrieved July 5, 2016, from Supply chain resource cooperative: https://scm.ncsu.edu/scm-articles/article/theincreasing-necessity-for-reverse-logistics

Johansson, R. (2003). Case Study Methodology. Retrieved July 3, 2017, from psyking.net: http://www.psyking.net/HTMLobj-3839/Case_Study_Methodology_Rolf_Johansson_ver_2.pdf

Johnson, \& Pyke. (2000). A Framework for Teaching Supply Chain Management. Journal of Production and Operations Management, 9(1). Retrieved Nov 1, 2015

Johnson, M., \& Pyke, D. (2000). A framework for teaching supply chain management. Production and Operations Management, 9(1), 2-18. Retrieved January 15, 2017

Jones, T. C., \& Riley, D. W. (1984). Using inventory for competitive advantage through supply chain management. Inernational Journal of Physical Distribution and Materials Management, 15(5), 16-26.

Jordan, C., \& Bak, O. (2016). The growing sale an scope of the supply chain: a reflection on supply chain graduate skills. Supply Chain Management: An International Journal, 21(5), 610-626. Retrieved October 24, 2016

Kaplan, D. A. (2017, April 18). supply chain eduation. Retrieved September 25, 2017, from supply chain dive: http://www/supplychaindive.com/news/supply-chain-educationcurriculum 
Kaplan, D. A. (2017, April 18). The supply chain curriculum: how universities are preparing the next generation of leaders. Retrieved Sep 25, 2017, from SupplyChainDive: http://www.supplychaindive.com/news/supply-chain-education-curriculum

Kellner, D. (2003). Toward a Critical Theory of Education. Democracy and Nature, 9(1), 51-64. Retrieved July 31, 2017, from School of Education, UCLA: http://www.tandfonline.com/doi/abs/10.1080/1085566032000074940?journalCode=cdna 20

Kennedy, J. F. (1963, January 29). 43 - Special Message to the Congress on Education. Retrieved from The American Presidency Project: http://www.presidency.ucsb.edu/ws/?pid=9487

Kincheloe, J. L. (2005). Critical Pedagogy Primer. Washington, CDC: Peter Lang.

Kostav, N., \& Paris, C. (2017, June 28). Companies try to contain fallout from global cyberattack. The Wall Street Jounal. Retrieved June 28, 2017, from https://www.wsj.com/articles/fallout-from-global-cyberattack-extends-into-second-day1498639146

Kroll, K. (2016, February). Customer Education: Guaranteeing an Perfect Fit. Inbound Logistics, pp. 34-40.

Lambert, D., Cooper, M., \& Pugh, J. (1998). Supply chain management: implementation issues and research opportunities. International Journal of Logistics Management, 9(2), 1-19.

Lancioni, R. (2000). New developments in supply chain management for the millenium. Industrial Marketing Management, 1-6. 
Lancioni, R., Forman, H., \& Smith, M. (2001). Logistics programs in universities: stovepipe vs. cross disciplinary. International Journal of Physical Distribution and Logistics Management, 31(1), 53-64.

Lawrence, S. R., \& Rosenblatt, M. J. (1972). Introducing international issues into operations management curricula. Production and Operations Management, 1(1), 103-117. Retrieved June 29, 2017

Leon, S., \& Uddin, N. (2016). Finding supply chain talent: an outreach strategy. Supply Chain Management: An International Journal, 20-44.

Lichtman, M. V. (2013). Qualitative research in education: a user's guide (3d edition). Sage. Retrieved from http://bookshelf.vitalsource.com/\#/books/9781452289519/cfi/6/26!/4/346/4/2@0:0

Lorentz, H., Toyli, J., Solakavi, T., \& Ojala, L. (2013). Priorities and determinants for supply chain management skills development in manufacturing firms. Supplky Chain Management: An International Journal, 358-375.

Lutz, H., \& Birou, L. (2013). Logitics education: a look a the current state of the art and science. Supply Chain Management, 18(4), 455-467.

Lynos, M., Lavelle, K., \& Smith, D. (2017). Gen Z Rizing. New York: Accenture.

Maloni, M. J., Scherrer, C. R., Campbell, S. M., \& Boyd, E. (2016). Attracting Students to the Field of Logistics,. Transportation Journal, 55(4), 420-442. Retrieved July 1, 2017, from http://muse.jhu.edu/article/633851/pdf 
Maloni, M., Carter, C., Kaufmann, L., \& Rogers, Z. (2015). Publication Productivity inteh Supply Chain Management Discipline: 2011-13. Transportation Journal, 54(3), 291-311.

Materials Handling Institute. (2014). 2014 Annual Report. Charlotte: MHI.

Materials Handling Management Institute. (2015). 2015 Annual Industry Report. Charlotte: MHI.

McCrea, B. (2011, July 28). Capturing the potential of education. Supply Chain Management Review.

McCrea, B. (2015, February 8). 5 Ways to Fill Supply Chain Management Gaps. Supply Chain Management Review.

McCrea, B. (2015, August 31). What does the future hold for the supply chain work force? Retrieved January 29, 2016, from supplychain247.com: http://www.supplychain247.com/article/what_does_the_future_hold_for_the_supply_cha in_work_force

McKimmon, A., Flothmann, C., Hoberg, K., \& Busch, C. (2017). Logistics competencies, skills, and training - a global perspective. Washington, DC: World Bank Group.

Melnyk, S. (2016, November 7). The emergence of the strategic leader. Retrieved January 30, 2017, from Supply Chain Management Review: http://www.scmr.com/article/the_emergence_of_the_strategic_leader

Melnyk, S., Stank, T., \& Closs, D. (2000). Supply Chain Management at Michigan State University: The Journey and Lessons Learned. Production and Inventory Management Journal, 2000(Third Quarter), 13-18. 
Merriam, S. B. (1992). Case study research in education, 2nd ed. San Francisco: Jossey-Bass.

Merriam, S., \& Tisdell, E. (2016). Qualitative Research: a guide to design and implementation (4th ed.). San Francisco: Wiley and Sons.

Merriam-Webster. (2017). case study. Retrieved June 30, 2017, from Merriam Webster Dictionary: https://www.merriam-webster.com/dictionary/case\%20study

Moise, I. (2017, July 17). FedEx struggles to bounce back from cyberattack. The Wall Street Journal, p. 2017. doi:https://www.wsj.com/articles/fedex-struggles-to-bounce-back-fromcyberattack-1500301593

Motorola University. (1998). Applying Six Sigma. Phoenix: Motorola University.

Mundy, R., Langley, C. J., \& Gibson, T. (1977). Industry evaluation of a transportation/logistics curriculum. Transportation Journal, 17(1), 33-39. Retrieved July 16, 2016, from www.jstor.org/stable/20712446

Mundy, R., Langley, C. J., \& Gibson, T. (1977). Industry Evaluation of a Transportation/Logistics Curriculum. Transportation Journal, 17(1), 33-39.

Neumann, G., Krzyaniak, S., \& Lassen, C. (2001). The Logistics Knowledge Portal: Gateway to More Individualized Learning in Logistics. 2001 World Conference on Educational Multimedia (pp. 1400-1405). Tampere, Finland: Association for Advancement of Computing in Education .

Niine, T., \& Koppel, O. (2015). The impact of technology trends on skills of logistics engineers A novel competence approach. 10th International DAAAM Baltic Conference - Industrial Engineering. Tallinn, Estonia. 
Obama, B. (2012). National global supply chain security strategy. Retrieved March 15, 2013, from Obama Whitehouse Archives: https://obamawhitehouse.archives.gov/sites/default/files/national_strategy_for_global_su pply_chain_security.pdf

Oliver, R. K., \& Webber, M. D. (1992). Supply chain management: logistics catches up with strategy. In M. Christopher (Ed.), Logistics (pp. 63-75). London: Chapman and Hall.

Oliver, R. K., \& Webber, M. D. (1992). Supply Chain Management: logistics catches up with strategy. In M. Christopher, Logistics: The Strategic Issues (pp. 63-75). London: Chapman and Hall.

Owusu-Bio, M. K., Manso, J. F., \& Adiwokor, E. (2015). Mapping the Interna Supply Chain for Educational Institutions. European Journal of Business Management, 32-42.

Ozelkan, E., \& Rajamani, D. (2006). An Effective Framework for Teaching Supply Chain Management. American Society for Engineering Education, 11.180.2-11.180.9.

Peca, K. (2000, November). Critical Theory. Retrieved August 1, 2017, from ERIC: http://files.eric.ed.gov/fulltext/ED450057.pdf

Peircy, J., Krampf, R., \& Banville, G. (1977). Transportation/logistics curriculum development: bridging the gap between industry and academia. Transportation Journal, 17(2), 75-82.

Piercy, J., Krampf, R., \& Bernville, G. (1977). Transportation/Logistics Curriculum Development: Bridging the Gap Between Industry and Academia. Transportation Journal, 17(2), 75-82. 
PLS Logistics. (2016, April 6). Shocking statistics about cargo theft. Retrieved July 17, 2017, from PLS Logistics: http://info.plslogistics.com/blog/shocking-statistics-about-cargotheft

PwC. (2016). Transportation \& logistics 2030 Volume 5: winning the talent race. PwC.

PwC. (2017). Transportation \& logistics 2030 Volume 5: Winning the talent race. PwC. Retrieved February 2, 2017, from https://www.pwc.com/gx/en/transportationlogistics/pdf/pwc-tl-2030-volume-5.pdf

Reddy, L. (2016, January 4). Other Voices: The manufacruing and logistics skills gap. Retrieved Feb 2, 2016, from supplychain247.com: http://www.supplychain247.com/article/other_voices_the_manufacturing_and_logistics_s kills_gap

Rogers, D., \& Lembke, R. (1998). Going backwards: reverse logistics trends and practices. Reno: UNR. Retrieved from http://www.business.unr.edu/faculty/ronlembke/reverse/reverse.pdf

Rogers, H., \& Braziotis, C. (2016). Current issues in teaching logistics management. Dynamics in Logsitics .

Rouse, M. (2014, February). omnichannel. Retrieved July 17, 2017, from TechTarget: http://searchcio.techtarget.com/definition/omnichannel

Roussell, J. (2014, October 24). Making Talent Part of Your Supply Chain Strategy. Retrieved October 31, 2016, from Industry Week: http://www.industryweek.com/print/plannignforecasting 
Ruamsook, K., \& Craighead, C. (2014). A supply chain talent "perfect storm". Supply Chain Management Review, 12-17.

Ruske, K.-D., \& Kauschke, P. (2012). Transportation and logistics 2030: volume 4: securing the supply chain. PwC. Retrieved July 19, 2017, from https://www.pwc.com/gx/en/transportation-logistics/pdf/tl2030_vol.4_web.pdf

Ryder. (2017). Best practices for new supply chain talent strategies. Ryder System, Inc. Retrieved July 20, 2017

Sachan, A., \& Datta, S. (2005). Review of supply chain management and logistics research. International Journal of Physical Distribution and Logistics Management, 35(9), 664705.

Sarrico, C., \& Rosa, M. (2016). Supply chain quality management in education. International Journal of Quality and Reliability Management, 33(4), 499-517.

Schwarz, L., \& Singhal, K. (1998). Introduction to the special issue on teaching POM: visions, topics, and pedagogies. Production and Operations Management, 7(2), 89-93. Retrieved June 27, 2017

Scott, S., Burnett, M., Dittman, P., Stank, T., \& Autry, C. (2015). Supply Chain Talent: Our Most Important Resource. Knowxville, TN: Uinversity of Tennessee, Global Supply chain Institute.

Seuring, S., Muller, M., Reiner, G., \& Kotzab, H. (2005). Is There a Right Research Design for Your Supply Chain Stude? In S. Seuring, H. Kotzab, M. Muller, \& G. Reiner, Research Methodologies in Supply Chain Management (pp. 1-12). Heidelberg: Physica-Verlag. 
Seuring, S., Müller, M., Westhaus, M., \& Morana, R. (2005). Conducting a Literature Review The Example of Sustainability in Supply Chains. In H. Kotzab, S. Seuring, M. Muller, \& G. Reiner, Research Methodologies in Supply Chains (pp. 91-106). Heidelberg, Germany: Physica Verlag.

Sharp, D. (2018, Feb 9). Citing Fraud, LL Bean imposes limits on its return policy. Retrieved Feb 21, 2018, from AP News: https://www.apnews.com/4e20f82acbc948969a98e7151b4d1622

Shina, A., Millhiser, W. P., \& He, Y. (2016). Matching supply with demand in supply chain management education. The International Journal of Logistics Management, 27(3), 837861. Retrieved Jun 15, 2017, from http://www.emeraldinsight.com/doi/pdfplus/10.1108/IJLM-03-2015-0058

Sittiwong, T. (2017). Curriculum development, logistics and supply chain. International Journal of Humanities and Social Sciences, 9(1), 9-17. Retrieved June 14, 2017

Southern, N. (2011). Historical perspective of the logistics and supply chain management discipline. Transportation Journal, 50(1), 53-64. Retrieved November 17, 2016

Soy, S. (1996). The Case Study as a Research Method. Retrieved July 4, 2017, from ischool.utexas: https://www.ischool.utexas.edu/ ssoy/usesusers/1391d1b.htm

Starr, M. (1997). Pedagogical challenge: teaching international production and operations management courses. Production and Operations Management, 6(2), 114-121. Retrieved June 27, 2017 
Stevens, L. (2017, July 27). Help Wanted: Amazon to host job fair for 50,000 postiions amid hiring squeeze. Retrieved from The Wall Street Journal: https://wwwlwsj.com.articles/help-wanted-amazon-to-host-job-fair-for-50,000-postionsamid-hiring-squeeze

Stifler, D. (2018, June 3). 2018 Top 25 supply chain management programs. Retrieved June 3, 2018, from gartner.com: https://www.gartner.com/user/registration/webinar?resId=3875874\&commId=322479\&c hannelId=15915\&srcId=null\&webinarType=UpcomingEvent

Stock, J. (2001). Doctoral research in logistics and logistics-related areas: 1992-1998. Journal of Business Logistics, 22(1), pp. 125-156.

Storey, J., Eberson, C., Godsell, J., \& Harrison, A. (2006). Supply chain management: theory, practice and future challenges. International Journal of Operations and Productrion Management, 26(7), 754-774.

Storey, J., Emberson, C., Godsell, J., \& Harrison, A. (2006). Supply chain management: theory, practice and future challenges. International Journal of Operations and Production Management, 26(7), 754-774.

Straker, D. (2016). What is critical theory? Retrieved July 27, 2017, from Chaning Minds: http://changingminds.org/explanations/critical_theory/concepts/critical_theory_is.htm

Tan, K. C. (2001). A framework of supply chain management literature. European Journal of Purchasing and Supply Management, 39-48.

Tzu, S. (1993). The art of war. (J. Huang, Trans.) New York: Quill. 
Tzu, S. (1993). The Art of War - New Translation. (J. Huang, Trans.) New York: Quill.

van Hoek, J. (2001). Logistics Education, Achieving market and research driven skill development. International Journal of Physical Distribution and Logistics Management, 21(7/8), 505-519. Retrieved November 1, 2014

van Hoek, R. I. (2000). Logistics Education. International Journal of Physical Distribution and Logistics Management, 31(7/8), 505-519.

van Hoek, R., Godsell, J., \& Harrison, A. (2010, October). Embedding "insights from industry" in supply chain programmes: the role of guest lecturers. Supply Chain Management: An International Journal, 16(2), 142-147.

Velazquez, E. A. (2015). The use of business simulators in teaching logistics. Mexico City, Mexico: Tecnologico de Monterrey.

Vidal, C., \& Goetschalckx, M. (1997). Strategic production - distribution models: A critical review with emphasis on global supply chain models. European Journal of Operations Research, 1-18.

von Donk, D. P., \& van der Vaaart, T. (2005). A Critical Discussion on the Theoretical and Methodological Advancements in Supply Chain Integration Research. In H. S. Kotzab, M. Muller, \& G. Reiner, Resaerch Methodologies in Supply Chain Management (pp. 3146). Heidelberg, Germany: Physica Verlag.

Walden, J. (2014). Operations and Supply Management. Dubuque, IA: Kendall Hunt.

Walden, J. (2015, May 29). Best Practices in Teaching Supply Chain Management. Sun City, South Africa, South Africa: South Africa Production and Inventory Control Society. 
Wieland, A., Handfield, R., \& Durach, C. (2016). Mapping the Lanscape of Future Research Themes in Supply Chain Management. Journal of Business Logistics, 37(3), 205-212. Retrieved October 30, 2016

World Shipping Council. (2017). Containers Lost at Sea. Retrieved July 18, 2017, from World Shipping Council: http://www.worldshipping.org/industryissues/safety/Containers_Lost_at_Sea_-_2017_Update_FINAL_July_10.pdf

Yazan, B. (2015). Case study methodology has long been a contested terrain in social sciences research which is characterized by varying, sometimes opposing, approaches espoused by many research methodologists. Despite being one of the most frequently used qualitative rese. Retrieved July 4, 2017, from The Qualitative Report: http://nsuworks.nova.edu/tqr/vol20/iss2/12/

Yen-Chun, J. W. (2007). Contemporary logsitics education: an international perspective. International Journal of Physical Distribution and Logistics Management, 27(7), pp. 504-528.

Zhu, D. (2015). Supply chain Management Research Models: An Overview of Current Literature. International Journal of Business and Applied Social Science, 1(1).

Zhu, D. (2015). Supply chian management research models: an overview of current literature. International Jpurnal of Business and Applied Social Science, 1(1), 1-16.

Zinn, W., \& Goldsby, T. (2017). In search of research ideas? Call a professional. Journal of Business Logistics, 38(1), 4-5. doi:10.1111/jbl.12160 
